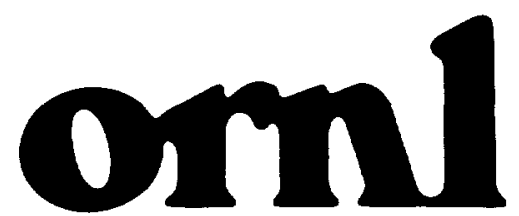

OAK RIDGE

NATIONAL

LABORATORY

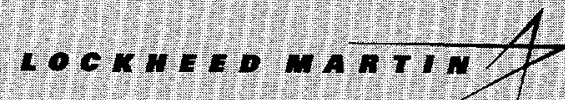

(1)

P)

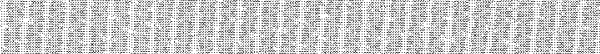

W.

1.t.

?!?

1.t.

(y)

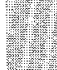

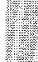

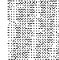

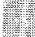

3itut:

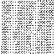

(1)

(3)

1.:

(1)

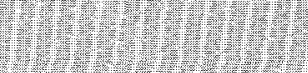

).

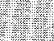

NANAGED AND OPERATED BY

LOCKHEED UARTN ENERGY RESEARCH CORPORATION FOR THE UNTIEO STIATES

DEPARTMENT OF ENERGY

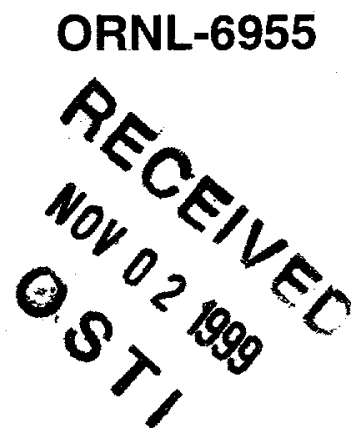

On the Mechanical Response of Chopped Glass/Urethane Resin Composite: Data and Model

M. Elahi

Y. J. Weitsman 
This report has been reproduced directly from the best available copy.

Available to DOE and DOE contractors from the Office of Scientific and Technical Information, P.O. Box 62, Oak Ridge, TN 37831; prices available from (423) 576-8401.

Available to the public from the National Technical Information Service, U.S. Department of Commerce, 5285 Port Royal Rd., Springfield, VA 22161.

This report was prepared as an account of work sponsored by an agency of the United States Government. Neither the United States Government nor any agency thereof, nor any of their employees, makes any warranty, express or implied, or assumes any legal liability or responsibility for the accuracy, completeness, or usefulness of any information, apparatus, product, or process disclosed, or represents that its use would not infringe privately owned rights. Reference herein to any specific commercial product, process, or service by trade name, trademark, manufacturer, or otherwise, does not necessarily constitute or imply its endorsement, recommendation, or favoring by the United States Government or any agency thereof. The views and opinions of authors expressed herein do not necessarily state or reflect those of the United States Government or any agency thereof. 


\section{DISCLAIMER}

Portions of this document may be illegible in electronic image products. Images are produced from the best available original document. 


\author{
M. Elahi and Y. J. Weitsman
}

October 1999

\author{
Prepared by the \\ OAK RIDGE NATIONAL LABORATORY \\ Oak Ridge, Tennessee 37831-6285 \\ managed by \\ LOCKHEED MARTIN ENERGY RESEARCH CORP. \\ for the \\ U.S. DEPARTMENT OF ENERGY \\ under contract DE-AC05-96OR22464
}





\section{CONTENTS}

LIST OF FIGURES

LIST OF TABLES

PREFACE vii

ABSTRACT

1. INTRODUCTION 1

2. CREEP RESPONSE.

2.1 ROOM-TEMPERATURE RESPONSE: DATA AND MODEL

2.2 ELEVATED TEMPERATURE RESPONSE: DATA AND MODEL …........................................ 4

3. SOME OBSERVATION REGARDING CREEP RUPTURE AND DAMGE GROWTH .................... 5

4. SOME ASPECTS OF THE RESPONSE OF URETHANE RESIN ………........................................... 6

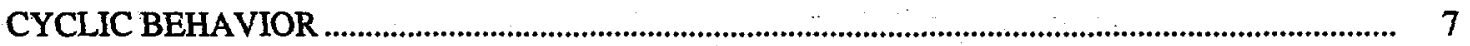

6. DISTILLED WATER: SORPTION AND EFFECT ON MECHANICAL RESPONSE .......................... 10

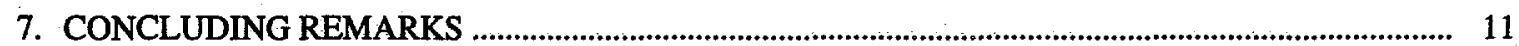

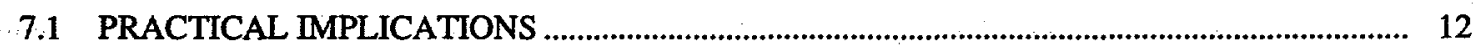

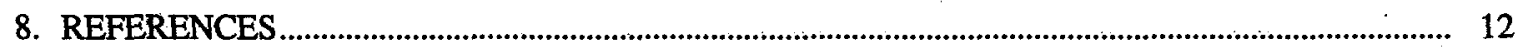




\section{LIST OF FIGURES}

Figure

Page

1. A schematic drawing of stress input history and strain output

Creep strains due to $\sigma=25 \mathrm{MPa}$ at five stations along a single coupon, implying a

$35 \%$ variability in stiffness

Typical data for creep (top) and recovery (bottom) within the linear range of response.

Data (ooo) and model $(\bullet \bullet), \sigma=25 \mathrm{MPa}, \mathrm{t}_{0}=30 \mathrm{~min}, \mathrm{~T}=23^{\circ} \mathrm{C}, \mathrm{D}_{0}=6.51 \times 10^{-5} \mathrm{MPa}^{-1}$,

$\mathrm{D}_{1}=9.72 \times 10^{-6} \mathrm{MPa}^{-1} \mathrm{~min}^{-\mathrm{n}}$, and $\mathrm{n}=0.086$

Scaled creep data at $23^{\circ} \mathrm{C}$ under various stress levels. Average values with scatter bands........ . $\quad 15$

Permanent residual strain vs. level of applied stress. Average values and scatter bands

Permanent residual strain vs. average values of maximum strains attained under loading.

Average values and scatter bands

Scaling factor for $D_{0}(\sigma)$ to be employed in Eq. (3

Scaling factor for $D_{1}(\sigma)$ to be employed in Eq. (3)

Two-step stress history model verification test. A step stress $\sigma_{1}=100 \mathrm{MPa}$ was applied and removed after 30 minutes. Following a relaxation period of 24 hours a second step stress $\sigma_{2}=75 \mathrm{MPa}$ was applied. Data (०॰) and model predictions: (i) based upon Eq. (3) $(\vartheta \bullet)$, (ii) based upon best power-law fit for $\sigma_{1}=100 \mathrm{MPa}(--)$.). (Filled symbols $\sigma_{1}=100 \mathrm{MPa}$, open symbols $\sigma_{2}=75 \mathrm{MPa}$ ).

Same as Fig. (9), but $\sigma_{1}=75 \mathrm{MPa}$ and $\sigma_{2}=100 \mathrm{MPa}$. Data and predictions are based upon

Eq. (3).

Scaled creep data at $\mathrm{T}=50^{\circ} \mathrm{C}$ under various stress levels. Average values

and scatter bands.

Scaled creep data at $\mathrm{T}=120^{\circ} \mathrm{C}$ under various stress levels. Average values

and scatter band

Temperature-induced enhancement of $D_{0}$

Time-temperature shift factor $\mathrm{a}_{\mathrm{r}} \mathrm{vs.}$ temperature $\mathrm{T}$.

Varying temperature verification test. Data $(-)$, model predictions [Eq. (5a)] $(-)$, and thermoelastic predictions $\longrightarrow$.

Long term creep data (open symbols) at various levels of stress and temperature and predictions based on Eq. (5). Average values (---) and scatter bands

Creep-to-failure data from a multigaged coupon under a step stress of $130 \mathrm{MPa}$.

Curves numbered no. 1 through no. 7 correspond to positions of strain gages,

starting from the top and numbers on the right correspond to stiffness as

recorded within the linear range of response. Failure occurred at gage no.3

Creep-to-failure response under gage no. 3 in Fig. 17, Data (000), predictions of "best fit"

power-law (-), and predictions accounting for damage growth (---)

An expanded view of strain vs. time upon advent of failure. Symbols same as Fig. 18 ..............

Strain-to-failure recorded under gage no. 2 in Fig. 17

An expanded view of strain-to-failure recorded under gage no. 2. Data (---) and predictions of "best fit" power-law (-)

An expanded view of creep-to-failure data under gage no. 4 in Fig. 17

Stress-strain behavior of urethane (neat resin) specimens

Creep of urethane neat resin $(-)$ as compared with that of $\mathrm{P} 4$ chopped glass/urethane

(-) for $\sigma=25 \mathrm{MPa}$, and $\mathrm{T}=23^{\circ} \mathrm{C}$. Thick lines exhibit extensometer readings, while

the thin line corresponds to strain gage record.

Recovery data. Symbols same as Fig. 24.

Schematic diagrams for cyclic testing 
27 Unscaled strain data at various levels of maximum stress at $R=0$, vs. number of cycles. Stress levels shown in bold numbers correspond to maximum strains, and those shown by plain numbers correspond to minimum strains. Average values and scatter bands are shown

30 Ratio of unloading compliance to initial compliance vs. number of cycles for various values of maximum stress with $R=0$. Average values and scatter bands are shown .................... $\quad 35$

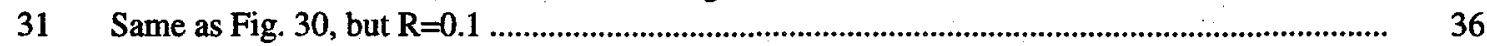

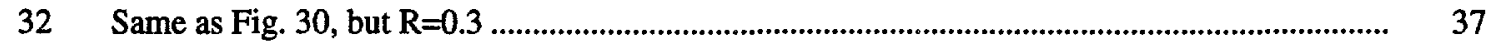

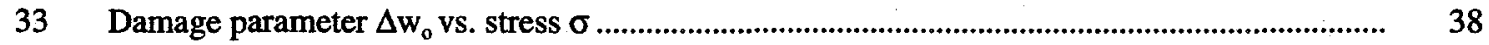

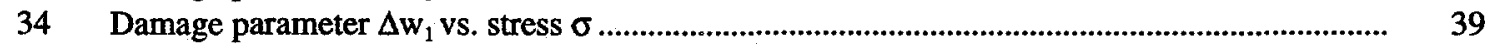

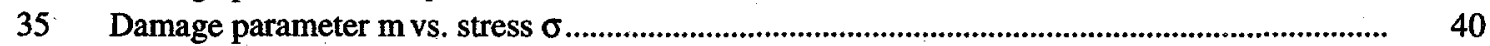

36 Scaled measured and predicted strain vs. number of cycles at various levels of maximum stress at $R=0$. Data (---) with scatter bands, as compared with predictions according to Eq. (19) and (20) $(-$. Bold numbers correspond to maximum strains, and plain numbers correspond to minimum strains

39 Weight-gain data (in percent dry weight) vs. square root of time for P4 chopped glass/urethane composite coupons, immersed in distilled water at temperature $\mathrm{T}=23^{\circ} \mathrm{C}$. Coupons were not pre-tested in creep prior to immersion

40 Weight-gain data (in percent dry weight) vs. square root of time for P4 chopped glass/urethane composite coupons, immersed in distilled water at temperature $\mathrm{T}=23^{\circ} \mathrm{C}$. Coupons were pre-tested in creep upon drying and prior to immersion..

Weight-loss data (in percent dry weight) upon re-drying of coupons immersed in distilled water at $\mathrm{T}=23^{\circ} \mathrm{C}$

46 Variation of the diffusion coefficient $D$ with temperature corresponding to data shown in Figs. 40-42

47 Comparative data for creep strains of two $\mathrm{P} 4$ chopped glass/urethane composite coupons at initially dry state (open symbols) and after saturation in distilled water at $\mathrm{T}=23^{\circ} \mathrm{C}$ (filled symbols). Stress $\sigma=25 \mathrm{MPa}$, loading duration $\mathrm{t}_{0}=30$ minutes.

48 Comparative data for recovery strains upon load removal at $t_{0}=30$ minutes. Exposure conditions and symbols same as in Fig. 47.

49 Comparative data for creep strains of four $\mathrm{P} 4$ chopped glass/urethane composite coupons at initially dry state (open symbols), after saturation in distilled water at $\mathrm{T}=36^{\circ} \mathrm{C}$ (gray symbols), and after redrying (black symbols). Stress $\sigma=25 \mathrm{MPa}$, loading duration $\mathrm{t}_{0}=30$ minutes...

50 Comparative data for recovery strains upon load removal at $t_{0}=30$ minutes. Exposure conditions and symbols same as in Fig. 49.

51 Same as Fig. 49 , but $\mathrm{T}=50^{\circ} \mathrm{C}$.

52. Same as. Fig. 50 , but $\mathrm{T}=50^{\circ} \mathrm{C}$...

53 Stiffness degradation of two $\mathrm{P} 4$ chopped glass/urethane composite coupons due to immersion in distilled water at $\mathrm{T}=23^{\circ} \mathrm{C}$. 


\section{LIST OF TABLES}

Table

Page

1 Test program for short-term creep and recovery of P4 chopped glass/urethane composite........

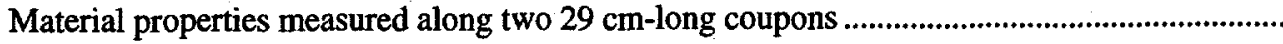

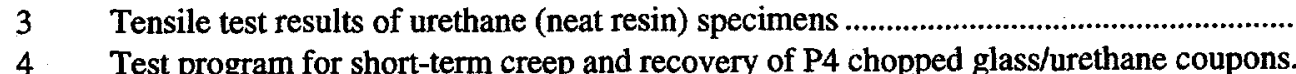

Note that all specimens were pre-tested in creep and recovery for subsequent scaling

of sample-to-sample stiffness variability

7

5 Polynomial fits for the damage parameters $\Delta \mathrm{w}_{0}, \Delta \mathrm{w}_{1}$, and $\mathrm{m}$ in Eq. (12).

6 Schedule of exposure to distilled water 



\section{PREFACE}

This report presents a portion of a larger investigation undertaken at Oak Ridge National Laboratory (ORNL) on the durability of polymeric composites for automotive structural applications. The ORNL project, which is entitled "Durability of Lightweight Composite Structures for Automotive Applications," is sponsored by the U.S. Department of Energy Office of Advanced Automotive Technologies.

The main purpose of this report is to demonstrate the applicability of a theoretically based methodology to model and predict the response of a class of randomly reinforced polymeric composites under consideration for automotive applications. Theoretical modeling and experimental investigations progressed interactively throughout this investigation, demonstrating the essential need for the systemic establishment of a comprehensive database conjointly with theory.

While this report is aimed towards the mechanics and materials community, several practical implications that may be useful to designers as well are listed in the conclusion section. 


\title{
ON THE MECHANICAL RESPONSE OF P4 CHOPPED GLASS/URETHANE RESIN COMPOSITE SYSTEM: DATA AND MODEL
}

\author{
M. Elahi* and Y. J. Weitsman*
}

\begin{abstract}
This report presents-data on the creep response of a polymeric composite that is a candidate material for automotive applications. The above data were used to establish the basis for the mechanical characterization of the material's response over a wide range of stresses and temperatures, as well as under cyclic loading and due to exposure to distilled water.

A constitutive model based upon fundamental principles of irreversible thermodynamics and continuum mechanics was employed to encompass the abovementioned database and to predict the response under more complex inputs. These latter tests verified the validity of the model.
\end{abstract}

\section{INTRODUCTION}

This report concerns the mechanical response of $\mathrm{P} 4$ chopped glass/urethane resin composites under a wide range of stresses and temperaturesas well as under exposure to distilled water. Attention is confined to the case of uniaxial tensile stresses, both static and cyclic.

The chopped-mat composites consist of a fiber preform and a polymeric matrix, which acts a binder. This preform is produced by depositing $5 \mathrm{~cm}$ long chopped glass fiber strands (Owens Corning chopped E-glass fibers produced specifically for the $\mathrm{P} 4$ process) in a random pattern deposited on a screen. The fiber strands are held in place by airflow. To preserve the shape and enhance the wettability during the structural reaction injection molding (SRIM), a powdered thermoplastic binder is blown into the chopped mat. Subsequently, hot air is blown into the mat to melt the binder, followed by a stream of cold air to set the binder. The glass preform is then loaded into a mold of a prescribed shape where the Bayer $420 \mathrm{IMR}$ resin (a urethane polymer with internal mold release) is injected into the preform at high pressure. After 4 minutes the part is taken out and is post cured at $121^{\circ} \mathrm{C}$ for 1 hour. The composite has a fiber volume fraction of $V_{f}=29.6 \%(47.3 \%$ by weight), a modulus of $E=12.9 \mathrm{GPa}$, tensile strength of $\sigma_{\text {ult }}=193 \mathrm{MPa}$, failure strain of $\varepsilon_{\mathrm{f}}=1.94 \%$, Poison's ratio of $v=0.336$, and coefficient of linear thermal expansion of $\alpha=18.1 \mu \varepsilon /{ }^{\circ} \mathrm{C}$.

Experiments were performed on flat coupons, typically measuring $20 \mathrm{~cm}$ by $2.5 \mathrm{~cm}$ in length and width and of $3 \mathrm{~mm}$ in thickness. All mechanical data were collected on an MTS hydraulic testing machine under load control, with strains recorded by means of strain gages and extensometry.

The abovementioned composite exhibits a wide scatter in its basic properties, such as stiffness, strength and strain-to-failure. Its mechanical response incorporates features attributable to viscoelastic creep coupled with distributed damage. In all the foregoing respects the response of this composite is analogous to that of a previously investigated swirl-mat material ${ }^{-3}$.

Consequently, it was possible to characterize the response of the composite at hand on the basis of an experimental program and a theoretical model similar to those established earlier ${ }^{1-5}$.

The usefulness of the model presented herein is validated by comparing model predictions against experimentally recorded responses to stress and temperature inputs, as well as input durations, which differed from those employed in the experimental characterization program.

\section{CREEP RESPONSE}

The creep response of the composite was characterized experimentally by collecting short-term creep and recovery strain data associated with the application of a step load of magnitude $\sigma_{o}$ and its removal after time $t_{o}$. In all characterizationtests $t_{o}=30 \mathrm{~min}$, with recovery strains recorded for an additional duration $t_{r} \geq 3 t_{o}$.

*MAES Department, University of Tennessee, Knoxville, TN 37996-2030 and Engineering Technology Division, Oak Ridge National Laboratory, M/S 8051, Oak Ridge, TN 37830-8051. 
The response was deemed to be linear when it satisfied the two following conditions: (i) strain was proportional to stress, and (ii) strain was completely recovered after a sufficiently long recovery time.

A schematic representation of the characterization scheme is shown in Fig. 1, with stress input given in Fig. 1(a), and the recorded strain output sketched in Fig. 1(b). In the latter figure $\varepsilon_{p}$ denotes unrecoverable, permanent strain, as encountered when $\sigma \geq \sigma_{d}$.

The above mentioned experiments were performed at five levels of $\sigma_{o}$ at three distinct temperatures $T$, with at least three replicate tests for each pair of values $\left(\sigma_{o}, T\right)$. A listing of the experimental program is given in Table 1.

Table 1. Test program for short-term creep and recovery of $P 4$ chopped glass/urethane composite

\begin{tabular}{|c|c|c|c|c|}
\hline $\begin{array}{c}\sigma_{\max } \\
\mathbf{M P a}(\mathbf{k s i})\end{array}$ & $\begin{array}{c}\text { Test temperature } \\
{ }^{\circ} \mathbf{C}\left({ }^{\circ} \mathbf{F}\right)\end{array}$ & $\begin{array}{c}\text { Creep time } \\
\mathbf{t}_{\mathrm{o}}(\mathbf{m i n})\end{array}$ & $\begin{array}{c}\text { Recovery } \\
\text { time (min) }\end{array}$ & $\begin{array}{c}\text { No. of tests per } \\
\text { temp. per stress }\end{array}$ \\
\hline $25(3.63)$ & $\begin{array}{c}23,50,120 \\
(73,122,248)\end{array}$ & 30 & $\geq 3 \mathrm{t}_{\mathrm{o}}$ & $\geq 3$ \\
\hline $50(7.25)$ & $\begin{array}{c}23,50,120 \\
(73,122,248)\end{array}$ & 30 & $\geq 10 \mathrm{t}_{\mathrm{o}}$ & $\geq 3$ \\
\hline $75(10.9)$ & $23,50,120$ & 30 & $\geq 10 \mathrm{t}_{\mathrm{o}}$ & $\geq 3$ \\
\hline $100(14.5)$ & $(73,122,248)$ & 30 & $\geq 10 \mathrm{t}_{\mathrm{o}}$ & $\geq 3$ \\
\hline $125(18.1)$ & $(73,122,248)$ & 30 & $\geq 10 \mathrm{t}_{\mathrm{o}}$ & $\geq 3$ \\
\hline
\end{tabular}

\subsection{ROOM-TEMPERATURE RESPONSE: DATA AND MODEL}

It was observed that at $T=23{ }^{\circ} \mathrm{C}$ the range of linear response was confined to $0 \leq \sigma \leq \sigma_{d}=40 \mathrm{MPa}$. Furthermore, it was possible to express the creep response in a power-law form as follows

$$
\varepsilon(t)=\left\{\begin{array}{lr}
\left(D_{o}+D_{1} t^{n}\right) \sigma_{o} & 0 \leq t \leq t_{o} \\
D_{1}\left[t^{n}-\left(t-t_{o}\right)^{n}\right] \sigma_{o} & t \geq t_{o}
\end{array} .\right.
$$

In Eqs. (1), $\sigma_{o} \leq \sigma_{d}$ and the response parameters are $7.39 \times 10^{-5}<\mathrm{D}_{0}<8.16 \times 10^{-5} \mathrm{MPa}^{-1}$, $7.24 \times 10^{-6}<D_{1}<12.7 \times 10^{-6} \mathrm{MPa}^{-1} \mathrm{~min}^{-n}, n=0.086$ and time $t$ is in minutes.

Note the wide spread in the values of $D_{o}$ and $D_{1}$, which reflects the sample-to-sample variability attributed to material inhomogeneity and processing non-uniformity. This wide scatter in material properties can easily mask the effects of the parameters, such as stress, temperatureand moisture that govern the material's response, thereby reducing any modeling effort to a futile exercise. Consequently, it was necessary to scale all deformation data collected in the experimental tasks presented in this report by the ratio of the specimen's stiffness to a common reference stiffness in order to account for sample-to-sample variability. The reference stiffness was selected as the average of all values recorded in the experimental program. The abovementioned scaling substantially reduced the data scatter (typically a four-fold reduction). The foregoing inhomogeneity was detectableeven within an individual coupon, which can be seen from the distinct, simultaneously recorded, creep curves by strain gages located at five distinct positions over a coupon's length, as shown in Fig. 2 .

It is also worth noting that while three parameters, $D_{o}$ and $D_{1}$, and $n$ are employed in Eq. (1) to express creep, employment of the Boltzman superposition integral to relate viscoelastic strain-stress response, namely 
$\varepsilon(t)=\int_{0}^{t} D(t-\tau) \frac{d \sigma(\tau)}{d \tau} d \tau$

yields an expression for the recovery strain that contains only two of the above parameters. Consequently, it is more convenient to first evaluate $D_{1}$, and $n$ from recovery data and subsequently determine $D_{o}$ from creep data. Typical creep and recovery data and their power-law representation are shown in Fig. 3.

Turning to the nonlinear range of creep response, involving the four stresses that exceed $40 \mathrm{MPa}$ listed in Table 1, it was necessary to first evaluate the creep and recovery responses of each individual coupon in the linear range $\left(\sigma_{o}=25 \mathrm{MPa}\right.$ and $\left.t_{o}=30 \mathrm{~min}\right)$ to establish its so called "reference signature". This enabled the appropriate scaling of subsequent deformation data, thereby accounting for sample-to-sample variability. As noted earlier, this procedure has significantly reduced the data scatter. Results are shown in Fig. 4: Although, these results exhibit a fairly small degree of nonlinearity, it is possible to discern the presence of nonlinear response in the data for the permanent residual strain $\varepsilon_{p}$ vs. $\sigma$ shown in Fig. 5. Equivalently, these data can be related to the maximum strain attained by the material while subjected to loading, as can be seen in Fig. 6 . Figures 5 and 6 contain empirical expressions for $\varepsilon_{p}$.

- Guided by previous investigations ${ }^{i-3}$, it is reasonable to attribute the aforementioned nonlinearity to the stress induced onset of profuse microcracking within the composite. As before, permanent deformation is ascribed to the roughness and geometric mismatches that arise over opposing micro-crack surfaces, which prevent their complete closure upon load removal.

It was possible to correlate the data shown in Fig. 4 by means of two scaled, stress dependent functions $D_{o}(\sigma)$ and $D_{1}(\sigma)$ shown in Figs. 7 and 8. The figures shown contain the curve-fitted, empirical expressions for the above terms. Note that $n=0.086$, remaining unchanged from the linear range. Consequently, one obtains for $\sigma_{\mathrm{o}}>\sigma_{\mathrm{d}}=40 \mathrm{MPa}$

$$
\varepsilon(t)=\left\{\begin{array}{lr}
{\left[D_{o}\left(\sigma_{o}\right)+D_{1}\left(\sigma_{o}\right) t^{n}\right] \sigma_{o}} & 0<t<t_{o} \\
D_{1}\left(\sigma_{o}\right)\left[t^{n}-\left(t-t_{o}\right)^{n}\right] \sigma_{o}+\varepsilon_{p} . & t>t_{o}
\end{array} .\right.
$$

While $D_{o}(\sigma)$ and $D_{1}(\sigma)$ relate the effect of stress-enhanced profuse micro-cracking("damage")on compliance, these expressions do not account for time-dependent damage growth. Thereby, Eqs. (3) remain valid for sufficiently short load durations $t_{o} \ll t_{f}$, where $t_{f}$ denotes failure time.

The predictive capability of the model, as expressed in Eqs. (1) and (3), was tested by performing twostage loading experiments. In one case a coupon was first subjectedto a step load $\sigma_{1}=100 \mathrm{MPa}$ for a duration $t_{o}=30 \mathrm{~min}$, then allowed to recover. In view of the results shown in Fig. 5 the above loading resulted in a permanent strain of $\varepsilon_{p} \sim 200 \mu$.

Subsequently, the coupon was subjected to a second step loading $\sigma_{2}=75 \mathrm{MPa}$. By hypothesis, no new damage occurs under $\sigma_{2}<\sigma_{1}$; thereby deformationshould now be simply scaled by a factor of $\sigma_{2} / \sigma_{1}=0.75$. Results, together with the foregoing prediction, are shown in Fig. 9.

Note that Fig. 9 exhibits two sets of predictions. One prediction is based upon the average values of $D_{o}(\sigma)$ and $D_{1}(\sigma)$ that correspond to the expressions incorporated in Figs. 7 and 8 , while the other prediction is based upon the values of $D_{o}(\sigma)$ and $D_{1}(\sigma)$ that provide the best power-law fit for the strain due to $\sigma_{1}$, which are specific to the coupon at hand. It is worthwhile to note that the actual strains under $\sigma_{2}$ in Fig. 9 are proportional to those under $\sigma_{1}$ by a factor of 0.74 (As compared with the theoretical ratio of 0.75 ).

The second verification test involved a similar two-stage loading experiment, except that now $\sigma_{2}>\sigma_{1}$. In this case, the strain under $\sigma_{2}$ is given by

$$
\varepsilon(t)=\left[D_{o}\left(\sigma_{2}\right)+D_{1}\left(\sigma_{2}\right) t^{n}\right] \sigma_{2}+\varepsilon_{p}\left(\sigma_{1}\right)
$$

Comparative results are shown in Fig. 10.

\subsection{ELEVATED TEMPERATURE RESPONSE: DATA AND MODEL}

The elevated temperature characterizationscheme was based upon creep and recovery data and followed the test program listed in Table 1. As noted therein, the elevated temperatures were $50^{\circ} \mathrm{C}$ and $120^{\circ} \mathrm{C}$. 
All elevated temperature tests were preceded by room-temperature experiments that characterized the response of each coupon within the linear range $(\sigma=25 \mathrm{MPa})$ and subsequently at the specific stress level $(\sigma=50,75,100$, or $125 \mathrm{MPa})$ under consideration. The purpose of room temperature pre-testing in the linear range was to account for, and thereby reduce, the effect of sample-to-sample variability, while the aim of roomtemperature testing at the corresponding stress-level within the nonlinear range of response was to separate the effects of stress from those of temperature.

Results, including data scatter, are shown in Figs. 11 and 12. The data scatter remains after scaling, which accounted for sample-to-sample stiffness variability. Note the pronounced nonlinearity in strain in relation to stress exhibited in Figs. 11 and 12. The nonlinearity increases with temperature. All samples tested at $\sigma=125 \mathrm{MPa}$ and $T=120^{\circ} \mathrm{C}$ failed within about three minutes.

It was possible to represent the data in Figs. 4, 11, and 12 in the standard format which, together with the power-law expression (1), reads

$\varepsilon(t ; \sigma ; T)=\left\{\hat{D}_{0}(\sigma ; T)+D_{1}(\sigma)\left[t / a_{T}(T)\right]^{n}\right\} \sigma+\alpha \Delta T$

where $\alpha$ denotes the coefficient of thermal expansion and $\Delta T=T-T_{\text {reference }}$.

It turned out that it was possible to express $\hat{D}_{o}(\sigma ; T)$ in product form, namely $\hat{D}_{o}(\sigma ; T)=D_{o}(\sigma) F(T)$. Values of $F(T)$ and the "shift-factor" $a_{T}(T)$ are drawn against $T$ in Figs. 13 and 14. These figures also contain the "best fit" empirical expressions.

Experimental verification of the predictive ability of Eq. (5) was based on two types of tests. In the first case the application and removal of a step load was accompanied by a documented temperature history, as shown in Fig. 15. Specific values of $D_{o}$ and $D_{1}$, for the sample at hand were obtained from a prior test at room temperature. In this case Eq. (5) reads

$\varepsilon(t ; T)=\left\{D_{0} F(T)+D_{1} \xi(t)^{n}\right\} \sigma+\alpha \Delta T$

where

$\xi(t)=\int_{o}^{t} d u / a_{T}[T(u)]$

Predictions based upon Eq. (5a) are compared against data in Fig. 15, with $\alpha=18 \mu \varepsilon /{ }^{\circ} \mathrm{C}$ and $T_{\text {reference }}=25^{\circ} \mathrm{C}$. This figure contains also the comparative linear thermoelastic predictions.

The second validation derives from the extension of model predictions, which are based on short-term (30-min.) data, whereby $t \ll t_{f}$, into the time domain, and comparing them with long-term creep data. Results, at several levels of stress and temperature are shown in Fig. 16. These include predicted scatter bands due to material variability. Note the remarkable agreements with all long-term data.

\section{SOME OBSERVATIONS REGARDING CREEP RUPTURE AND DAMAGE GROWTH}

While creep rupture per se falls outside the scope of this investigation, ${ }^{\dagger}$ detailed data were collected from multiply-gaged samples in order to explore some features of damage growth in the composite consideredherein.

The experiment utilized two $29 \mathrm{~cm}$.-long coupons, with strains recorded at seven equally spaced locations over its length, with an additional strain recorded by means of an extensometer. Values of Poisson's ratio were recorded within the linear range at the seven foregoing locations for one of the coupons. Results for specimen no. 2 are shown in Fig. 17 and listed in Table 2. Figure 17 includes a listing of the initial stiffnesses under each of the seven gages and the extensometer, with accompanying numbers indicating ordered gage positions starting from the top. Note the wide spread in strain data, which is consistent with Fig. 2. More significantly,

\footnotetext{
*These data were collected on creep load frames by W. Ren at ORNL.

Ongoing creep-rupture experiments are being performed elsewhere at ORNL under this project.
} 
Table 2. Material properties. measured along two $29 \mathrm{~cm}$-long coupons

\begin{tabular}{|c|c|c|c|}
\hline & Specimen no. 1 & Specimen no. 1 & Specimen no. 2 \\
\hline $\begin{array}{c}\text { Strain gage } \\
\text { number }\end{array}$ & $\begin{array}{c}\text { Stiffness, } \\
\mathrm{E}(\mathrm{GPa})\end{array}$ & $\begin{array}{c}\text { Poison's ratio, } \\
\mathrm{v}\end{array}$ & $\begin{array}{c}\text { Stiffness, } \\
\mathrm{E}(\mathrm{GPa})\end{array}$ \\
\hline 1 & 10.69 & 0.30 & 9.86 \\
\hline 2 & 12.30 & 0.35 & 9.79 \\
\hline 3 & 11.99 & 0.39 & $9.24^{b}$ \\
\hline 4 & $12.11\left(12.89^{a}\right)$ & 0.40 & $10.41\left(11.31^{a}\right)$ \\
\hline 5 & 11.68 & 0.37 & 11.31 \\
\hline 6 & $10.11^{b}$ & 0.36 & 12.00 \\
\hline 7 & 11.99 & 0.31 & 11.10 \\
\hline Average & 11.53 & 0.35 & 10.53 \\
\hline
\end{tabular}

${ }^{a}$ Extensometer was used.

${ }^{b}$ Indicates failure location.

the location of failure is associated with the position of lowest stiffness, with localization ranging within approximately two centimeters about the failed cross section. It can also be seen that strain rises sharply with time prior to failure at $t=t_{f}=2041 \mathrm{~min}$. Local values of cross-sectional areas were considered in all multigaged coupons.

Focusing attention on the strain recorded at the failed location, it was attempted to relate its time dependence to growing damage, in addition to the effect of stress: As a first step the above strain was related by means of the power-law given in Eq. (3), which should well fit the short-time data*. A very good fit, up to $t^{*}=1000 \mathrm{~min}$., was indeed established by utilizing $D_{o}(\sigma)=1.19 \times 10^{-4} \mathrm{MPa}^{-1}$, $D_{1}(\sigma)=2.00 \times 10^{-5} \mathrm{MPa}^{-1} \mathrm{~min}^{-n}$ and $n=0.086$. Beyond $t^{*}$ creep data exceeded values predicted by the power expression, by the amount shown in Fig. 18 and, in an expanded view, in Fig. 19. The excessive strain was attributed to damage growth.

Let $g(t)$ denote the time-dependent portion of damage growth. Thus, for $0<t<t_{f}$ one has ${ }^{4}$

$$
\varepsilon(t ; \sigma, g(t)) / \sigma=D_{o}(\sigma)+D_{1}(\sigma) t^{n}+D_{o}(\sigma) g(t)+D_{1}(\sigma) \int_{0}^{t}(t-\tau)^{n} g^{\prime}(\tau) d \tau
$$

where $g(0)=0$.

The last two terms on the right hand side of Eq. (6) should account for the excessive strain shown in Fig. 19.

Inspection of Fig. 19 suggests that $g(t)$ should contain a combination of slowly varying and rapidly varying functions of time. This motivates the following representation

$g(t)=\hat{A} t^{p}+\hat{B} t^{q}$

with $q \gg p$.

Substitution of Eq. (7) into the last two terms on the right side of Eq. (6) yields, after some manipulations ${ }^{\dagger}$

*Recall that Eq. (3) reflects the experimental observation that for short times $D_{0}$ and $D_{1}$ do not depend on load duration.

${ }^{\dagger}$ These manipulations include a two terms Taylor series expansion of $\Gamma(p+n)$ about $\Gamma(p)$ and similarly for $\Gamma(q+n)$. 


$$
\begin{aligned}
D_{o}(\sigma) g(t)+D_{1}(\sigma) \int_{o}^{t}(t-\tau)^{n} g^{\prime}(\tau) d \tau & \cong D_{o}(\sigma)\left[A\left(\frac{t}{t_{f}}\right)^{p}+B\left(\frac{t}{t_{f}}\right)^{q}\right]+ \\
& D_{1}(\sigma) t_{f}^{n}\left[A \frac{\Gamma(n+1)}{1+n \Psi(p+1)}\left(\frac{t}{t_{f}}\right)^{n+p}+B \frac{\Gamma(n+1)}{1+n \Psi(q+1)}\left(\frac{t}{t_{f}}\right)^{n+q}\right] .
\end{aligned}
$$

In Eq. (8) $\Gamma$ and $\Psi$ denote the Gamma and Digamma functions, respectively.

A reasonable data fit for the effect of time dependent damage growth was achieved by selecting $p=4$ and $q=75, A=0.5752$ and $B=3.1825$. Results are shown in Figs. 18 and 19 .

The latter figures suggest that the deformation of the composite at hand involves three distinct processes. For times up to approximately $t_{f} / 2$ stress-induced damage, probably in the form of interfacial fiber/matrix microcracks remains fixed. Thus at earlier times all creep is due to molecular-level motions within the polymeric phase. This creep is modeled very accurately by Eq. (3). Subsequently, geometric changes due to the growth of the micro-cracks contribute to the overall deformation of the composite. This effect is reflected through the lower power $p$ in Eq. (8).

Finally, the fibers themselves unravel within the strands and break. This last stage, which develops very rapidly and leads to failure, is modeled by the high exponent $q$ in Eq. (8).

It is interesting to note that traces of the phenomenon shown in Fig. 18 are recorded by the neighboring gages (\#2 and \#4), which straddle the failed cross-section. These are shown in Figs. 20, 21, and 22. Note, however, the substantial diminutions in the amplitudes of the strain increments near failure, when compared to the data shown in Figs. 18 and 19. It is furthermore worth noting that at those neighboring locations, strains are predicted by the power-lawexpression (3) for times nearly up to failure. Consequently, it is possible to conclude that failure is localized within a region of approximately two centimeters about the failed crosssection.

\section{SOME ASPECTS OF THE RESPONSE OF URETHANE RESIN}

Exploratory tests were performed to evaluate the stress-strainand creep response of the "neat" resin. Stressstrain to failure results are shown in Fig. 23, with material properties, as reduced from that figure, listed in Table 3. Note the general agreement between results derived from two different samples, in contrast with the consistent disparity between strain gage and extensometer readings. A possible explanation for that disparity is that it stems from the unequal lengths of the strain gage $(1.25 \mathrm{~cm})$ and extensometer $(2.5 \mathrm{~cm})$. Whereby these two devices record distinct average values. It appears that linearity persists up to about $\sigma=10 \mathrm{MPa}$.

Creep and recovery data are shown in Figs. 24 and 25 respectively, for $\sigma=25 M P a$. Note the residual permanent strain that persists in the recovery range. Typical data for the composite are shown in Figs. 24 and 25 for comparison.

Table 3. Tensile test results of urethane (neat resin) specimens

\begin{tabular}{|c|c|c|c|c|c|c|}
\hline Specimen no. & & E $(\mathbf{G P a})$ & $\sigma_{\text {wit }}(\mathrm{MPa})$ & $\boldsymbol{\varepsilon}_{\mathbf{r}}(\mu \varepsilon)$ & $\mathrm{v}$ & $\mathrm{t}_{\mathrm{r}}(\mathrm{sec})$ \\
\hline E-1 & Strain gage & 4.35 & 64.64 & 16806 & 0.33 & 21 \\
\hline E-1 & Extensometer & 3.50 & 64.64 & 22085 & & \\
\hline E-2 & Strain gage & 4.59 & 58.19 & 14039 & 0.36 & 17 \\
\hline E-2 & Extensometer & 3.47 & 58.19 & 19145 & & \\
\hline Average & Strain gage & 4.47 & 61.42 & 15423 & 0.34 & 19 \\
\hline Average & Extensometer & 3.49 & 61.42 & 20615 & & \\
\hline
\end{tabular}




\section{CYCLIC BEHAVIOR}

The cyclic tensile behavior of the composite was investigated under a "saw-tooth" stress input by recording the resulting strain response. These are shown schematically in Fig. 26.

The test plan involved the imposition of four levels of $\sigma_{\max }$, each with three corresponding levels of $\sigma_{\min }$ (or $R=\sigma_{\min } / \sigma_{\max }$ ). Cycling was done at a frequency of $1 \mathrm{~Hz}$ and continued up to 2000 cycles. Three replicate specimens were used at each pair of values $\left(\sigma_{\max }, R\right)$. The details are given in Table 4 . All strains were recorded by means of extensometry.

Table 4. Test program for short-term cyclic fatigue of $P 4$ chopped glass/urethane coupons (Note that all specimens were pre-tested in creep and recovery for subsequent scaling of sample-to-sample stiffness variability)

\begin{tabular}{|c|c|c|c|c|}
\hline $\begin{array}{c}\boldsymbol{\sigma}_{\max } \\
\mathbf{M P a}(\mathrm{ksi})\end{array}$ & $\begin{array}{c}\text { No. of specimens } \\
\text { per } \mathbf{R} \text { per } \boldsymbol{\sigma}\end{array}$ & $\begin{array}{c}\text { Fatigue ratio, } \\
\mathbf{R}\end{array}$ & $\begin{array}{c}\text { Frequency } \\
(\mathbf{H z})\end{array}$ & $\begin{array}{c}\text { Maximum } \\
\text { no. of cycles }\end{array}$ \\
\hline $50(7.25)$ & 3 & $0,0.1,0.3$ & 1 & 2000 \\
\hline $75(10.9)$ & 3 & $0,0.1,0.3$ & 1 & 2000 \\
\hline $100(14.5)$ & 3 & $0,0.1,0.3$ & 1 & 2000 \\
\hline $125(18.1)$ & 3 & $0,0.1,0.3$ & 1 & 2000 \\
\hline
\end{tabular}

As noted in the foregoing sections, all coupons were subjected to creep and recoverytests at $\sigma=25 \mathrm{MPa}$ prior to cyclic loading in order to evaluate the scatter in their properties and thereby scale out the sample-tosample variability.

Results for $R=0,0.1$, and 0.3 , each at four levels of $\sigma_{\max }$, are shown in Figs. 27, 28, and 29, respectively. In those figures, the bold faced numbers denote stress levels that correspond to $\varepsilon_{\max }$, while the plane numbers are associated with $\varepsilon_{\min }$. Note that at $\sigma_{\max }=125 \mathrm{MPa}$ all coupons failed prior to $2000 \mathrm{cycles}$, while at $\sigma_{\max }=100 \mathrm{MPa}$ failure occurred only at $R=0$. It is also possible to observe the sharp upswings in strains vs. number of cycles upon the approach of failure, as well as the trend towards widening of scatter bands with amplitude of $\sigma_{\max }$.

As noted previously ${ }^{1,3}$, it is possible to relate the strain response to cyclic stress input with growing damage which, for power-law creep, results in the following form.

$\varepsilon(t)=D_{o} \eta(t) \sigma(t)+D_{1} \int_{0}^{t}(t-\tau)^{n} \frac{d}{d \tau}[\eta(\tau) \sigma(\tau)] d \tau$

Obviously, for cyclic input it is possible to relate time to the number of cycles.

In Eq. (9), damage $\eta$ was measured as the cycle-to-cycle enhancement in compliance. Thus, for the $i^{t h}$ cycle

$\eta_{i}=\frac{S_{i}}{D_{o}}=\frac{1}{D_{o}} \frac{\varepsilon_{i}^{\max }-\varepsilon_{i}^{\min }}{\sigma_{\max }-\sigma_{\min }}$

Scaling was affected relative to the initial compliance in the linear range, $D_{o}$, which was specific to each sample. Values of $\eta_{i}$ for $R=0,0.1$, and 0.3 at each of the corresponding stress levels are shown in Figs. 30, 31 , and 32, respectively, vs. number of cycles $i$.

It was possibleto represent the family of curves shown in the latter figures by an empirical power-law form, namely

$\eta_{i}=1+\left(\Delta w_{o}+\Delta w_{1} i^{m}\right) H\left(\sigma-\sigma_{d}\right)$ 
Employment of "best fit" subroutines resulted in sets of values for $\Delta w_{o}, \Delta w_{1}$, and $m$ shown in Figs. 33, 34, and 35. In turn, these sets could be related by means of the following empirical expressions:

$f(\sigma, R)=A+B \sigma+C R+D \sigma^{2}+E \sigma R+F R^{2}+G \sigma^{2} R+H \sigma R^{2}+I \sigma^{2} R^{2}$,

where values of $A, B, \ldots, I$ for $\Delta w_{o}, \Delta w_{1}$, and $m$ are listed in Table 5. These values correspond to $\sigma$ in $M P a$.

Although damage growth occurs throughout the loading history, its increments were recorded only intermittently, namely over the unloading range of each cycle. In fact, a more detailed experimentalevaluation of damage growth may be nearly impossible. For this reason, it is assumed herein that all damage growth, within each individual loading cycle, is focused at the time when $\sigma=\sigma_{\max }$. This assumption appears to be a reasonable approximation, since damage is strongly governed by stress.

Table 5. Polynomial fits for the damage parameters $\Delta w_{o}, \Delta w_{1}$, and $m$ in Eq. (12)

\begin{tabular}{|c|c|c|c|}
\hline Coefficients & $\Delta w_{o}$ & $\Delta w_{1}$ & $m$ \\
\hline A & $-4.8726 \mathrm{E}-02$ & $2.6291 \mathrm{E}-03$ & $1.0682 \mathrm{E}-01$ \\
\hline B & $1.6740 \mathrm{E}-03$ & $1.5632 \mathrm{E}-04$ & $1.7360 \mathrm{E}-03$ \\
\hline C & $1.0254 \mathrm{E}-06$ & $-2.2792 \mathrm{E}-06$ & $1.6120 \mathrm{E}-06$ \\
\hline D & $1.7061 \mathrm{E}-09$ & $1.3295 \mathrm{E}-09$ & $-1.6950 \mathrm{E}-09$ \\
\hline E & $1.1319 \mathrm{E}-06$ & $-5.3333 \mathrm{E}-08$ & $-2.9198 \mathrm{E}-7$ \\
\hline F & $2.8071 \mathrm{E}-02$ & $1.4010 \mathrm{E}-02$ & $-8.1695 \mathrm{E}-02$ \\
\hline G & $4.3893 \mathrm{E}-07$ & $-1.7871 \mathrm{E}-06$ & $-5.3496 \mathrm{E}-06$ \\
\hline H & $-5.6754 \mathrm{E}-03$ & $-2.8800 \mathrm{E}-05$ & $2.2227 \mathrm{E}-03$ \\
\hline I & $-3.4439 \mathrm{E}-06$ & $4.2741 \mathrm{E}-07$ & $-4.0188 \mathrm{E}-05$ \\
\hline
\end{tabular}

The above assumption implies that damage growth is introduced incrementally, via $\Delta \eta_{i}$, where

$\Delta \eta_{i}=\eta_{i}-\eta_{i-1}=\Delta w_{1}\left[i^{m}-(i-1)^{m}\right] \quad i \geq 1$

Consequently

$\eta_{N}=\eta\left(t_{N}\right)=\Delta w_{o} H(t)+\sum_{i=1}^{N} \Delta \eta_{i} H[t-(k+2 i-1) a]$

Note, that insertion of Eq. (14) into the convolution integral (9) results in substantial computational simplifications, since integrations now incorporate step and Dirac delta functions.

Consider now the "saw-tooth" stress history shown in Fig. 26(a). For computational purposes it is advantageousto introduce $\hat{t}=t-t_{o}, \hat{\sigma}=\sigma-\sigma_{L}$, whereby the stressrate is $r=\frac{\sigma_{L}}{t_{o}}=\frac{\sigma_{u}-\sigma_{L}}{a}=\frac{\hat{\sigma}_{u}}{a}$, where $t_{o}=k a$.

The stress-time variation can be expressed by

$$
\hat{\sigma}(\hat{t})=\left\{\begin{array}{rr}
r(\hat{t}-2 i a) & i a<\hat{t}<(2 i+1) a \\
-r[\hat{t}-2(i+1) a] & (2 i+1) a<\hat{t}<2(i+1) a
\end{array} \quad i=0,1, \ldots\right.
$$

resulting in

$\sigma(t)=r t\left[H(t)-H\left(t-t_{o}\right)\right]+r t_{o} H(\hat{t})+\hat{\sigma}(\hat{t}) H(\hat{t})$

Upon a straightforward manipulation one obtains 
$\frac{d \sigma}{d t}=r\left[H(t)-H\left(t-\dot{t}_{o}\right)\right]+\frac{d \hat{\sigma}(\hat{t})}{d \hat{t}} H(\hat{t})$

thereby

$\frac{d \sigma}{d t}=r\left[H(t)-H\left(t-t_{o}\right)\right]+\left\{\begin{array}{ll}r & i a<\hat{t}<(2 i+1) a \\ -r & (2 i+1) a<\hat{t}<2(i+1) a .\end{array} \quad i=0,1, \ldots\right.$

Upon utilization of Eqs. (9)-(18), with expression (14) re-cast in terms of $\hat{t}$, and performing several tedious integrations one obtains

$\varepsilon_{j}^{\min }=\varepsilon[t=k a+2(j+1) a]=\varepsilon[\hat{t}=2(j+1) a]=I_{1}+I_{2}+I_{3}+I_{4}+I_{5} ; \quad j=0,1, \ldots$

where

$$
\begin{aligned}
& I_{1}=D_{o} \sigma_{L} \eta_{j+1} \\
& I_{2}=\frac{D_{1} r}{n+1}\left\{[2(j+1) a+k a]^{n=1}-[2(j+1) a]^{n+1}\right\} \\
& I_{3}=D_{1} \sum_{i=0}^{j} \frac{r}{n+1}\left\{-[2(j+1) a-(2 i+1) a]^{n+1}+[2(j+1) a-2 i a]^{n+1}\right\} \eta_{i+1} \\
& I_{4}=D_{1} \sum_{i=0}^{j} \frac{r}{n+1}\left\{[2(j+1) a-2(i+1) a]^{n+1}-[2(j+1) a-(2 i+1) a]^{n+1}\right\} \eta_{i+1} \\
& I_{5}=D_{1}[2(j+1) a]^{n} \sigma_{L} \eta_{o}+D_{1} \sigma_{L} \sum_{i=0}^{j}\left\{[2(j+1) a-(2 i+1) a]^{n}\right\}\left(\eta_{i+1}-\eta_{i}\right)
\end{aligned}
$$

and

$$
\varepsilon_{j}^{\max }=\varepsilon[t=k a+(2 j+1) a]=\varepsilon[\hat{t}=(2 j+1) a]=J_{1}+J_{2}+J_{3}+J_{4}+J_{5} ; j=1,2, \ldots
$$

where

$$
\begin{aligned}
& J_{1}=D_{o} \sigma_{u} \eta_{j} \\
& J_{2}=\frac{D_{1} r}{n+1}\left\{[k a+(2 j+1) a]^{n=1}-[(2 j+1) a]^{n+1}\right\} \\
& J_{3}=D_{1} \sum_{i=0}^{j} \frac{r}{n+1}\left\{-[(2 j+1) a-(2 i+1) a]^{n+1}+[(2 j+1) a-2 i a]^{n+1}\right\} \eta_{i} \\
& J_{4}=D_{1} \sum_{i=1}^{j} \frac{r}{n+1}\left\{-[(2 j+1) a-2 i a]^{n+1}-[(2 j+1) a-(2 i-1) a]^{n+1}\right\} \eta_{i} \\
& J_{5}=D_{1}[(2 j+1) a]^{n} \sigma_{L} \eta_{o}+D_{1} \sigma_{L} \sum_{i=1}^{j}\left\{[(2 j+1) a-(2 i+1) a]^{n}\right\}\left(\eta_{i}-\eta_{i-1}\right) .
\end{aligned}
$$

Note, however, that in view of Eq. (3), it is necessary to add the permanent component $\varepsilon_{p}$ to $\varepsilon_{\min }$. In view of the cyclic nature of the stress, the value of $\varepsilon_{p}$ was related to the cyclically increasing value of $\varepsilon_{\max }$ according to the expression given in Fig. 6.

The predicted results for $\varepsilon_{\max }$ and $\varepsilon_{\min }$ vs. number of cycles $i$ are shown by the solid lines in Figs. 36, 37, and 38. Note the excellent agreement with the scaled deformation curves. It should be noted that 
predictions do depart from data in those cases where failures occurred prior to 2000 load cycles. The above discrepancy is due to the fact that expression (11) does not contain a failure criterion akin to that discussed in Chapter 3.

\section{DISTILLED WATER: SORPTION AND EFFECT ON MECHANICAL RESPONSE}

This section presents sorption data for the P4 chopped glass/urethane compositeexposed to distilled water at several levels of temperature, and the effects of such exposures on mechanical response. Attention is focused on distilled water, since this fluid was shown to provide the most severe environmentfor a similar composite.

\subsection{SORPTION BEHAVIOR}

The experimental plan involved coupons of the same dimensions as noted previously. All coupons were dried in a desiccating chamber until attaining a stable weight. Subsequently, they were immersed in distilled water at various temperatures, with periodic weight-gain measurements until-and at times beyond-saturation. Randomly selected coupons were then re-dried in a desiccant chamber and weight losses monitored periodically. The exposure schedule is listed in Table 6, and the results are shown in Figs. 39-45.

Table 6. Schedule of exposure to distilled water

\begin{tabular}{|c|c|c|c|c|}
\hline $\begin{array}{c}\text { Exposure } \\
\text { temperature }\end{array}{ }^{\circ} \mathbf{C}\left({ }^{\circ} \mathbf{F}\right)$ & $\begin{array}{c}\text { No. of } \\
\text { specimens }\end{array}$ & $\begin{array}{c}\text { Saturation time } \\
\text { (hours) }^{1 / 2}\end{array}$ & $\begin{array}{c}\text { Desorption time } \\
\text { (hours) }^{1 / 2}\end{array}$ & Remarks \\
\hline $23(73)$ & $12^{a}$ & $85-90^{b}$ & $30-35$ (in progress) & \\
\hline $36(97)$ & 6 & 52 & 27 & $\begin{array}{c}\text { Some weight loss due } \\
\text { to leaching }\end{array}$ \\
\hline $50(122)$ & 6 & 31 & 22 & $\begin{array}{c}\text { Noticeable weight loss } \\
\text { due to leaching }\end{array}$ \\
\hline
\end{tabular}

$a_{\text {Six }}$ of these were pre-tested for creep and recovery prior to immersion.

$b_{\text {Estimate. }}$

Note the relatively narrow scatter in both weight-gain and weight-loss data. Figure 39 corresponds to coupons that were not mechanically tested prior to immersion.

The foregoing results lead to the following observations:

(i) Temperature accelerates the diffusion process

Employment of a well-established methodology ${ }^{7}$, the data in Figs. 39-42 yield a correlation between the diffusion coefficient $\mathrm{D}$ and temperature $\mathrm{T}$, as listed below:

$$
\begin{aligned}
& D\left(23^{\circ} \mathrm{C}\right)=5.230 \times 10^{-7} \mathrm{~mm}^{2} / \mathrm{sec}, D\left(36^{\circ} \mathrm{C}\right)=1.171 \times 10^{-6} \mathrm{~mm}^{2} / \mathrm{sec}, \\
& D\left(50^{\circ} \mathrm{C}\right)=2.634 \times 10^{-6} \mathrm{~mm}^{2} / \mathrm{sec} .
\end{aligned}
$$

A plot of $\log D v s .1 / T\left(T\right.$ in $\left.{ }^{\circ} \mathrm{K}\right)$ is shown in Fig. 46. These results can be represented by:

$$
\log D=2.1165-\frac{2486.2}{T}
$$

where $T$ is in ${ }^{\circ} K$.

The above values are between one and two orders of magnitude higher than those which obtain for the familiar epoxy resin composites. 


\section{(ii) Losses in material integrity increase with exposure temperature}

This phenomenon is noted by comparing the weight-gain data shown in Figs. 39-42. These data demonstrate weight-losses that increase with immersion temperature. Furthermore, note the diminishing levels of maximum weight-gains as the foregoing temperature rises. The magnitude of these weight-losses can be determinedby comparing weight-gain records against the weight-loss data exhibited in Figs. 43-45. Accordingly, exposureat $36^{\circ} \mathrm{C}$ results in a net loss of $0.4 \%$, while at $50{ }^{\circ} \mathrm{C}$ this amount is about $1.2 \%$. These losses are caused by the leaching out of matter from the composite.

\subsection{EFFECTS OF IMMERSION ON MECHANICAL RESPONSE}

The effects of immersion in distilled water on mechanical response were recorded experimentally by comparing creep and recovery data of test coupons prior to and after their immersion. All data were collected at room temperature under a step stress as noted in Chapter 2, with $\sigma_{o}=25 \mathrm{MPa}$ and load duration of $t_{o}=30 \mathrm{~min}$. Recovery strains were recorded during an additional 90 minutes. Results are shown in Figs. 47-52 and summarized in Figs. 53, 54, and 55.

Note the increase in creep strains when comparing the dry and immersed data, with increasing disparity due to higher immersion temperatures. Furthermore, it can be observed that prior exposure to distilled water results in permanent residual deformation, where none existed in the absence of such exposure. The amplitude of this permanent deformation tends to increase with immersion temperature. The abovementioned enhancements in both creep strains and permanent deformation are clear indicators of fluid-induced irreversible degradations.

\section{CONCLUDING REMARKS}

An experimentalprogram was performed regardingthe response of random $\mathrm{P} 4$ chopped glass/urethaneresin composite. The program was guided by a theoretical model derived from basic principles of irreversible thermodynamics and continuum mechanics, which was developed to predict the behavior of the specific class of materials investigated herein.

The experimental data were employed to quantify the material parameters included in the theoretical formulation. These parameters accounted for the effects of stress and temperature on the ensuing deformation. With these parameters at hand it was possible to utilize the model in a predictive mode and assess its usefulness through comparisons with responses to more complex inputs. These comparisons proved to be satisfactory.

The foregoing results demonstrate the applicability of the methodology employed herein to a technically significant class of polymeric materials, namely those where creep is accompanied by the formation and growth of a multitude of internal microcracks.

\subsection{PRACTICAL IMPLICATIONS}

The model presented herein can be utilized in three major ways:

(i) Predict long-term behavior on the basis of short-term data.

(ii) Interpret and employ accelerated deformation data, obtained at elevated temperatures, to assess long-term response.

(iii) Analyze stress-strain response under exposure to fluctuating stress and temperature inputs. 


\section{REFERENCES}

1. Smith, L. and Weitsman, Y. (1998). "Inelastic Behavior of Randomly Reinforced Polymeric Composites Under Cyclic Loading," Mechanics of Time-Dependent Materials, Vol. 1, pp. 293-305.

2. Smith, L. and Weitsman, Y. (1998). "The Visco-Damage Mechanical Response of Swirl-Mat Composites," International Journal of Fracture (in print).

3. Elahi, M. and Weitsman, Y. (1999). Some Aspects of the Deformation Response of Swirl-Mat Composites, ORNL/TM-13521, Engineering Technology Division, Bldg. 9204-1, MS 8051, Box 2009, Oak Ridge National Laboratory, Oak Ridge, TN 37831-8051.

4. Abdel-Tawab, Kh. and Weitsman, Y. (1998). "A Coupled Viscoelasticity/Damage Model with Application to Swirl-Mat Composites," International Journal of Damage Mechanics, Vol. 7, No. 4, pp. 351-380.

5. Abdel-Tawab, Kh. and Weitsman, Y. (1998). "A Strain-Based Formulation for the Coupled Viscoelasticity/Damage Behavior," Contract Technical Report No. MAES97-3.0-CM, Department of Mechanical and Aerospace Engineering and Engineering Science, The University of Tennessee, Knoxville, TN 37996-2030.

6. Corum, J. M., Battiste, R. L., Brinkman, C. R., Ren, W., Ruggles, M. B., and Yahr, G. T. (1998) Durability-Based Design Criteria for an Automotive Structural Composite: Part 1. Design Rules, ORNL-6930, Engineering Technology Division, Bldg. 9204-1, MS 8051, Box 2009, Oak Ridge National Laboratory, Oak Ridge, TN 37831-8051.

7. Shen, C.-H. and Springer, G. S. (1980). "Moisture Absorption and Desorption of Composite Materials," in Environmental Effects on Composite Materials (G. S. Springer-Editor), Technomic Pub. Co., pp. 15-33. 


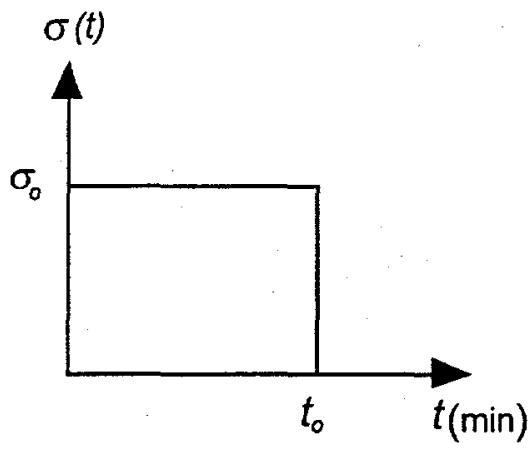

a. Stress

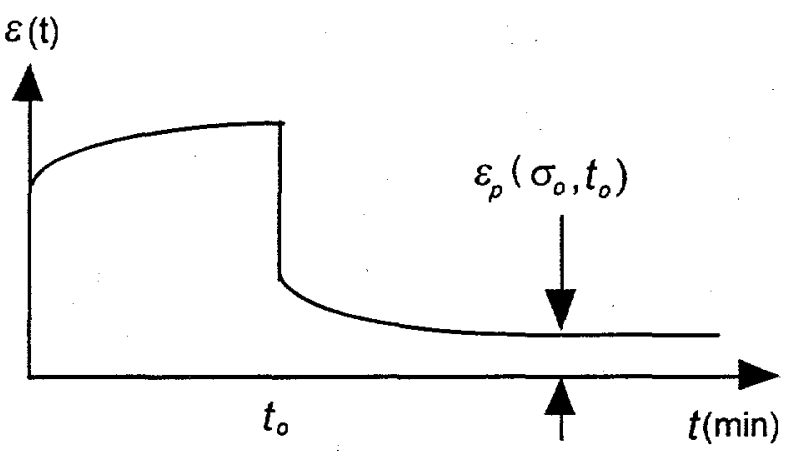

b. Strain

Fig. 1. Schematic drawings of stress input history and strain output.

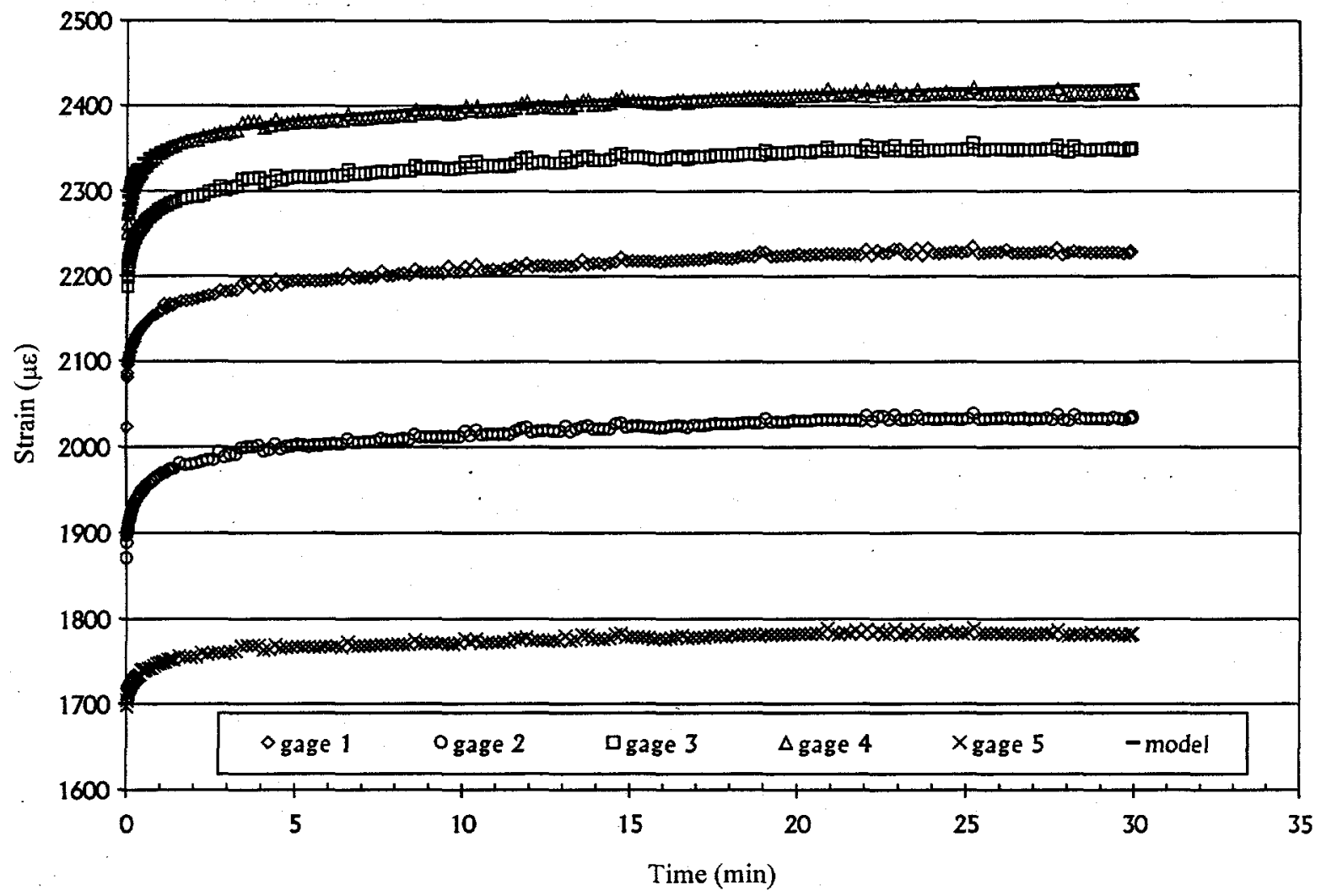

Fig. 2. Creep strains due to $\sigma=25 \mathrm{MPa}$ at five stations along a single coupon, implying a $35 \%$ variability in stiffness. 

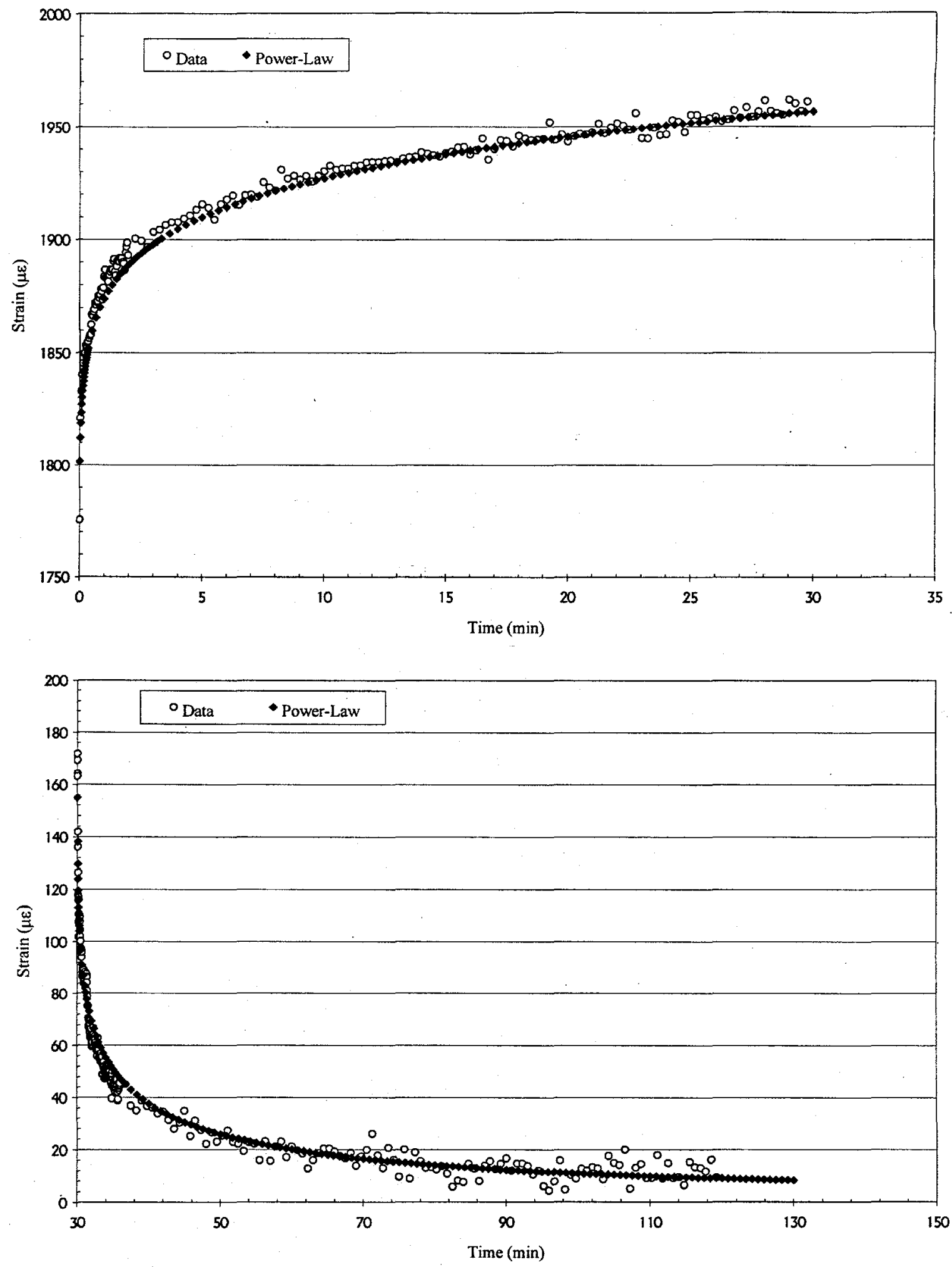

Fig. 3. Typical data for creep (top) and recovery (bottom) within the linear range of response. Data (ooo) and model $(\bullet \bullet \bullet) . \sigma_{0}=25 \mathrm{MPa}, \mathrm{t}_{0}=30 \mathrm{~min}$., $\mathrm{T}=23^{\circ} \mathrm{C}$, $\mathrm{D}_{0}=6.51 \times 10^{-5} \mathrm{MPa}^{-1}, \mathrm{D}_{1}=9.72 \times 10^{-6} \mathrm{MPa}^{-1} \mathrm{~min}^{-1}$, and $\mathrm{n}=0.086$. 


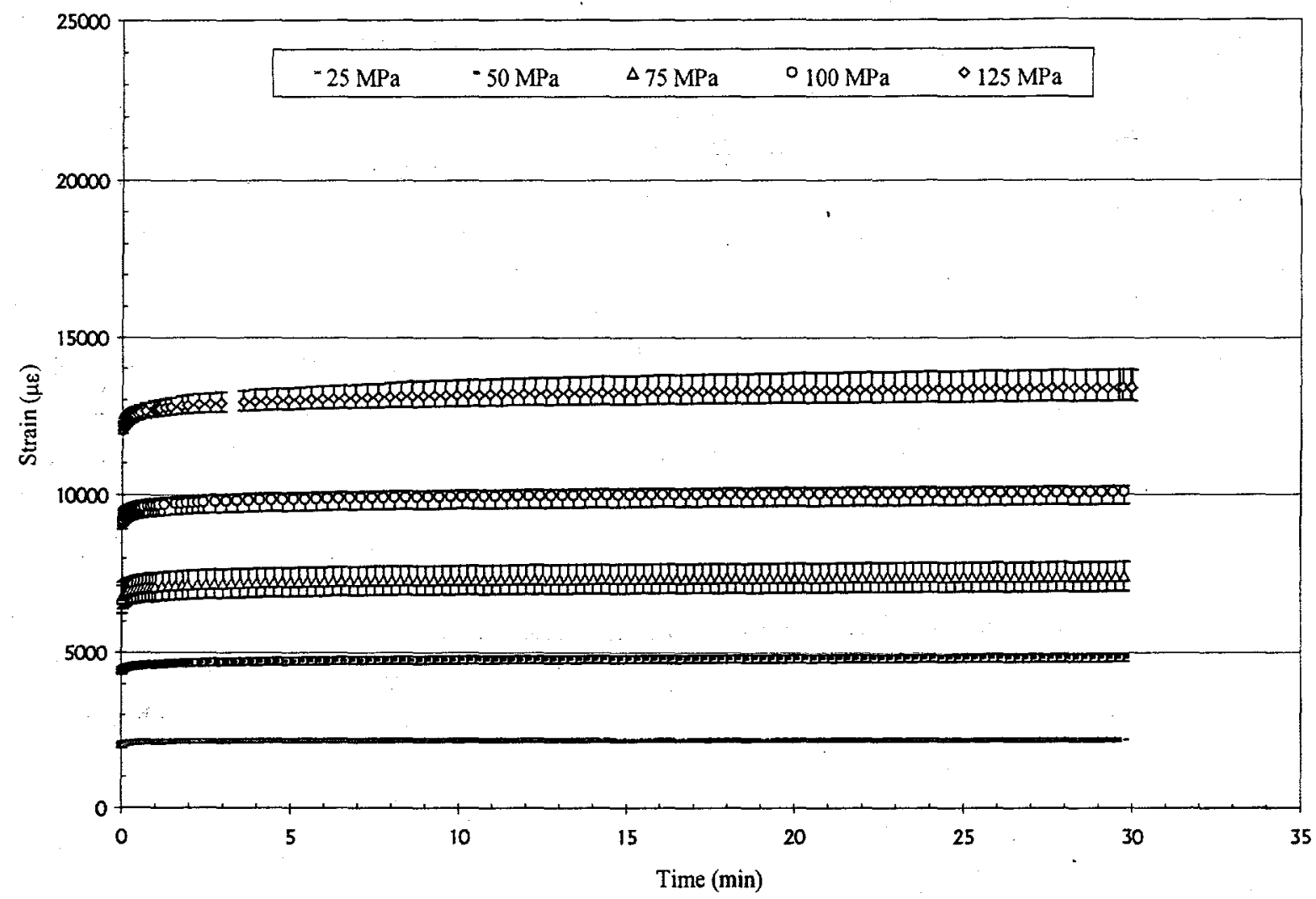

Fig. 4. Scaled creep data at $23^{\circ} \mathrm{C}$ under various stress levels. Average values and scatter bands. 


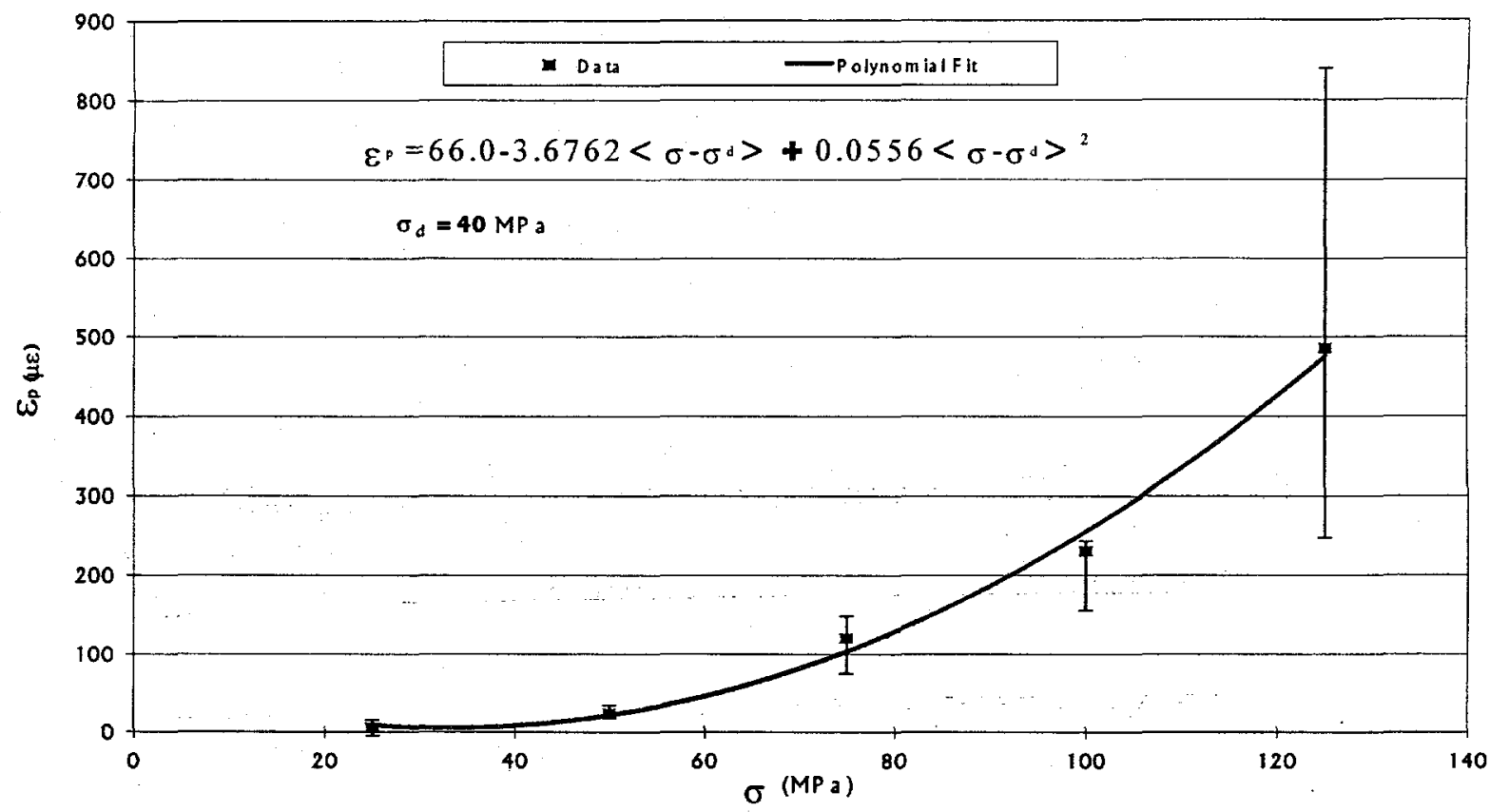

Fig. 5. Permanent residual strain vs. level of applied stress. Average values and scatter bands.

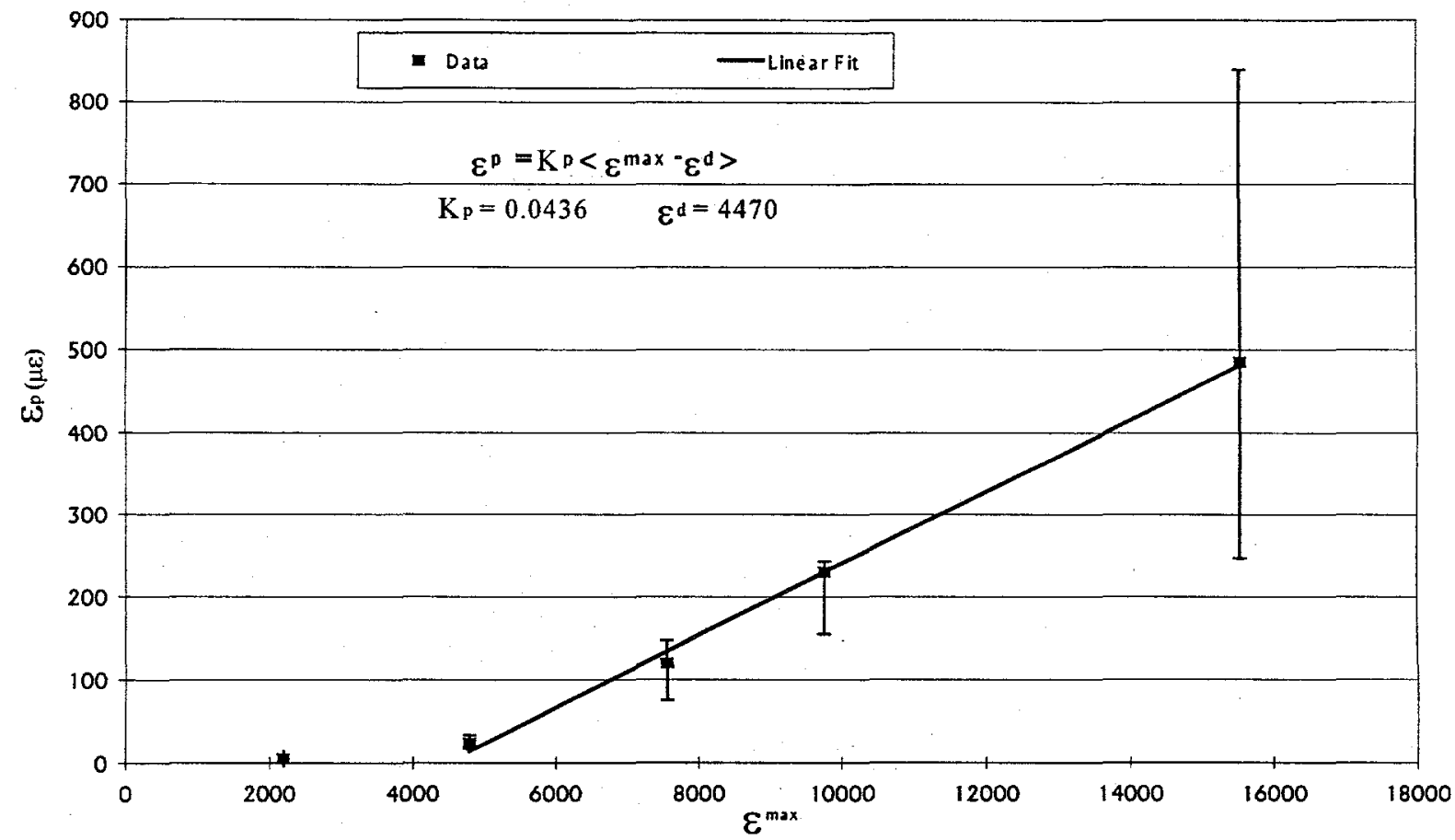

Fig. 6. Permanent residual strain vs. averaged values of maximum strains attained under loading. Average values and scatter bands. 


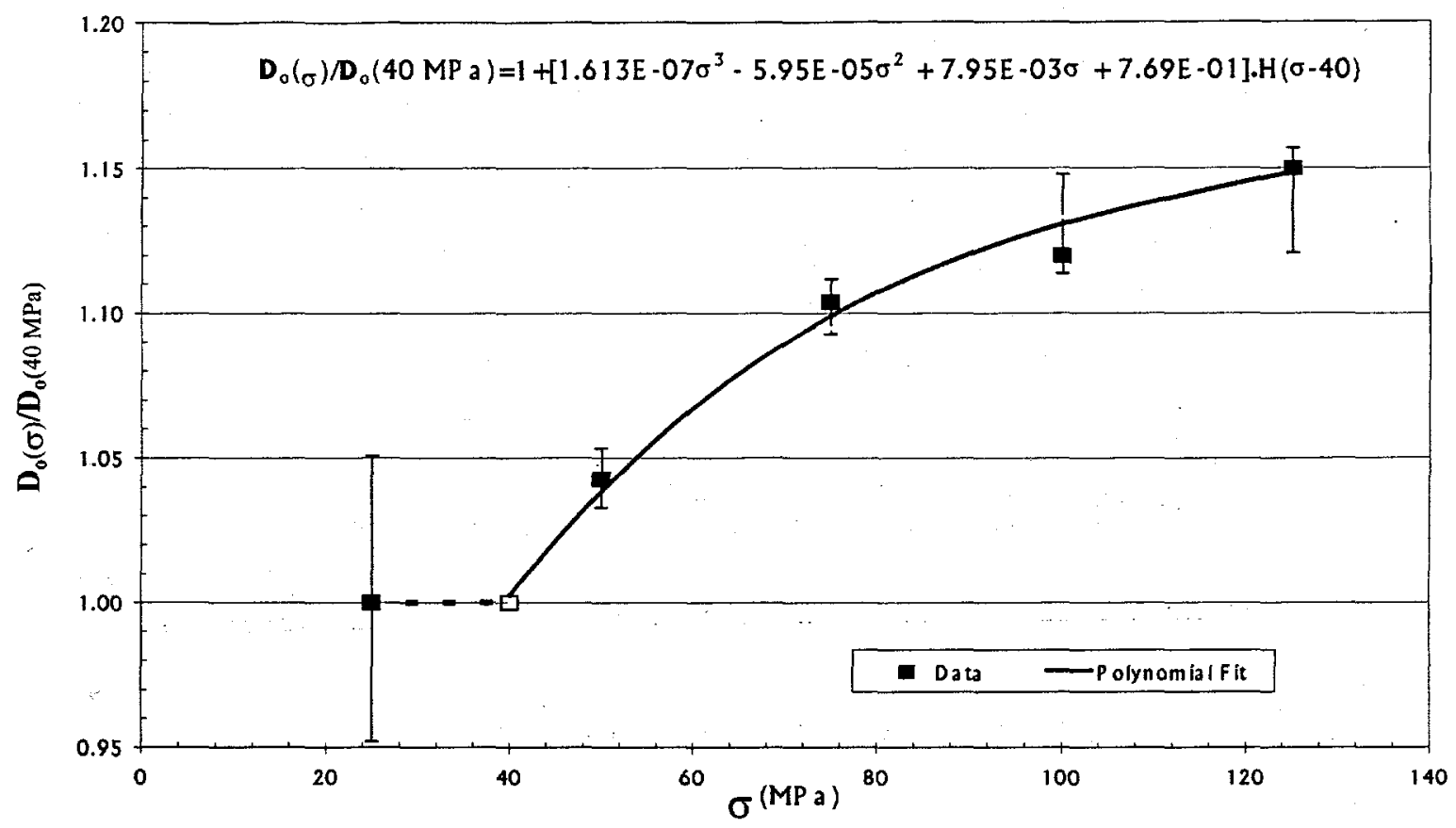

Fig. 7: Scaling factor for $D_{0}(\sigma)$ to be employed in Eq. (3).

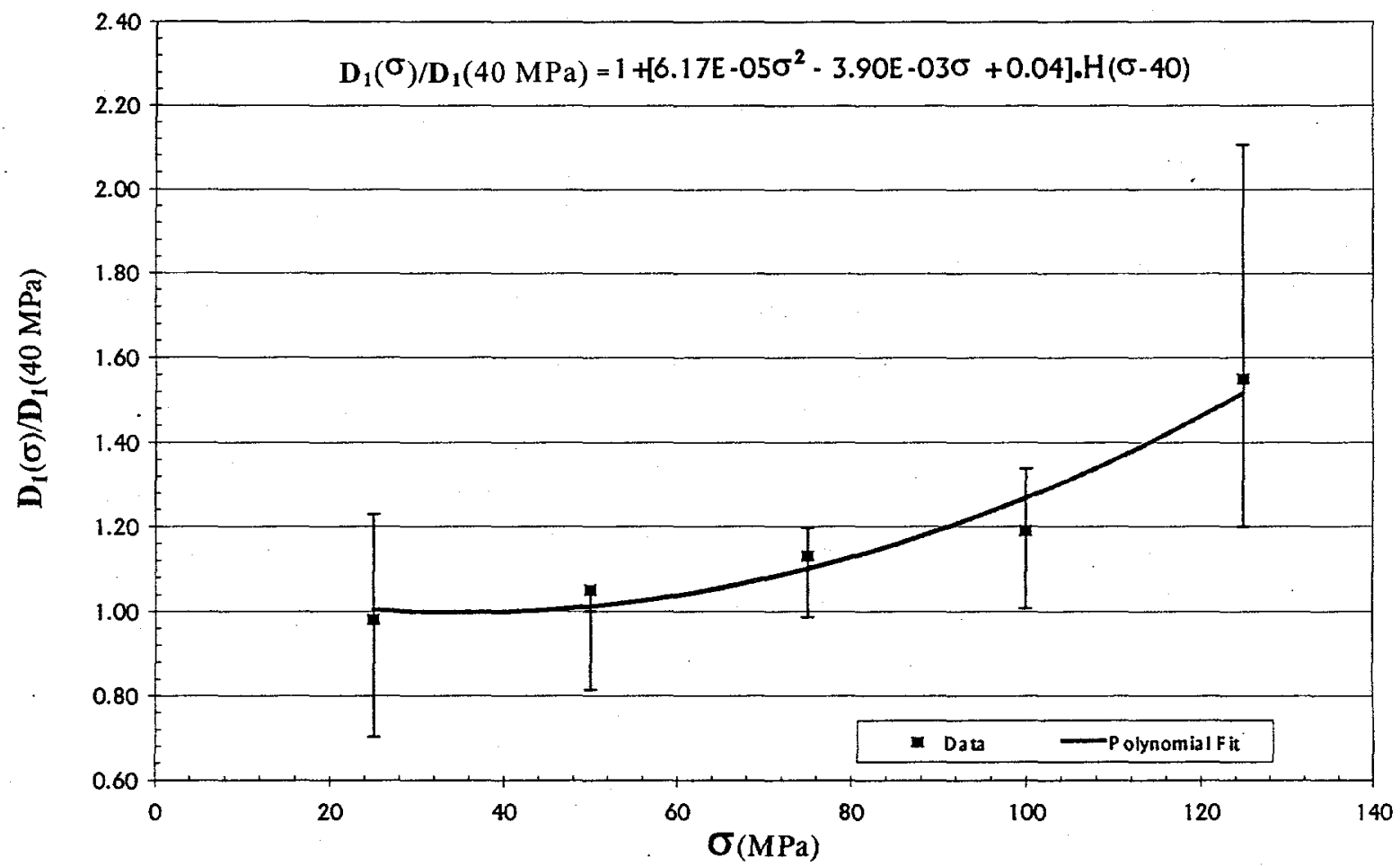

Fig. 8: Scaling factor for $D_{1}(\sigma)$ to be employed in Eq. (3). 


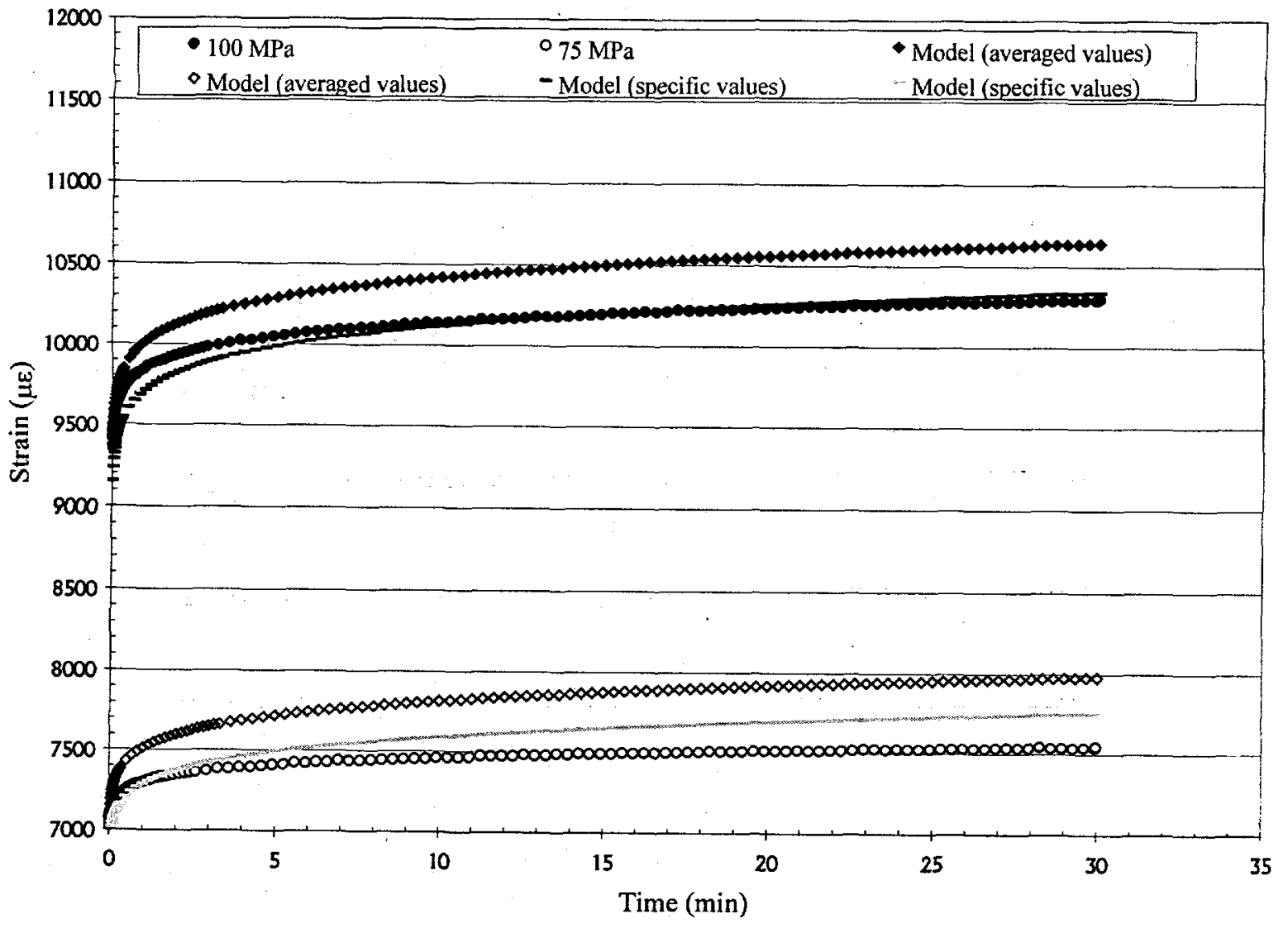

Fig. 9: Two-step stress history model verification test. A step stress $\sigma_{1}=100 \mathrm{MPa}$ was applied and removed after 30 minutes. Following a relaxation period of 24 hours a second step stress $\sigma_{2}=75 \mathrm{MPa}$ was applied. Data $(\bullet \bullet)$ and model predictions: (i) based upon Eq. (3) $(\diamond \bullet)$, (ii) based upon best power-law fit for $\sigma_{1}=100 \mathrm{MPa}(---)$. (Filled symbols $\sigma_{1}=100 \mathrm{MPa}$, open symbols $\sigma_{2}=75 \mathrm{MPa}$ ). 


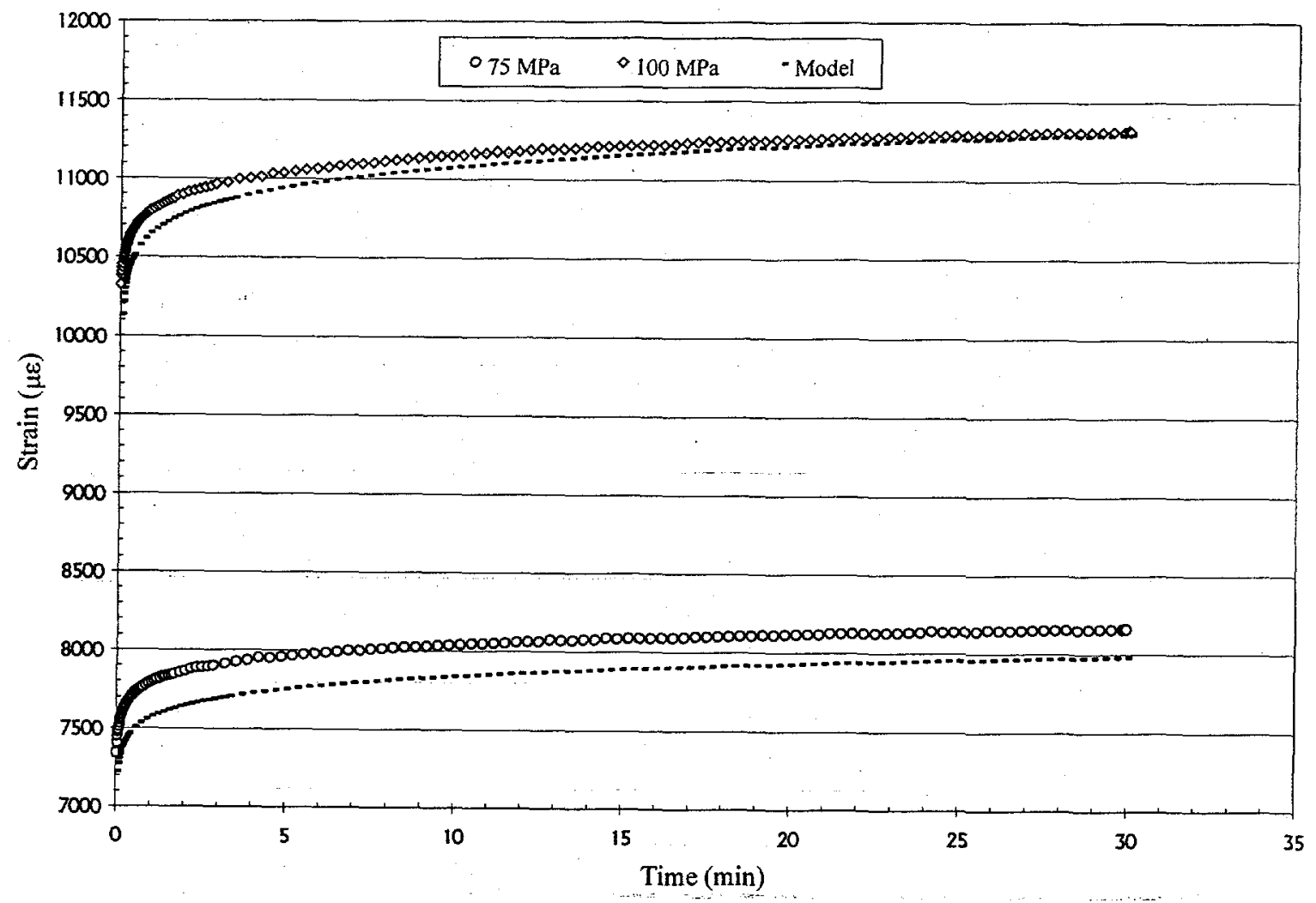

Fig. 10. Same as Fig. (9), but $\sigma_{1}=75 \mathrm{MPa}$ and $\sigma_{2}=100 \mathrm{MPa}$.

Data and predictions are based upon Eq. (3). 


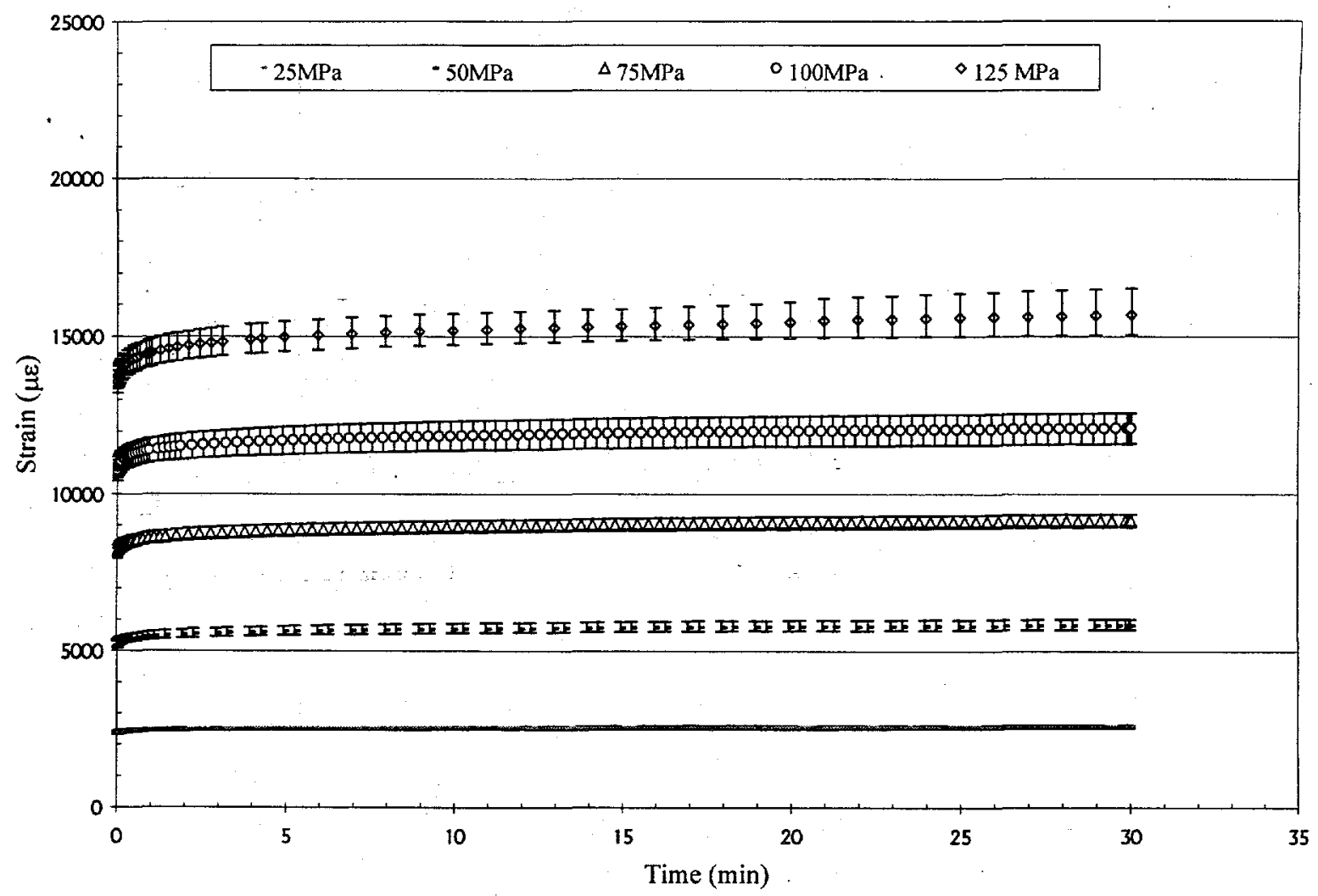

Fig. 11. Scaled creep data at $\mathrm{T}=50^{\circ} \mathrm{C}$ under various stress levels. Average values and scatter bands. 


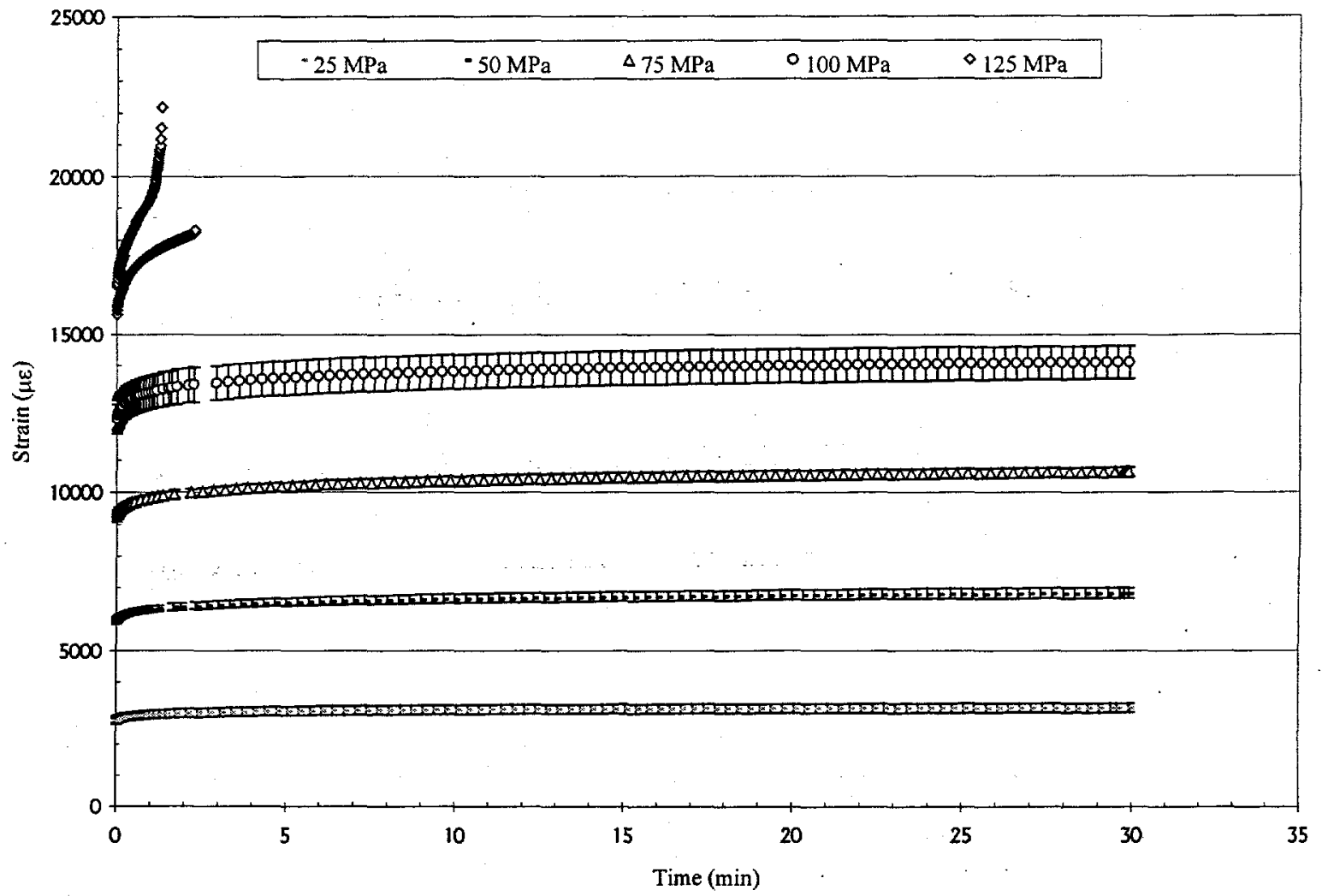

Fig. 12. Scaled creep data at $\mathrm{T}=120^{\circ} \mathrm{C}$ under various stress levels. Average values and scatter bands. 


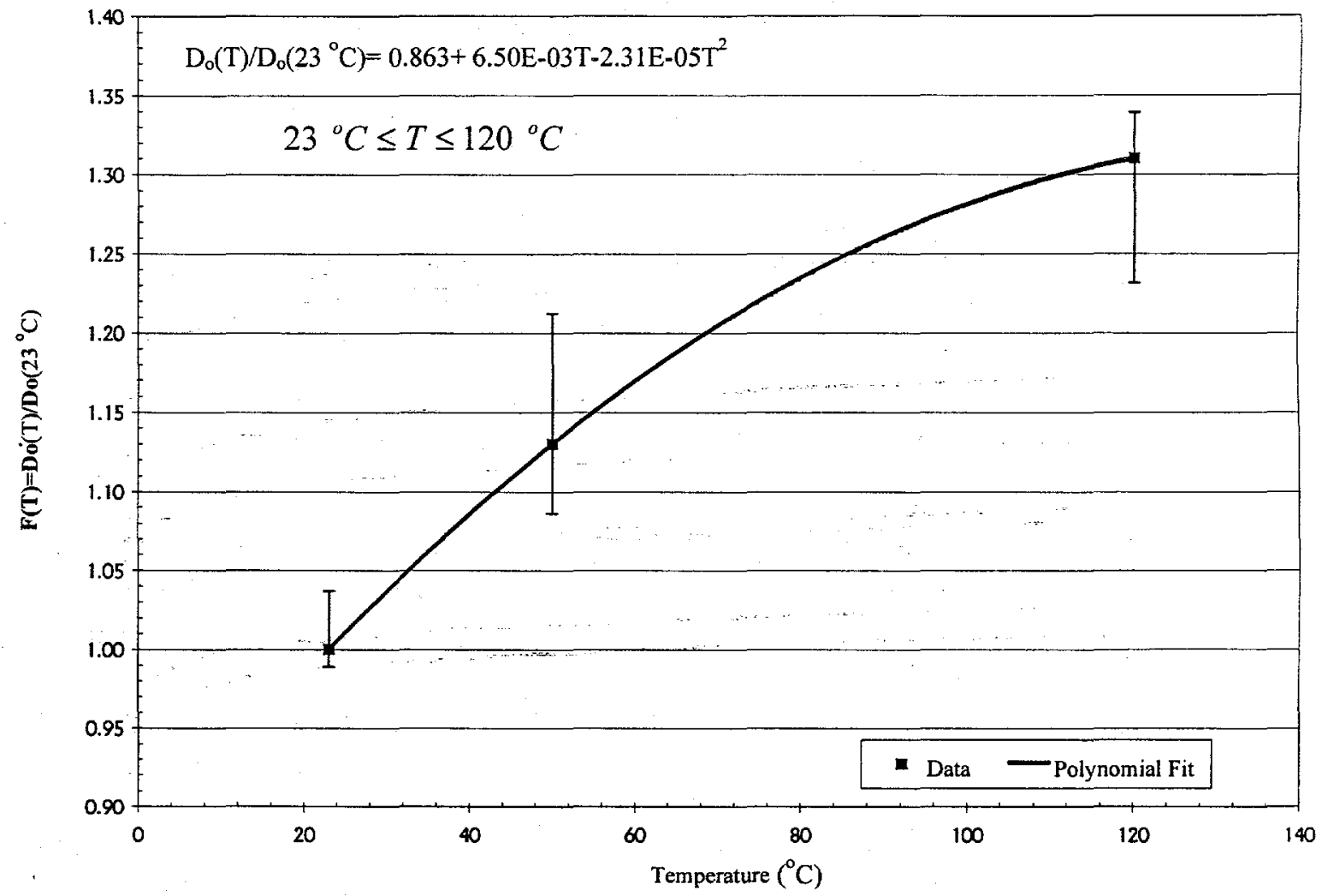

Fig. 13. Temperature-induced enhancement of Do.

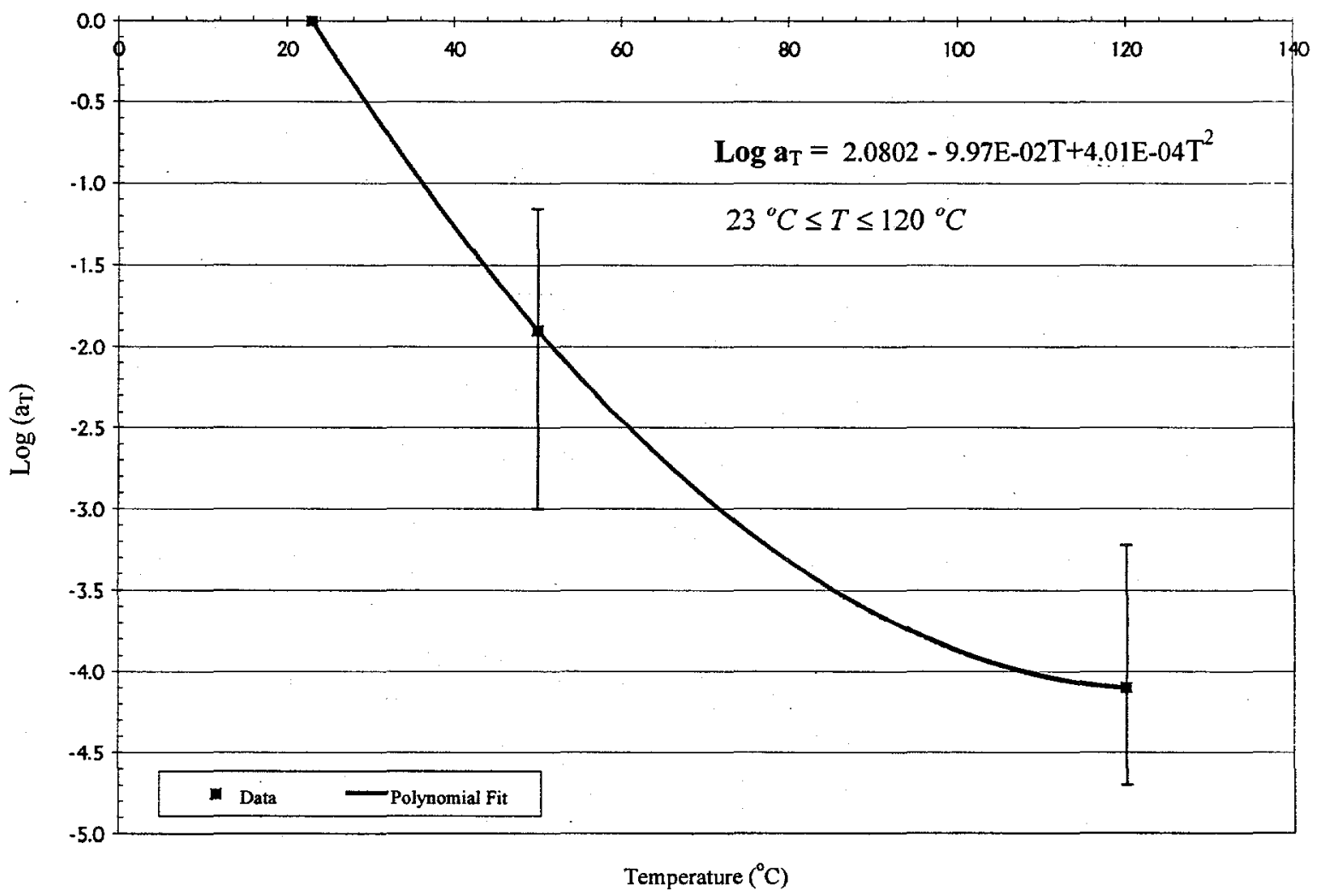

Fig. 14. Time-temperature shift factor aT vs. temperature $T$. 


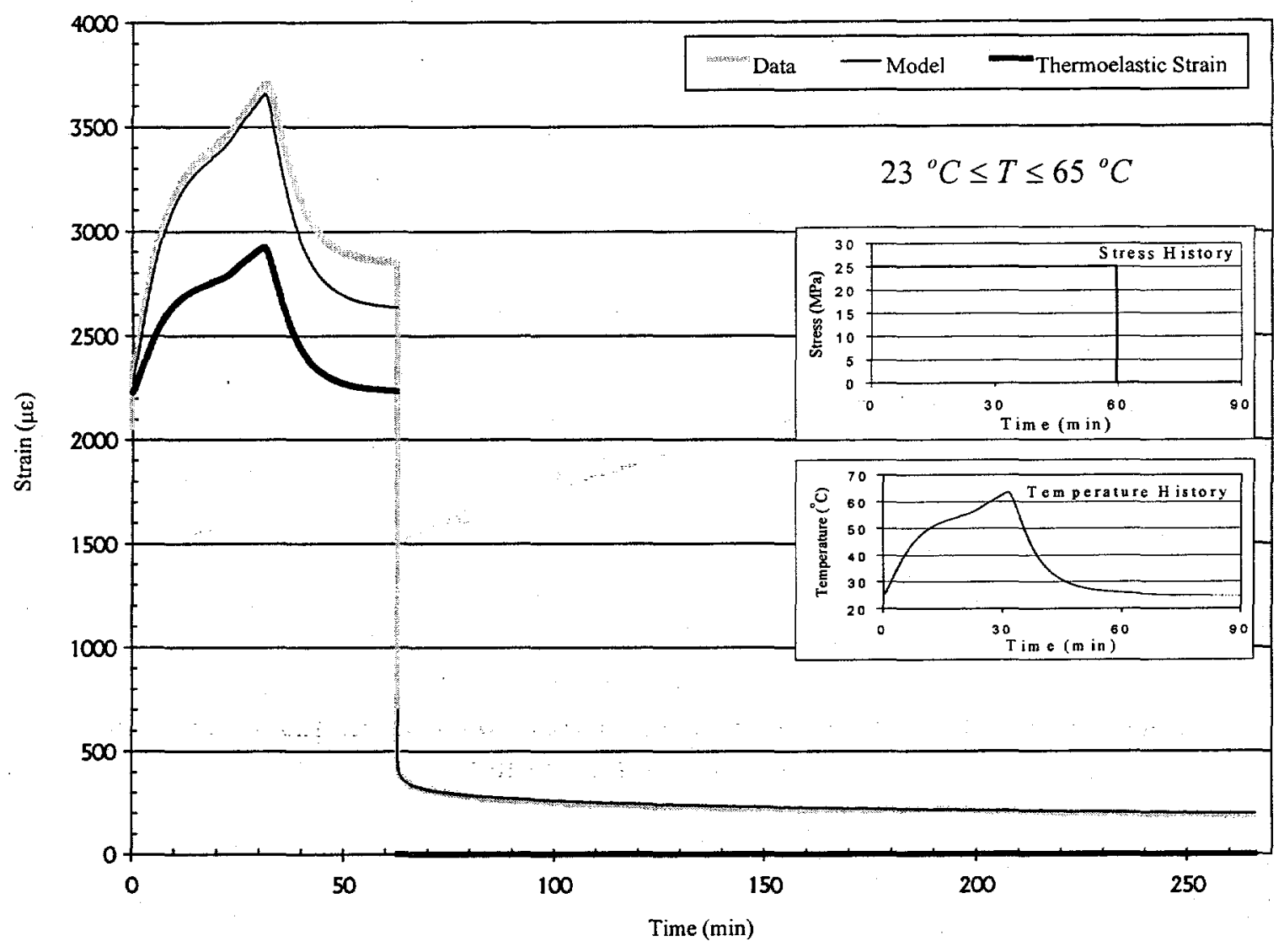

Fig. 15. Varying temperature verification test. Data (mane), model predictions (Eq..(5a)) ( - ), and thermoelastic predictions ( - ). 


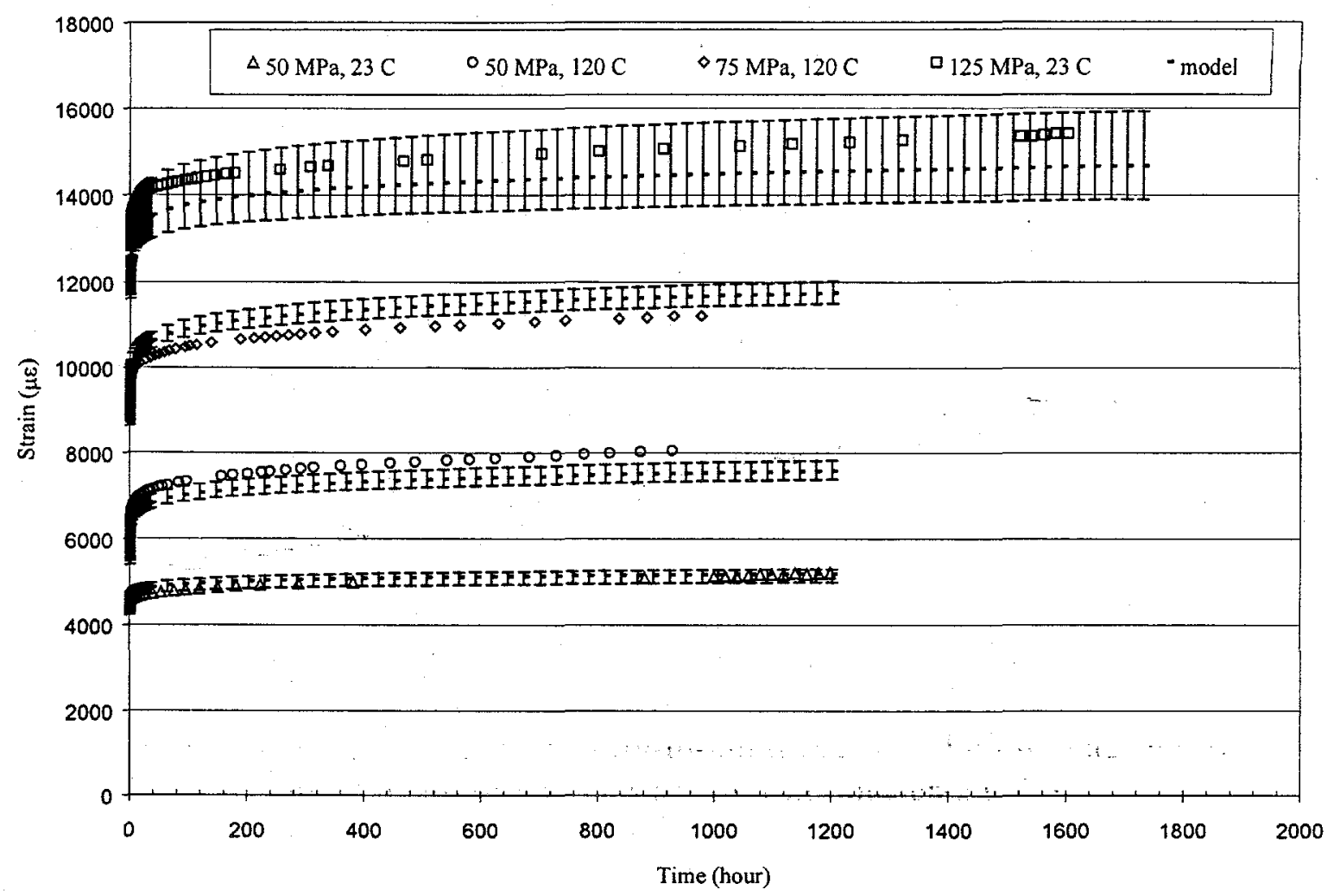

Fig. 16. Long-term creep data (open symbols) at various levels of stress and temperature and predictions based on Eq. (5). Model average values (---) and scatter bands. 


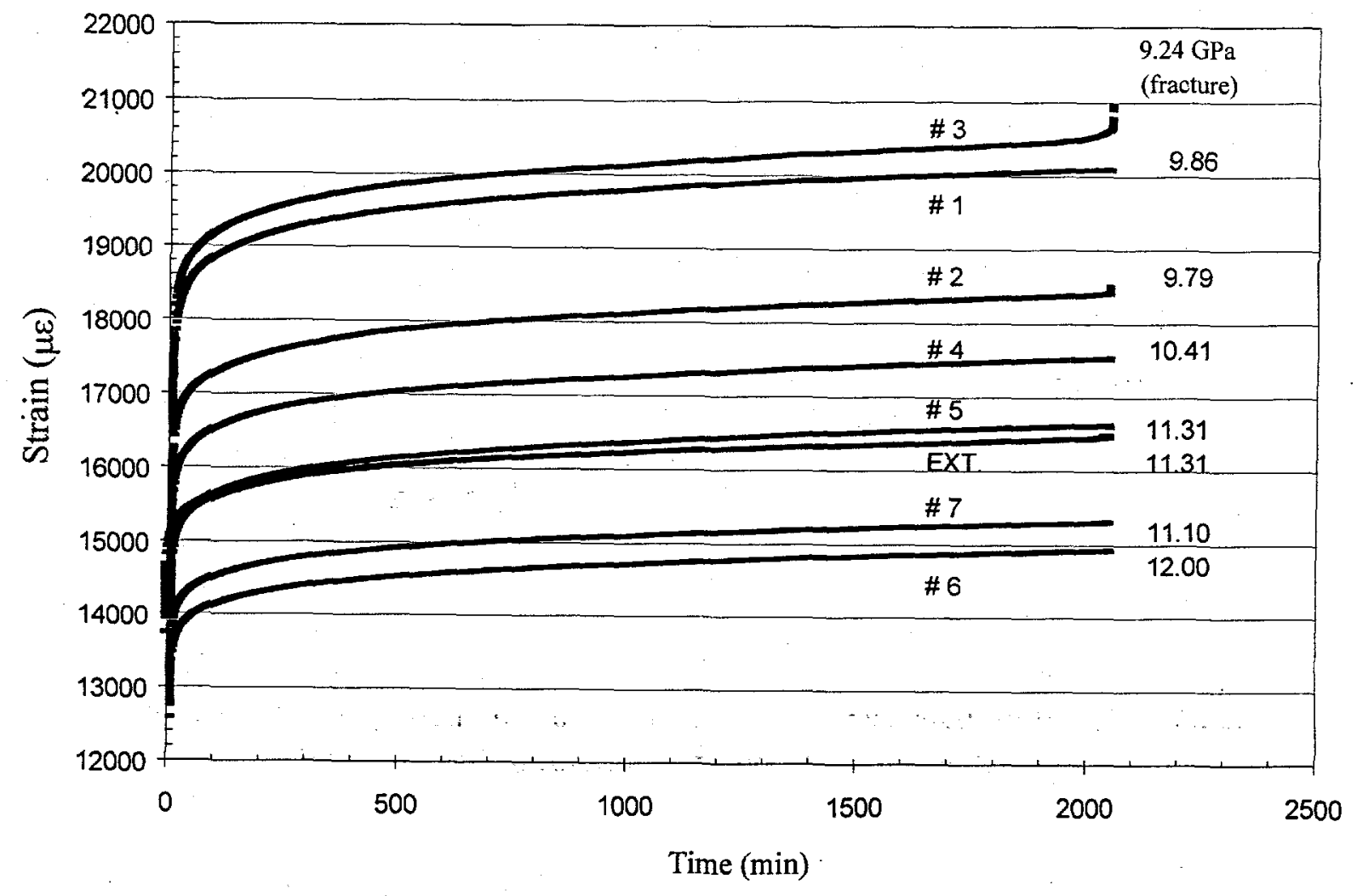

Fig. 17. Creep-to-failure data from a multigaged coupon under a step stress of 130 MPa. Curves numbered no. 1 through no. 7 correspond to positions of strain gages, starting from the top and numbers on the right correspond to stiffness as recorded within the linear range of response. Failure occurred under gage no. 3. 


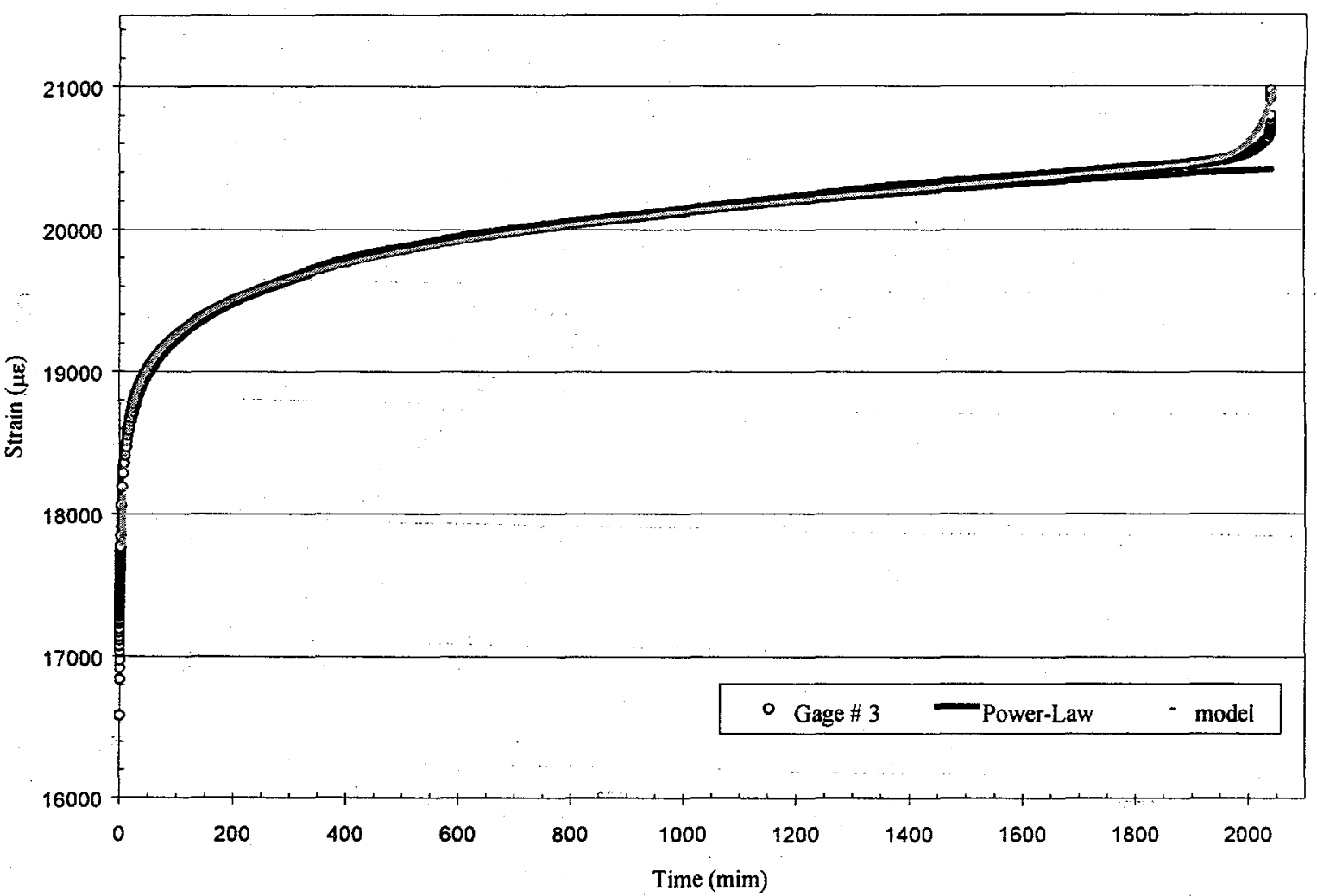

Fig. 18. Creep-to-failure response under gage no. 3 in Fig. 17. Data (ooo), prediction of "best fit" power-law (-), and prediction accounting for damage growth (---). 


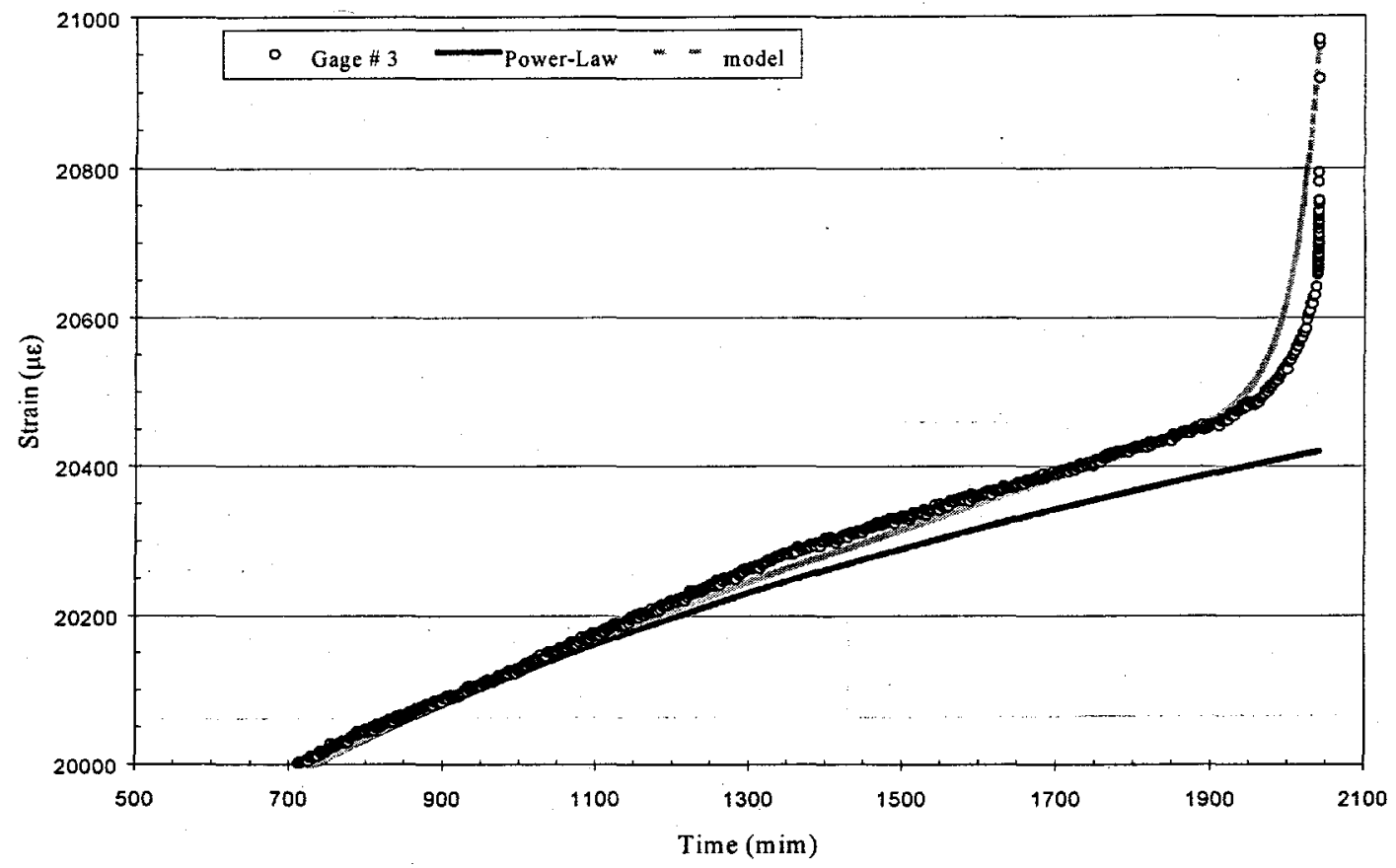

Fig. 19. An expanded view of strain vs. time upon the advent of failure. Symbols same as Fig. 18.

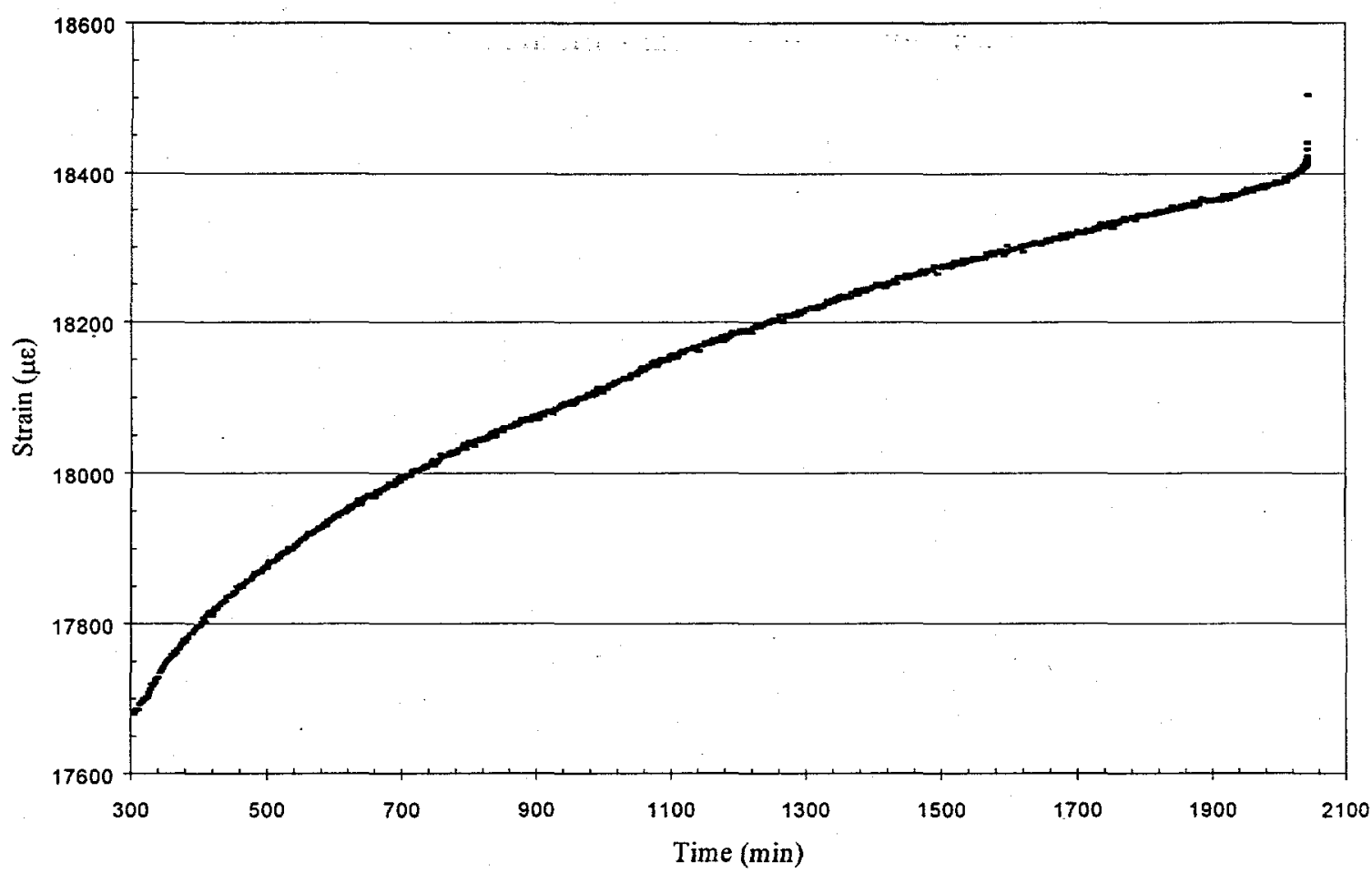

Fig. 20. Strain-to-failure recorded under gage no. 2 in Fig. 17. 


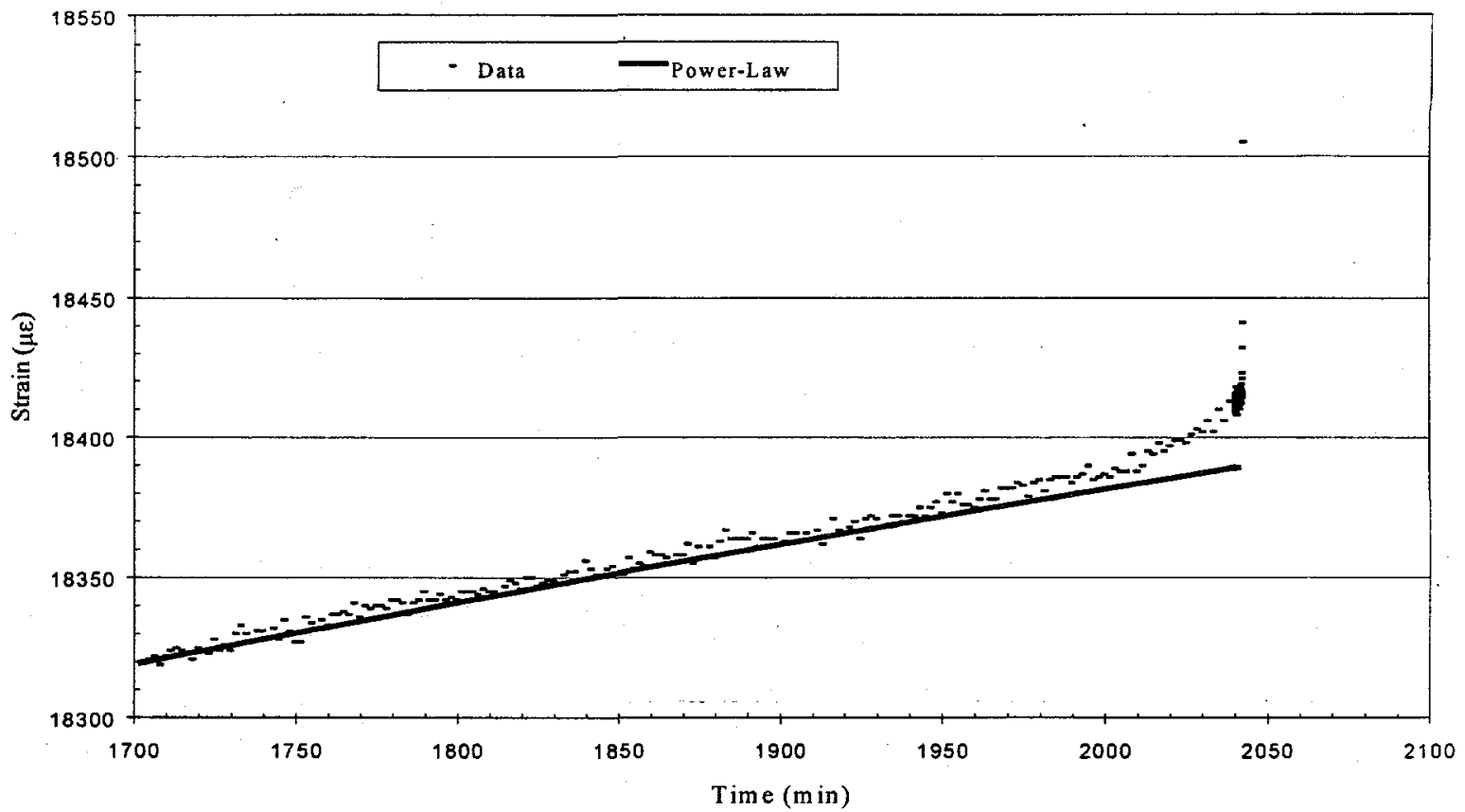

Fig. 21. An expanded view of strain-to-failure recorded under gage no. 2. Data (--) and predictions of "best fit" power-law (-).

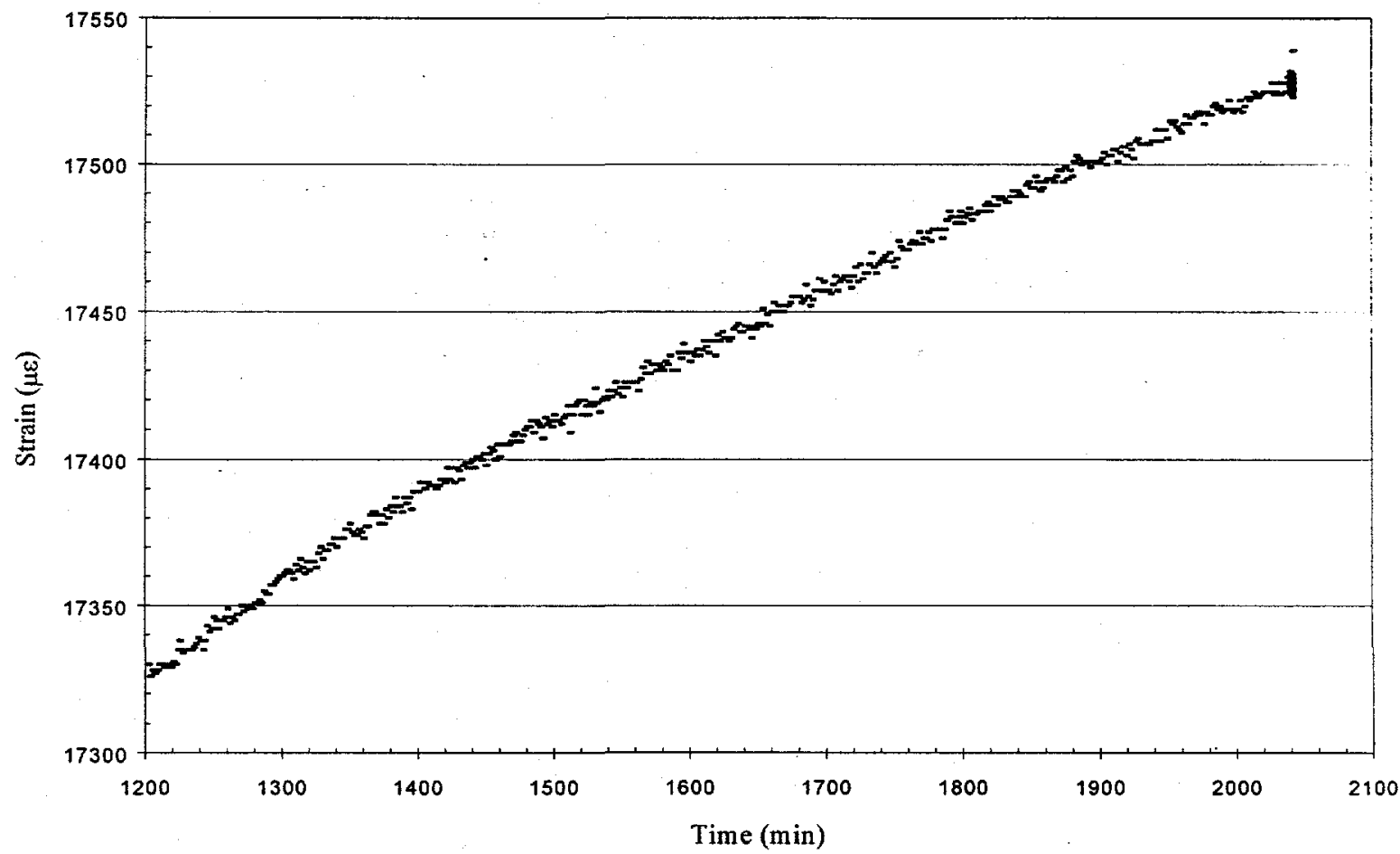

Fig. 22. An expanded view of creep-to-failure data under gage no. 4 in Fig. 17. 


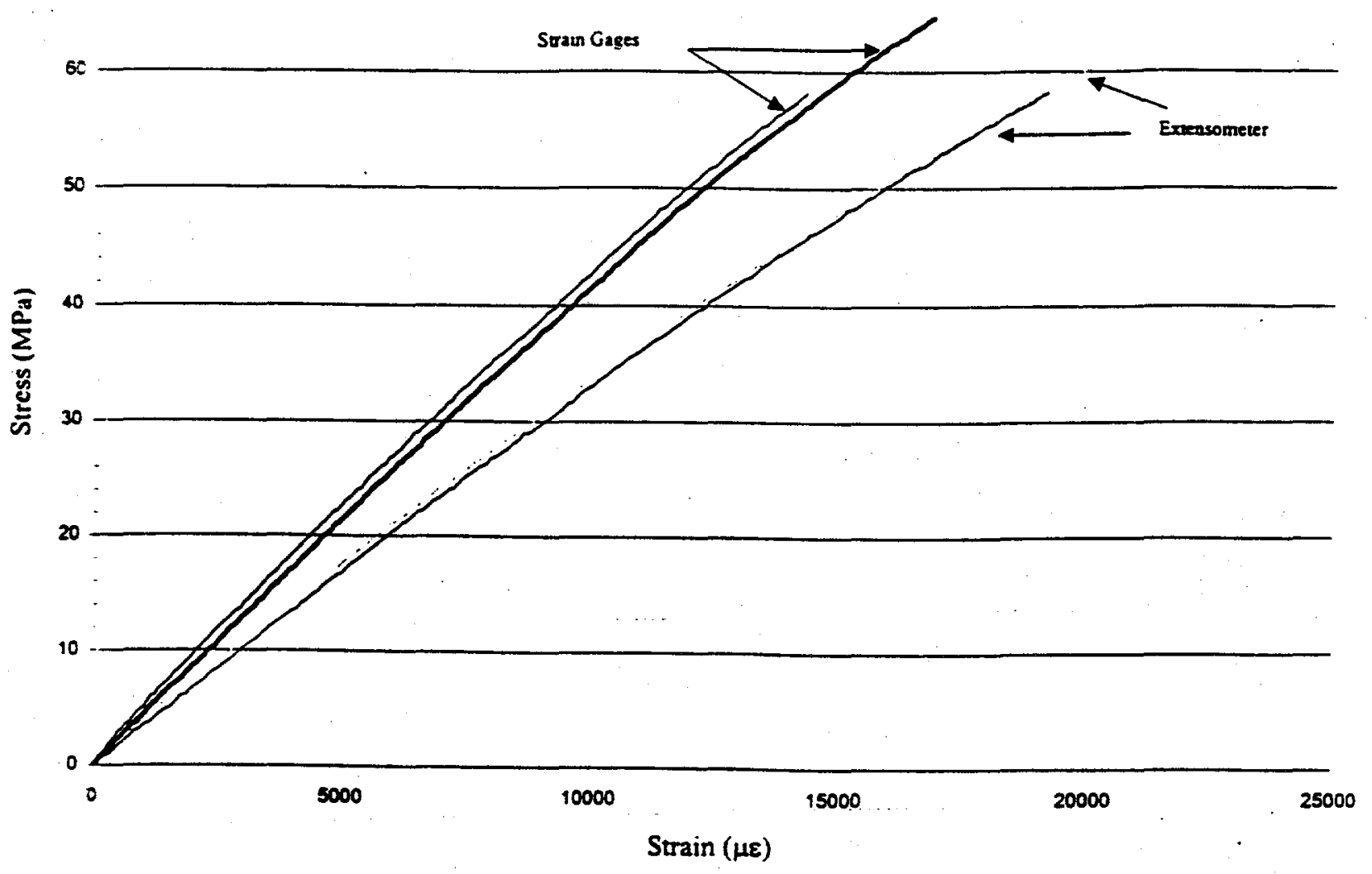

Fig. 23. Stress-strain behavior of urethane (neat resin) specimens. 


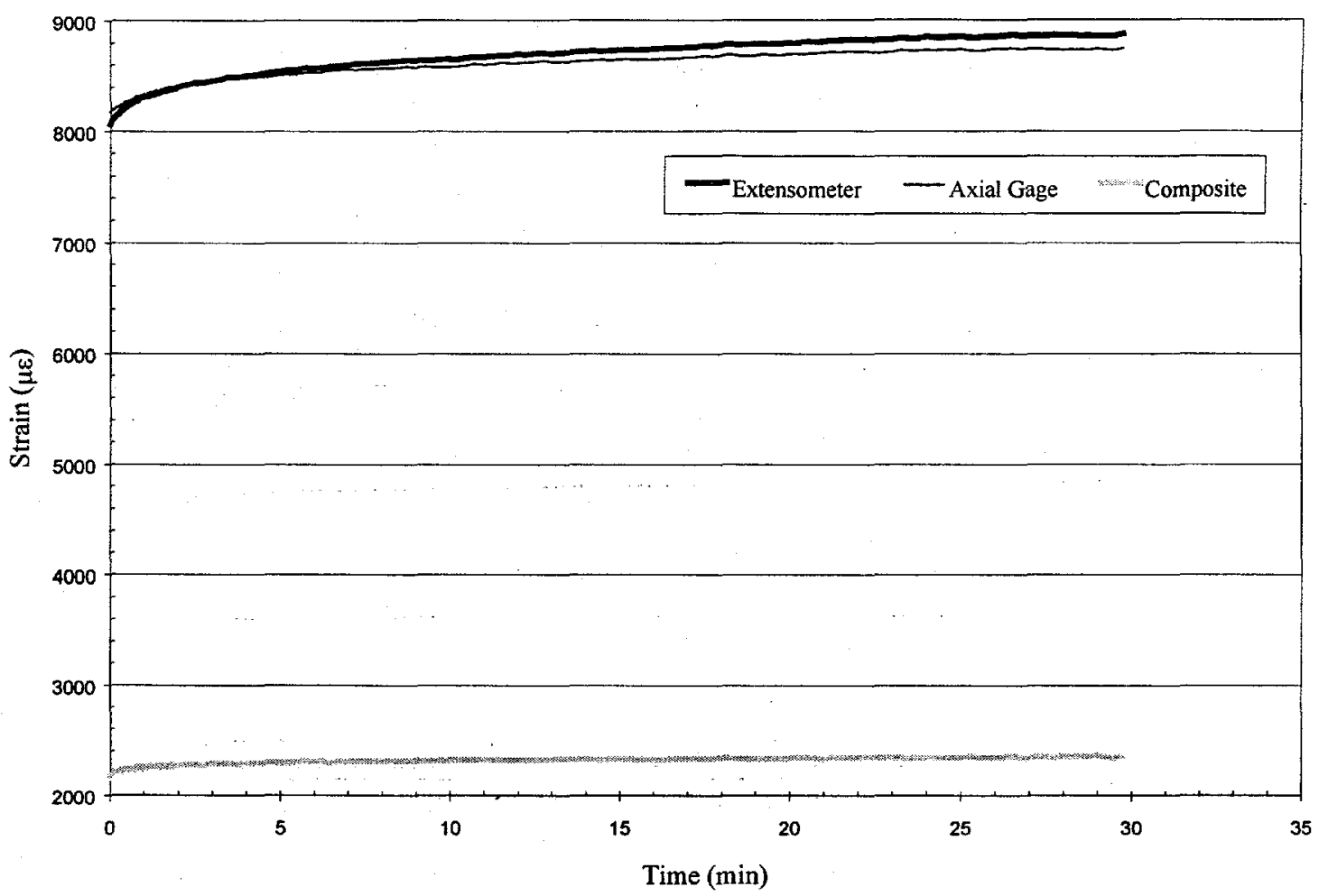

Fig. 24. Creep of urethane neat resin $(\rightarrow$ as compared with that of $P 4$ chopped glass/urethane ( while the thin line corresponds to strain gage record.

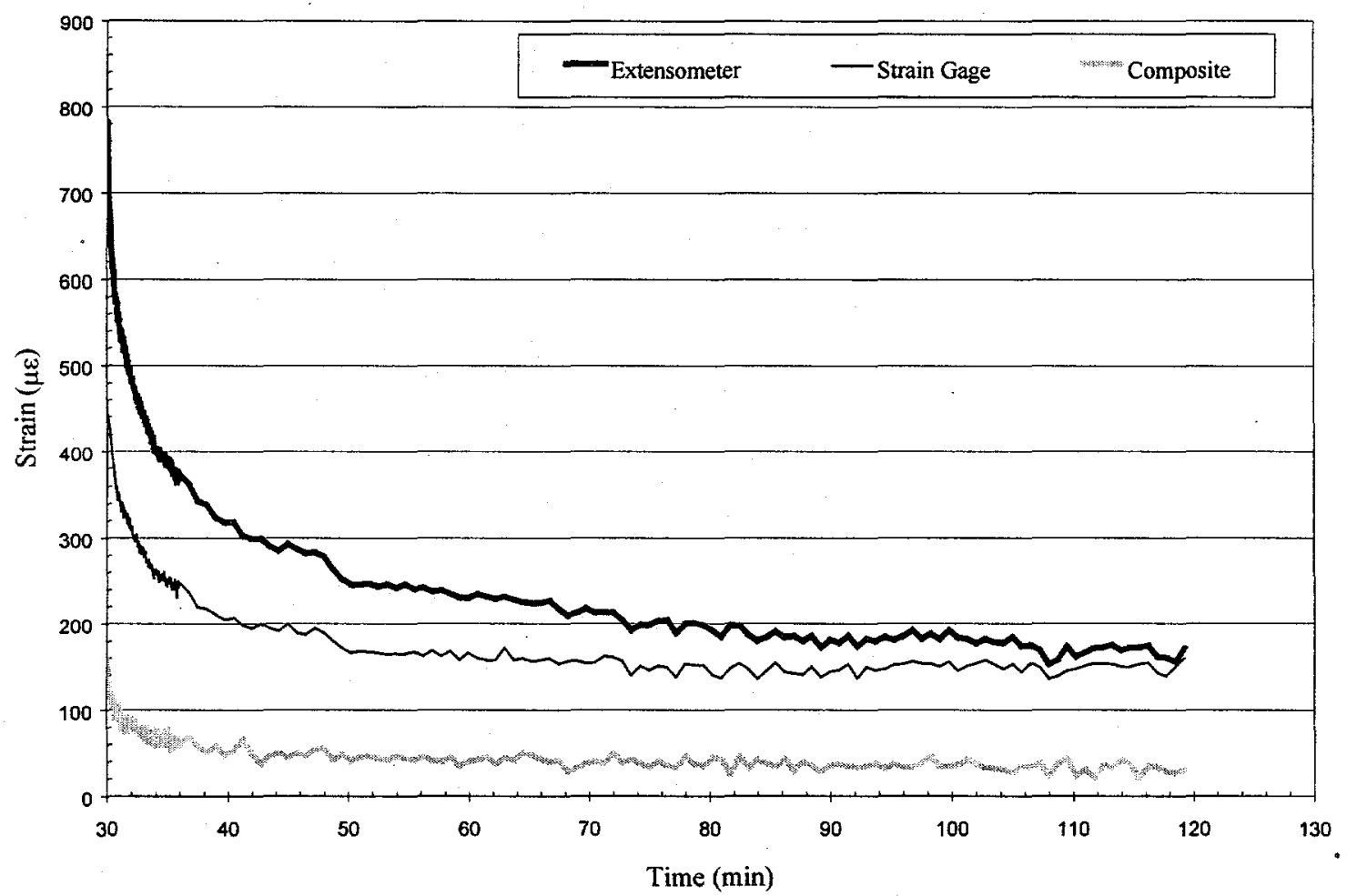

Fig. 25. Recovery data. Symbols same as Fig. 24. 


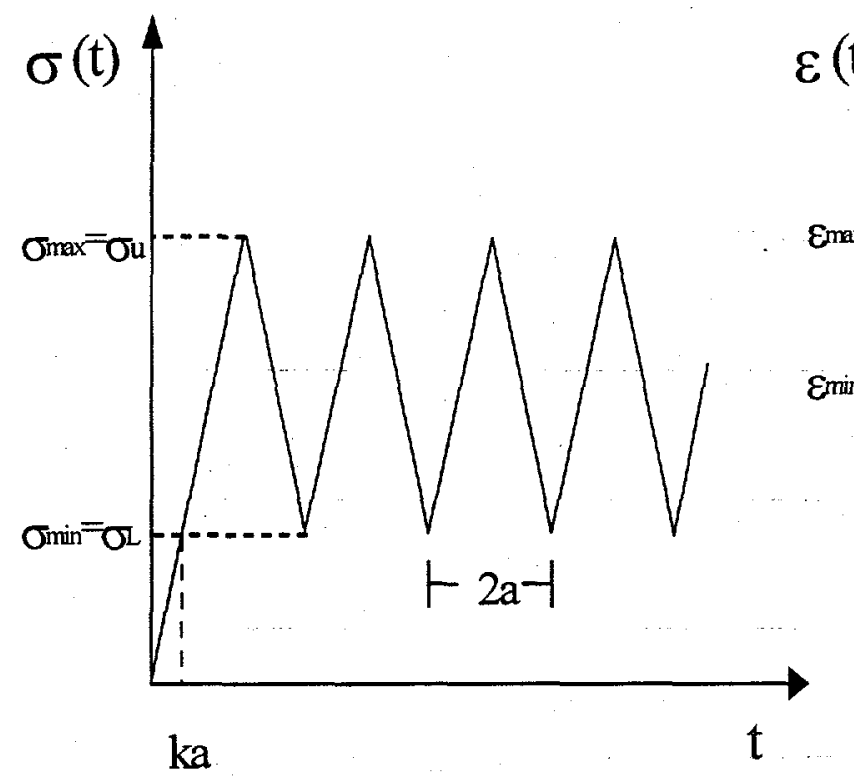

a. Saw tooth stress input

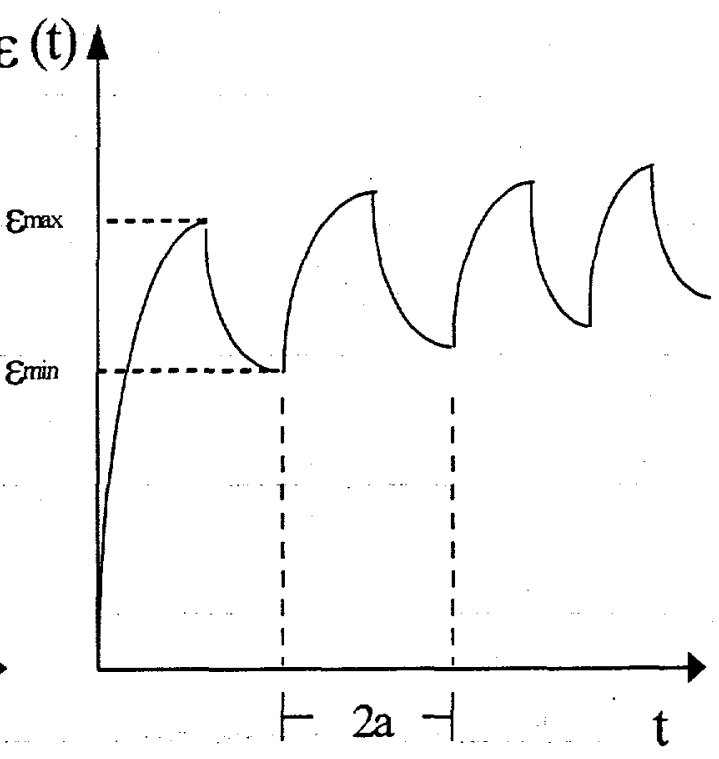

b. Strain response

Fig. 26. Schematic diagrams for cyclic testing. 


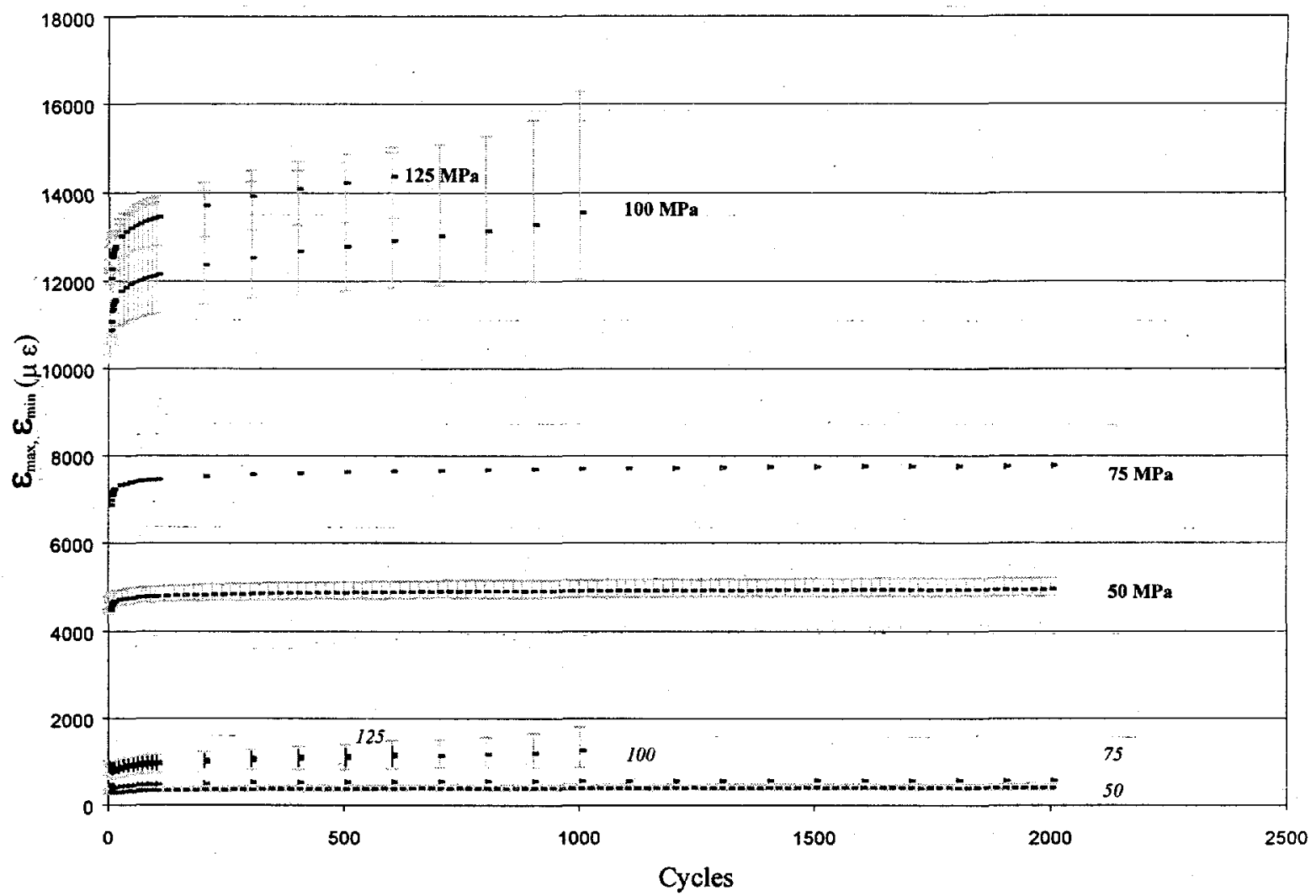

Fig. 27. Unscaled strain data at various levels of maximum stress at $R=0$, vs. number of cycles. Stress levels shown in bold numbers correspond to maximal strains, and those shown by plain numbers correspond to minimum strains. Average values and scatter bands are shown. 


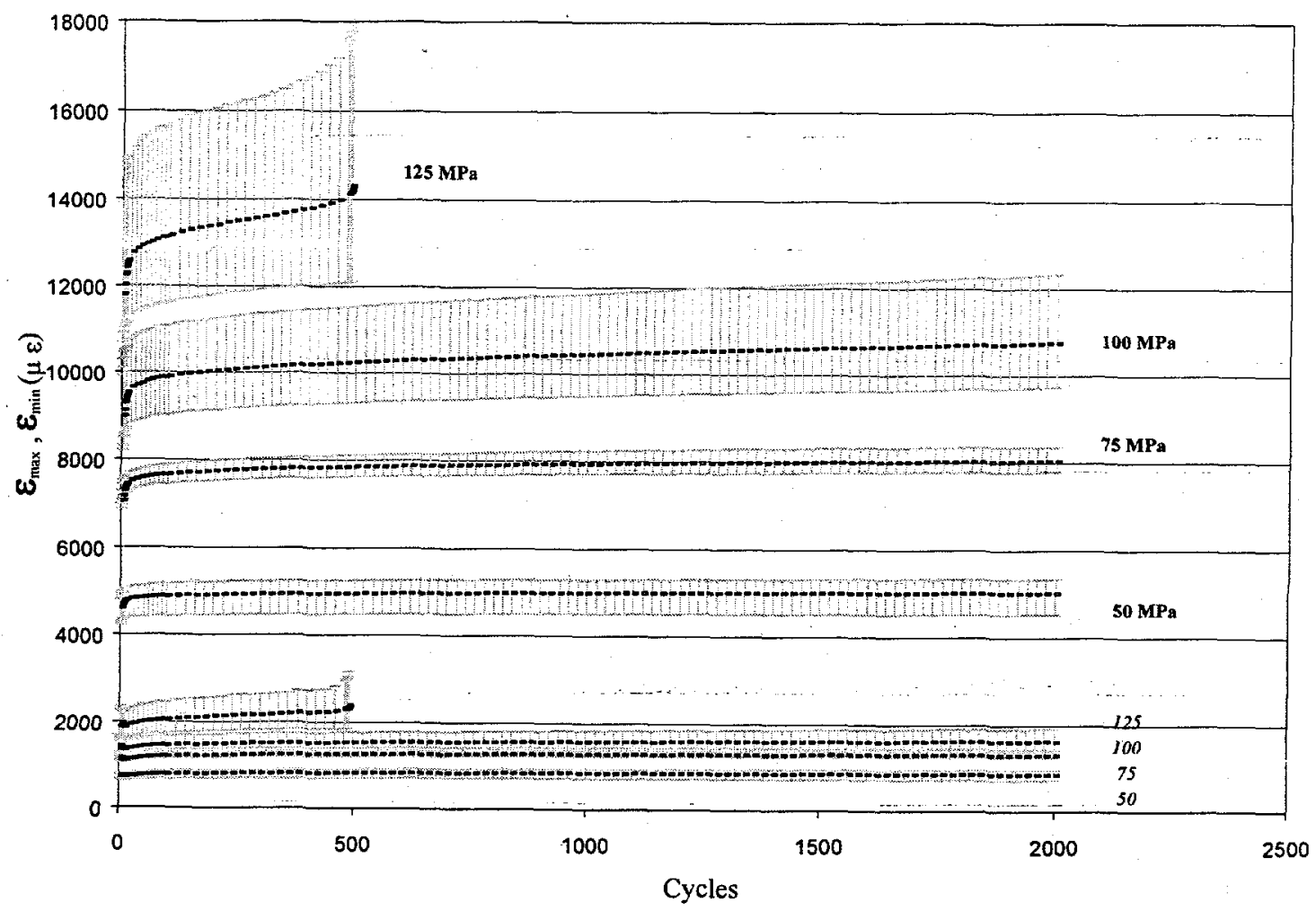

Fig. 28: Same as Fig. 27, but $R=0.1$. 


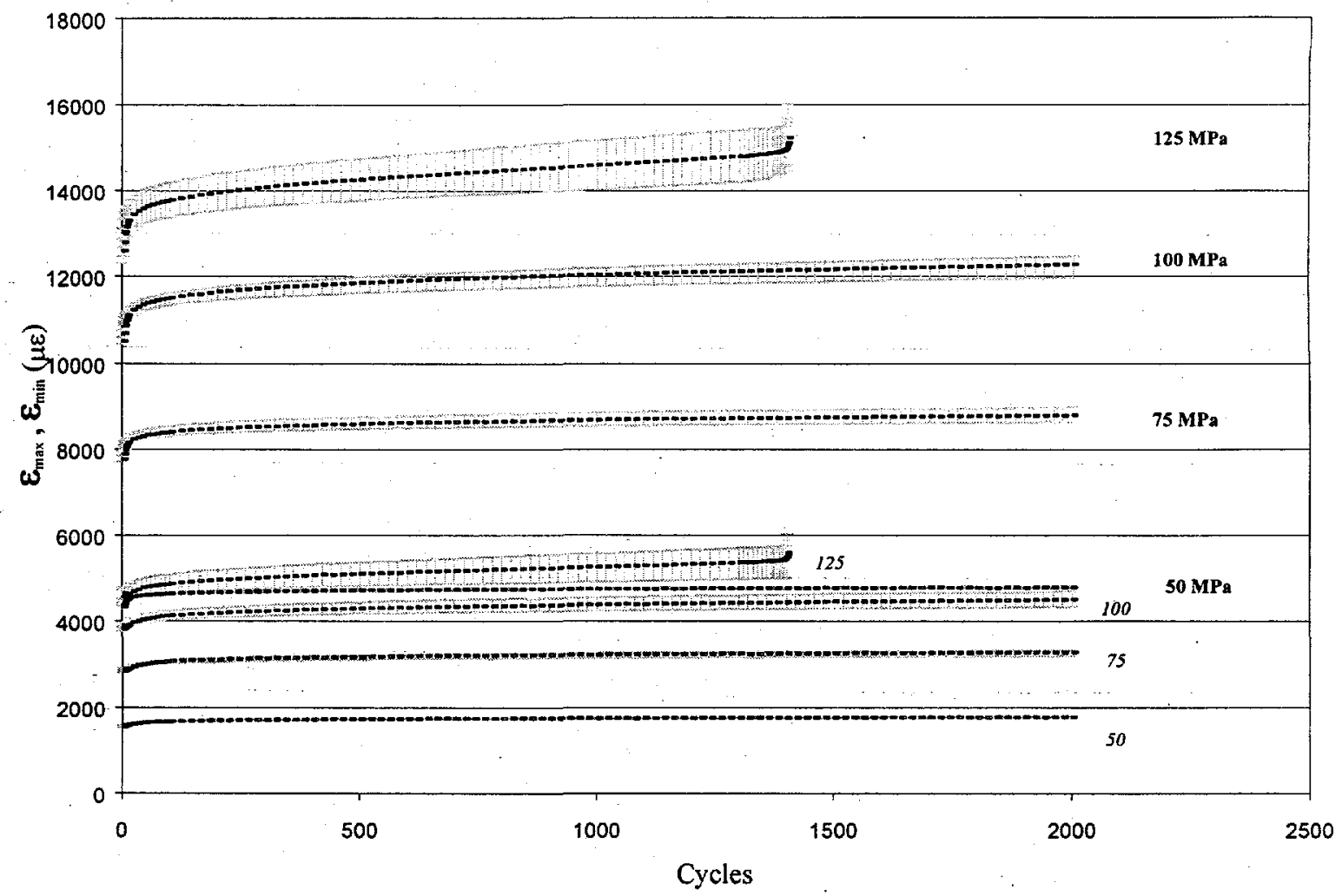

Fig. 29. Same as Fig. 27, but $R=0.3$. 


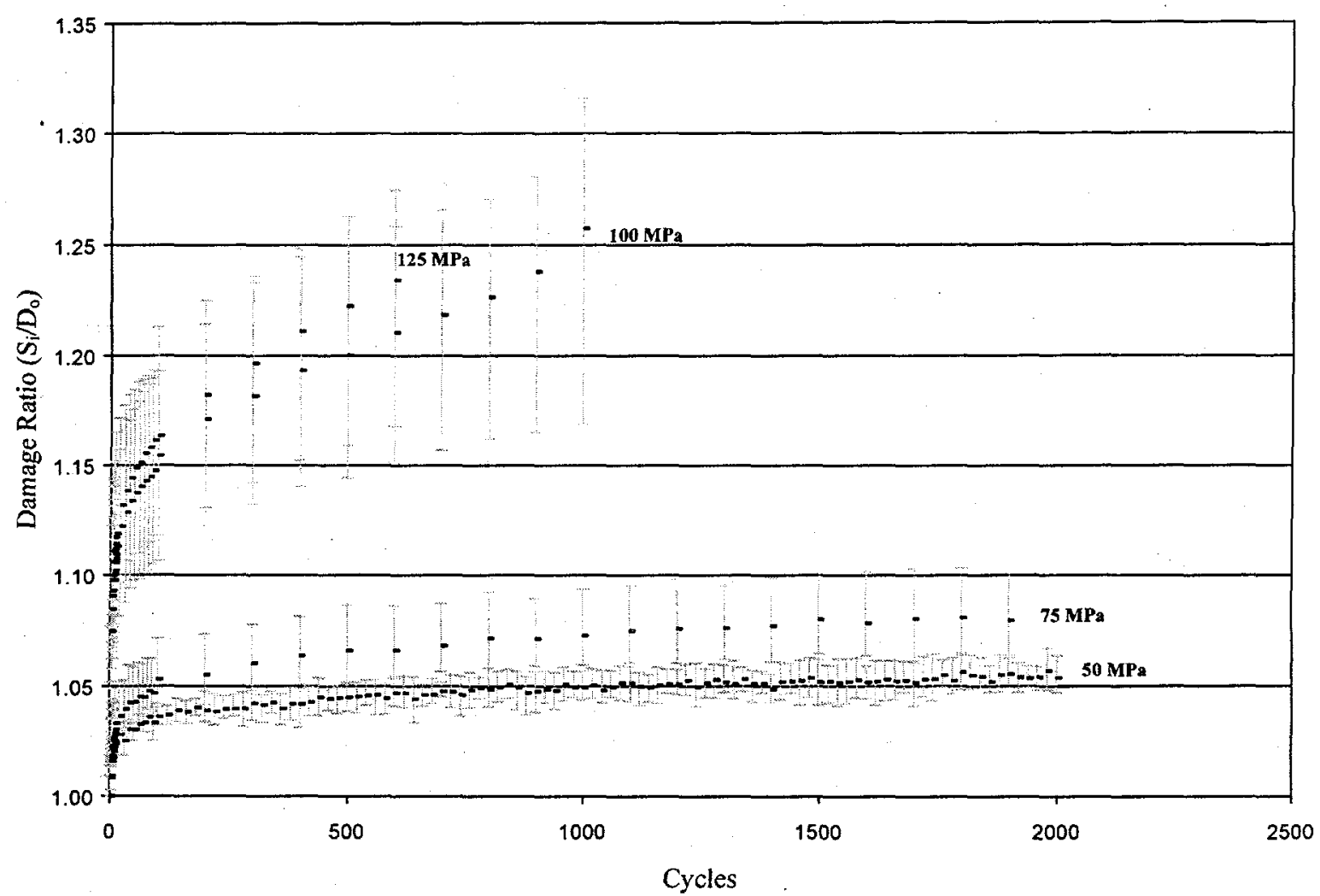

Fig. 30. Ratio of unloading compliance to initial compliance vs. number of cycles for various values of maximal stress with $R=0$. Average values and scatter bands are shown. 


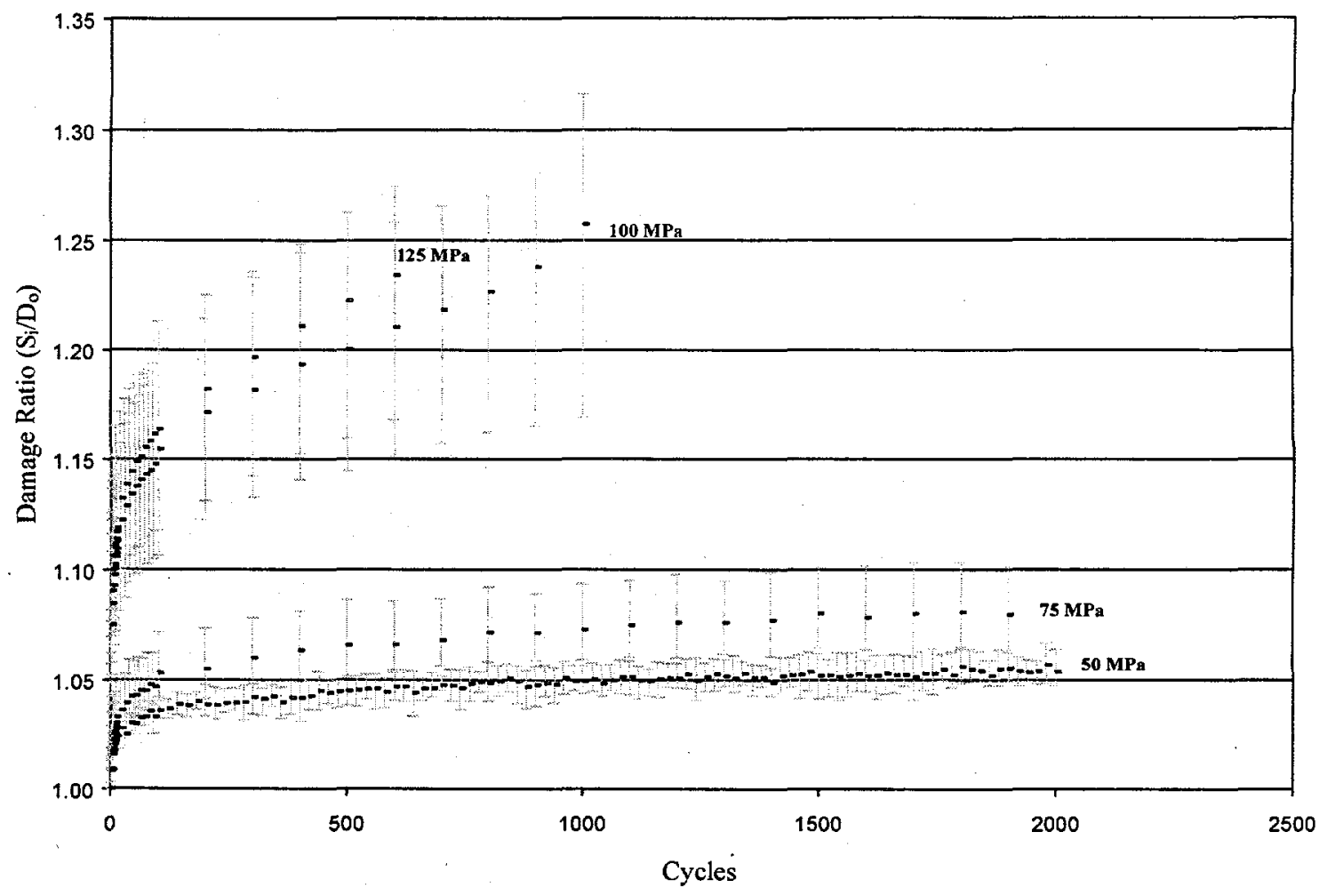

Fig. 31. Same as Fig. 30, but $R=0.1$. 


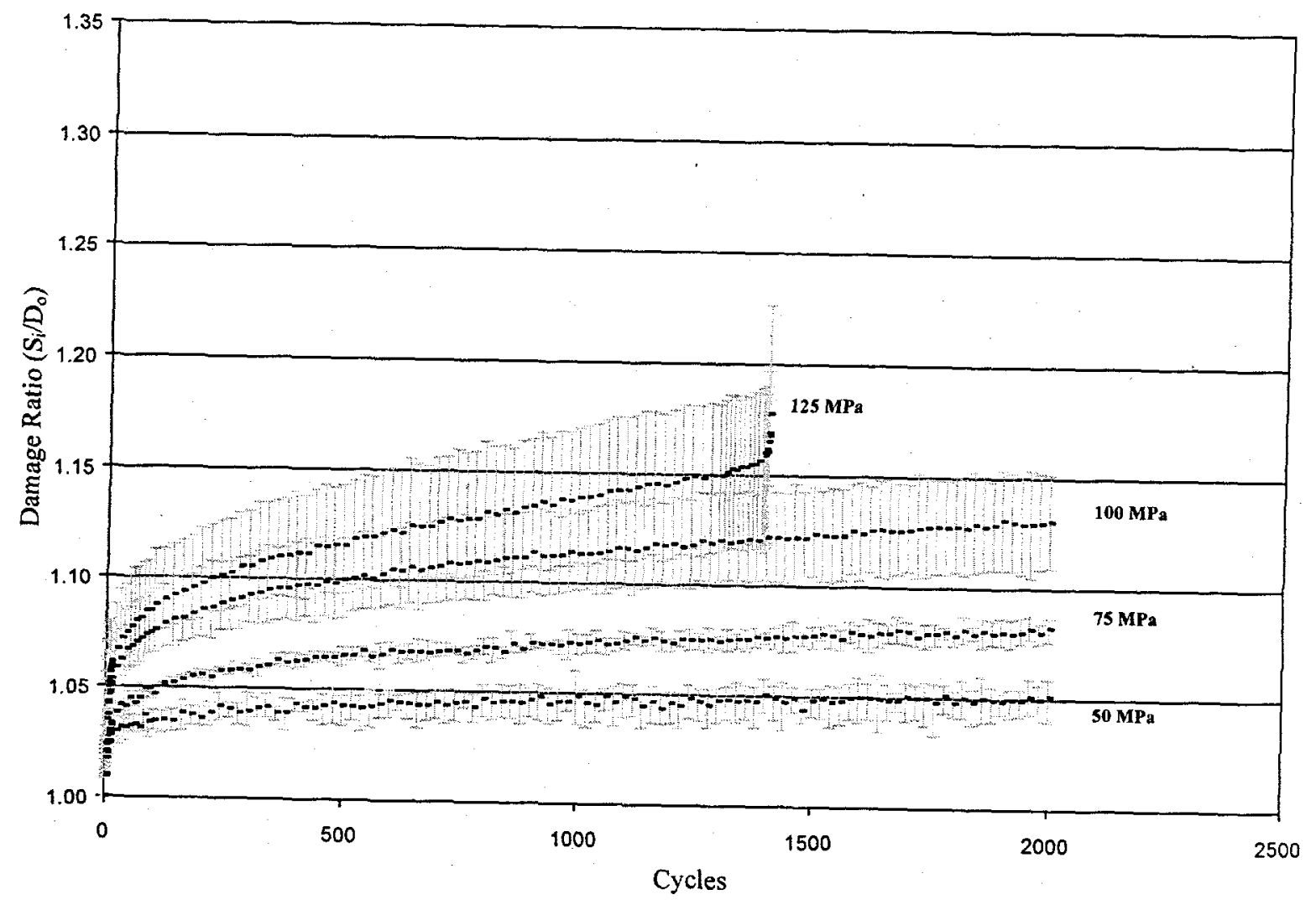

Fig. 32. Same as Fig. 30, but $R=0.3$. 


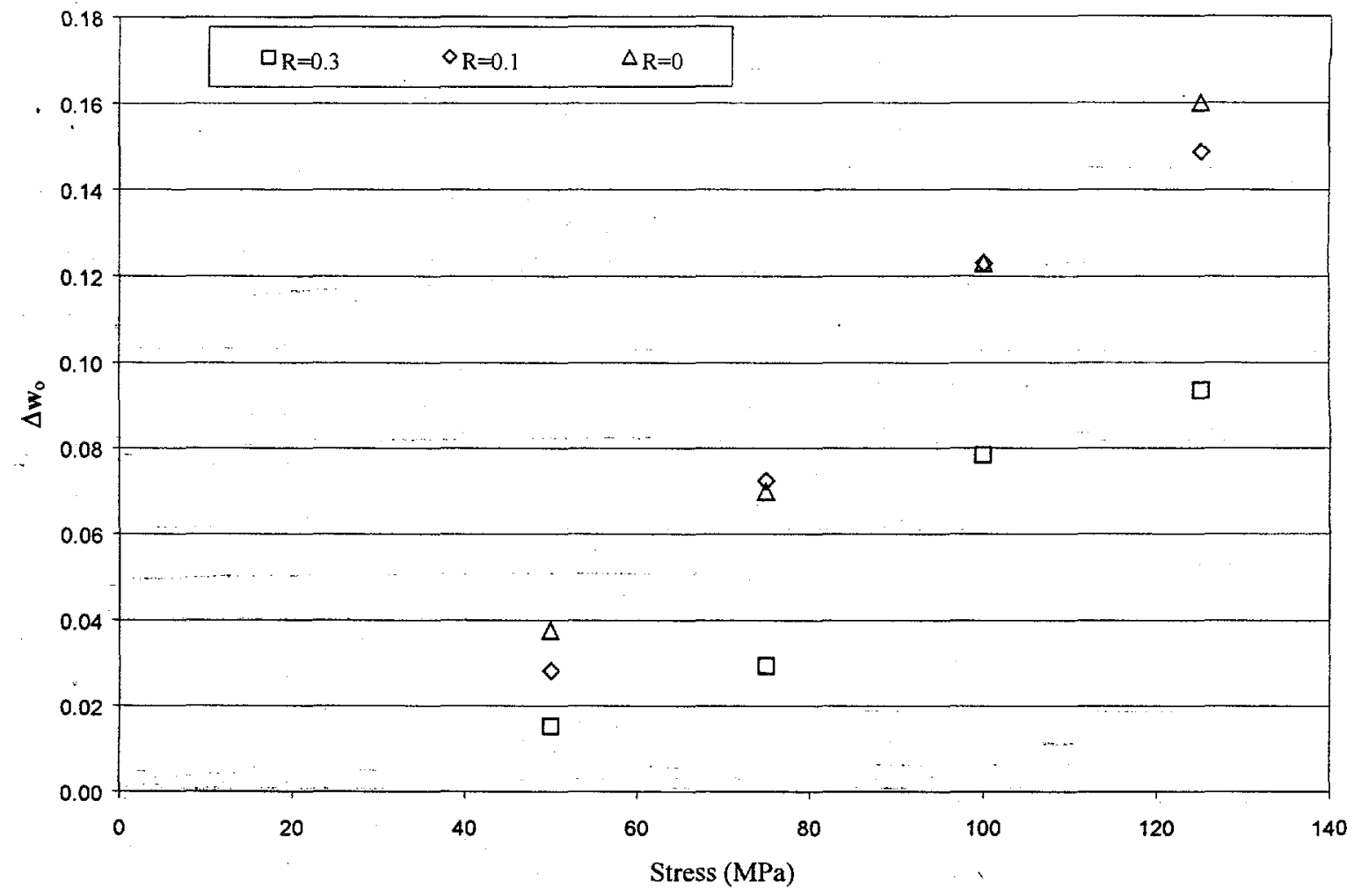

Fig. 33. Damage parameter $\Delta w_{o}$ vs. stress $\sigma$. 


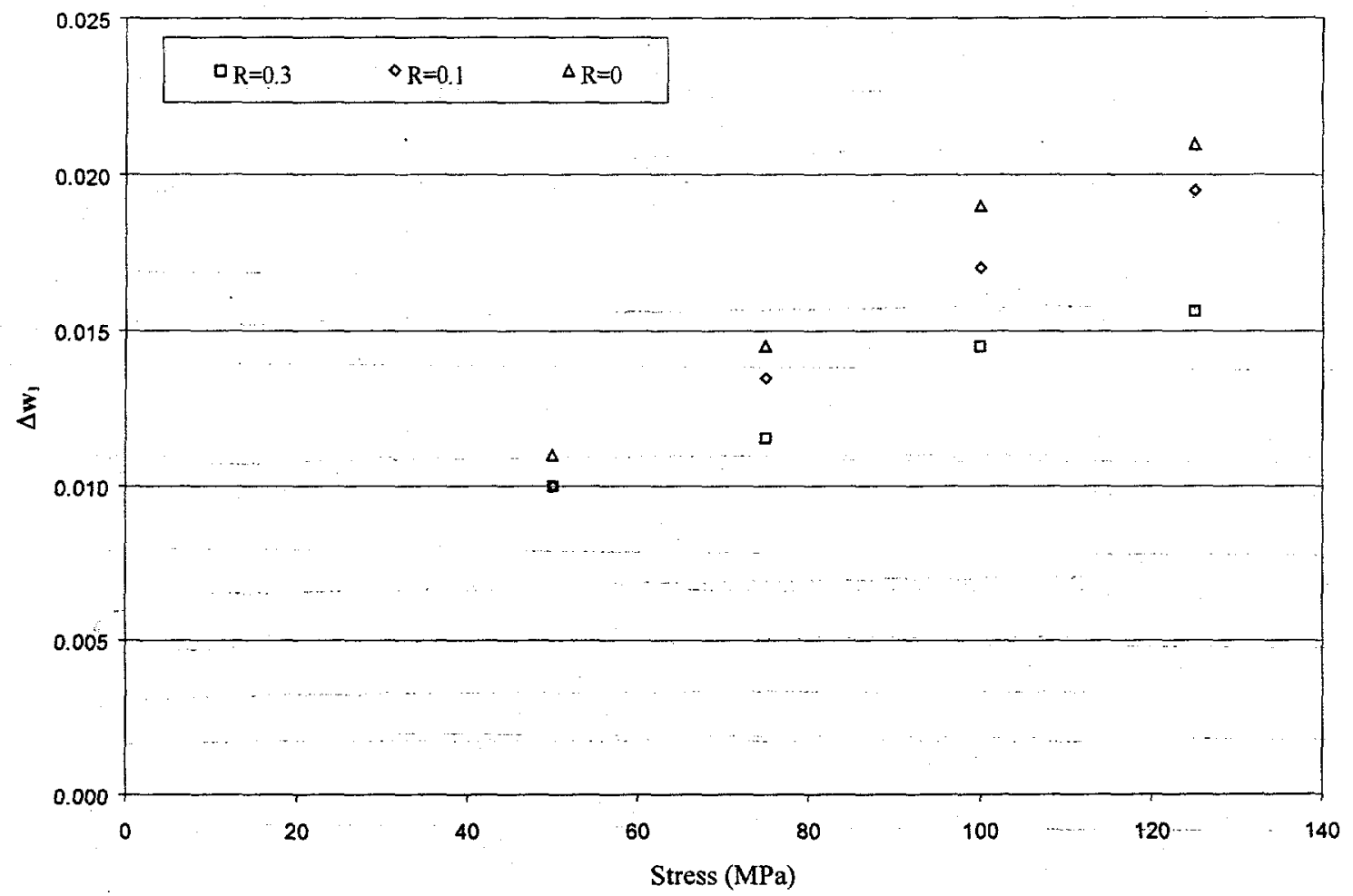

Fig. 34. Damage parameter $\Delta w_{1}$ vs. stress $\sigma$. 


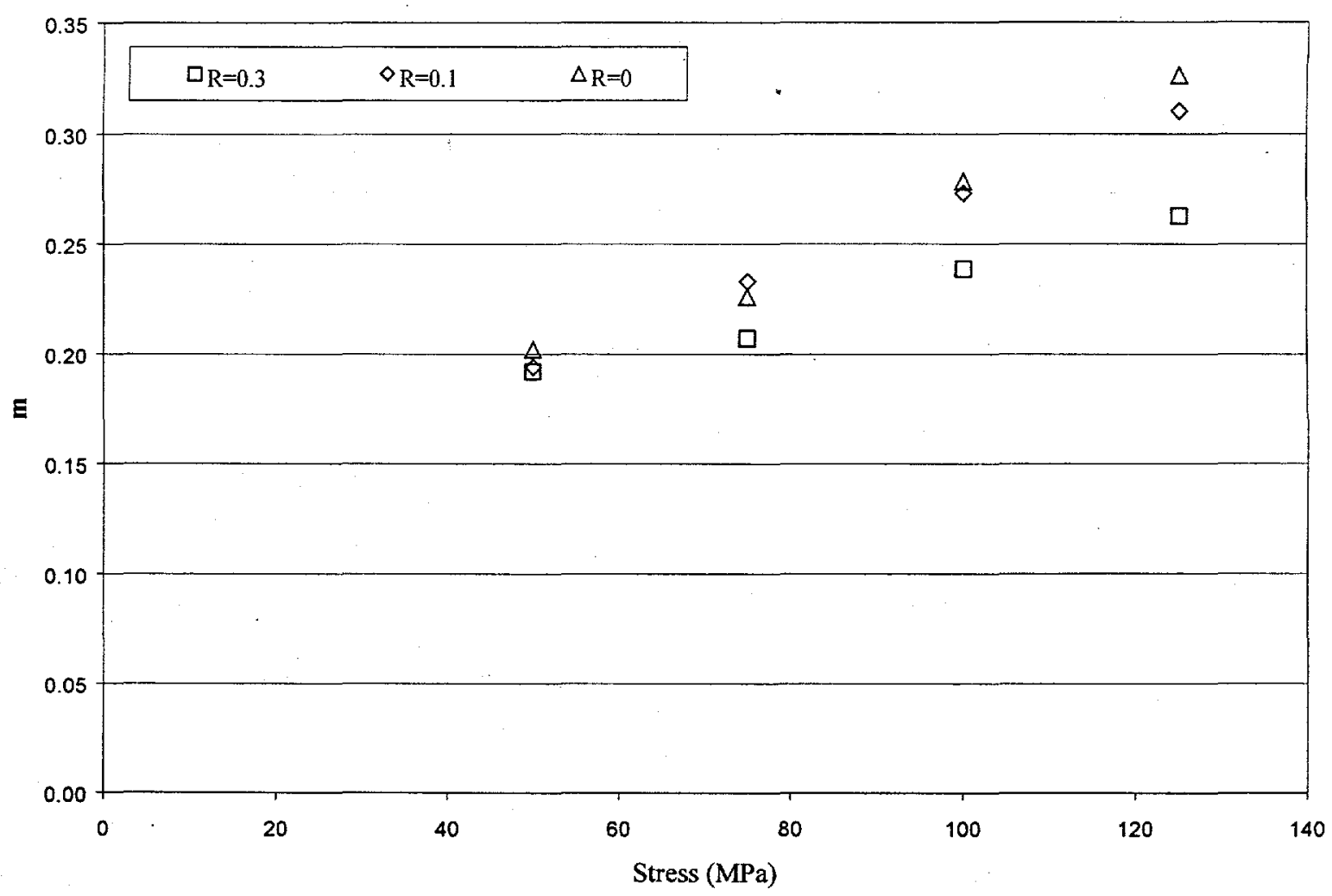

Fig. 35. Damage parameter $m$ vs. stress $\sigma$. 


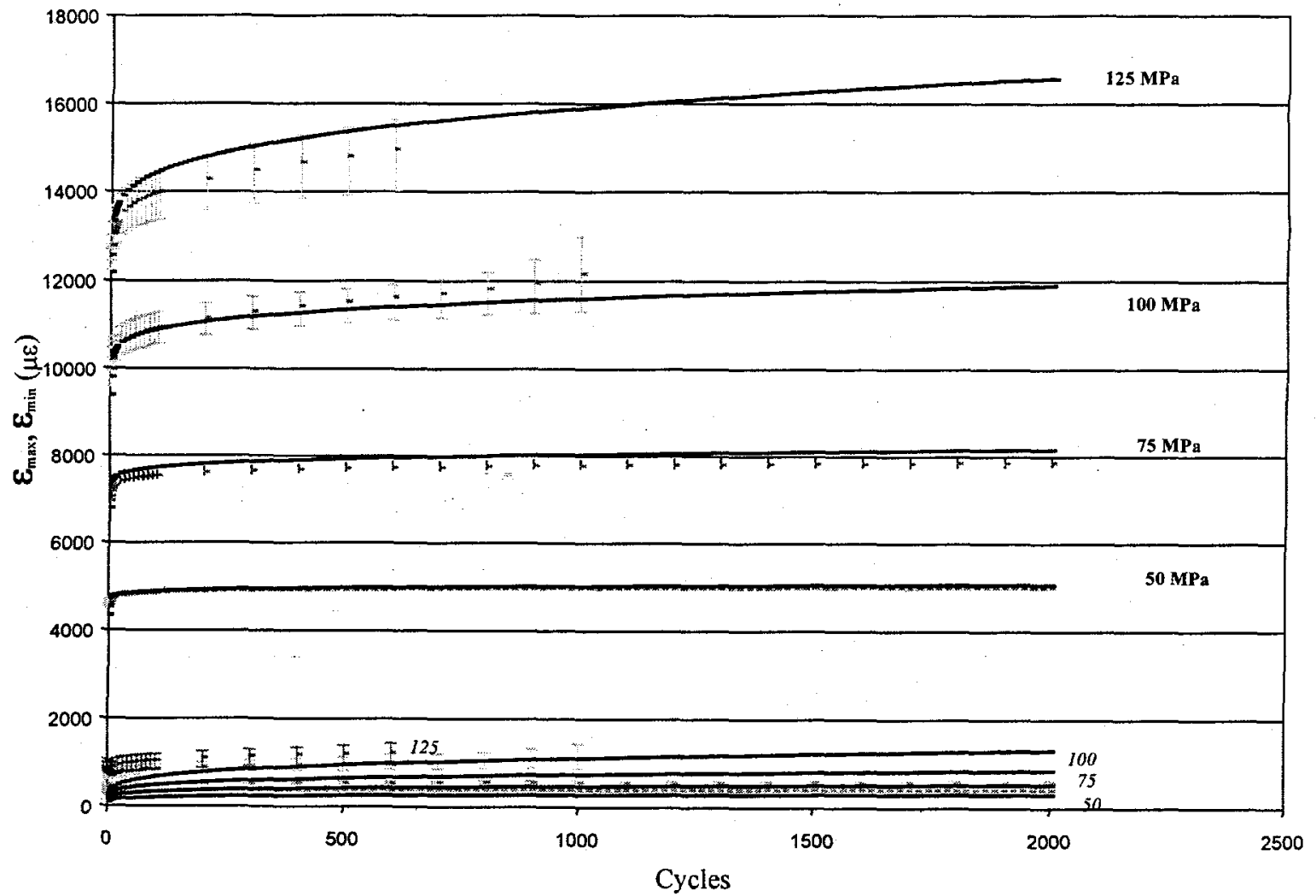

Fig. 36. Scaled measured and predicted strain vs. number of cycles at various levels of maximum stress at $R=0$. Data (---) with scatter bands, as compared with predictions according to Eqs. (19) and (20) ( $\rightarrow$ ). Bold numbers correspond to maximum strains, and plain numbers correspond to minimum strains. 


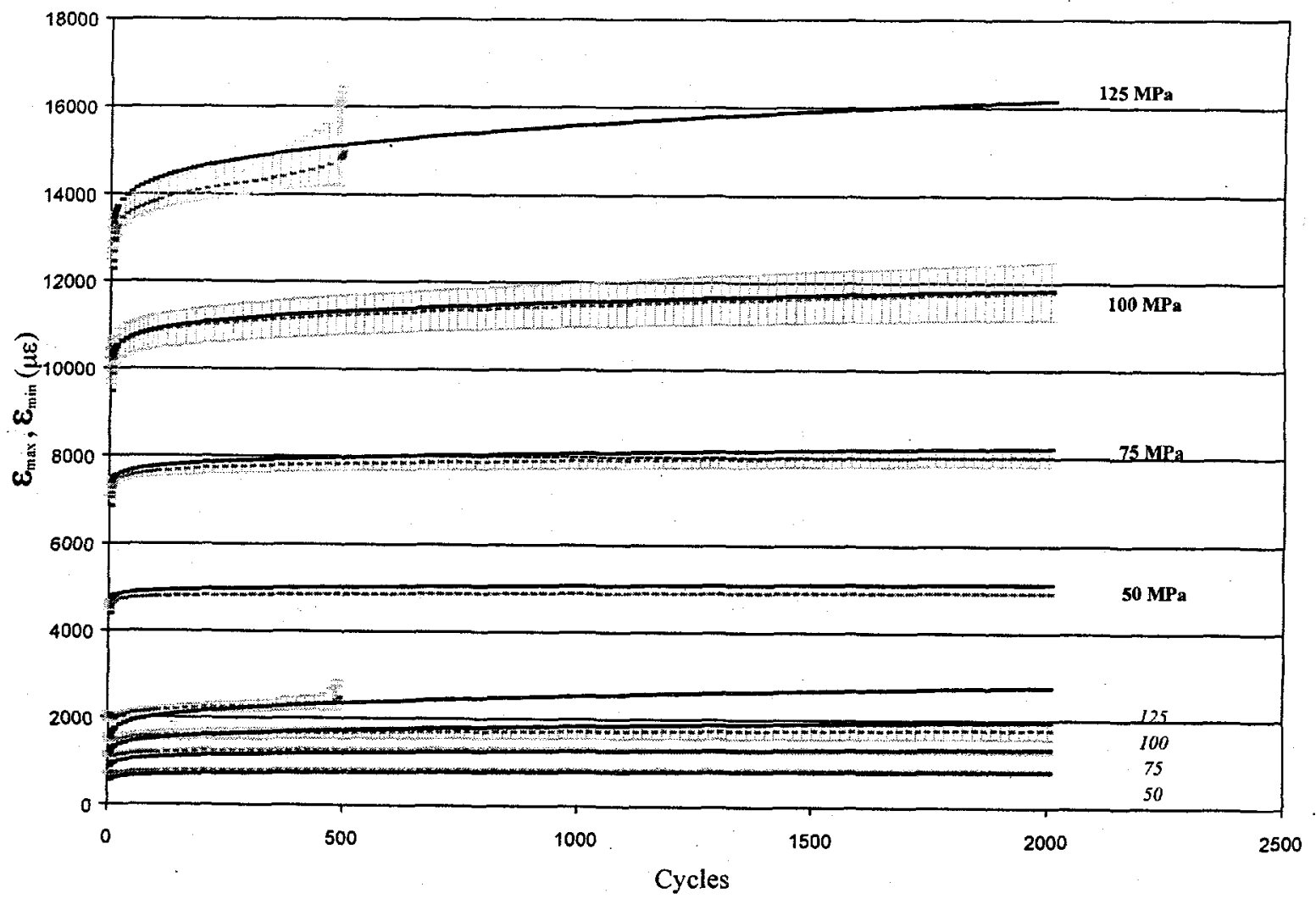

Fig. 37. Same as Fig. 36, but $R=0.1$. 


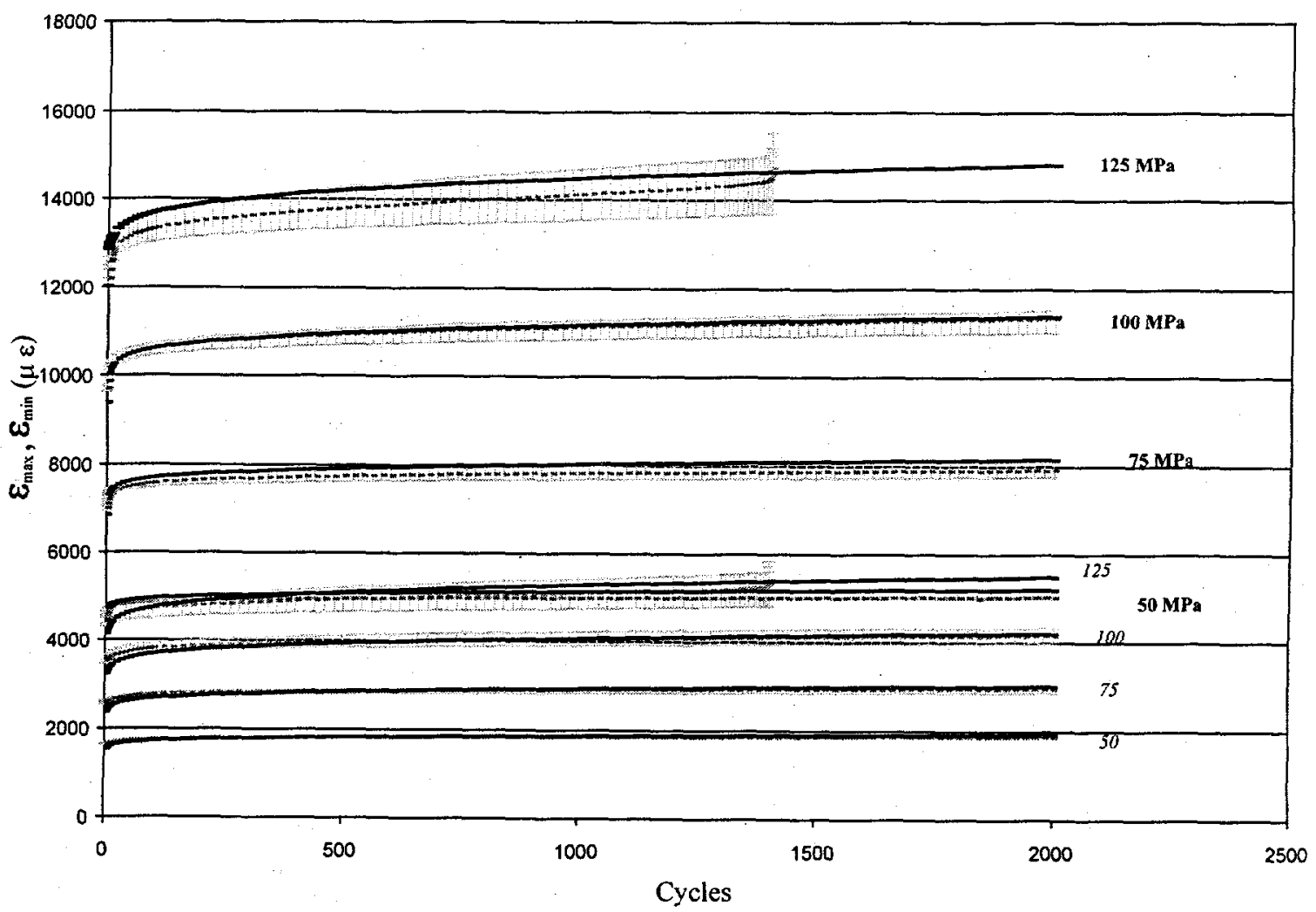

Fig. 38. Same as Fig. 36, but $R=0.3$. 


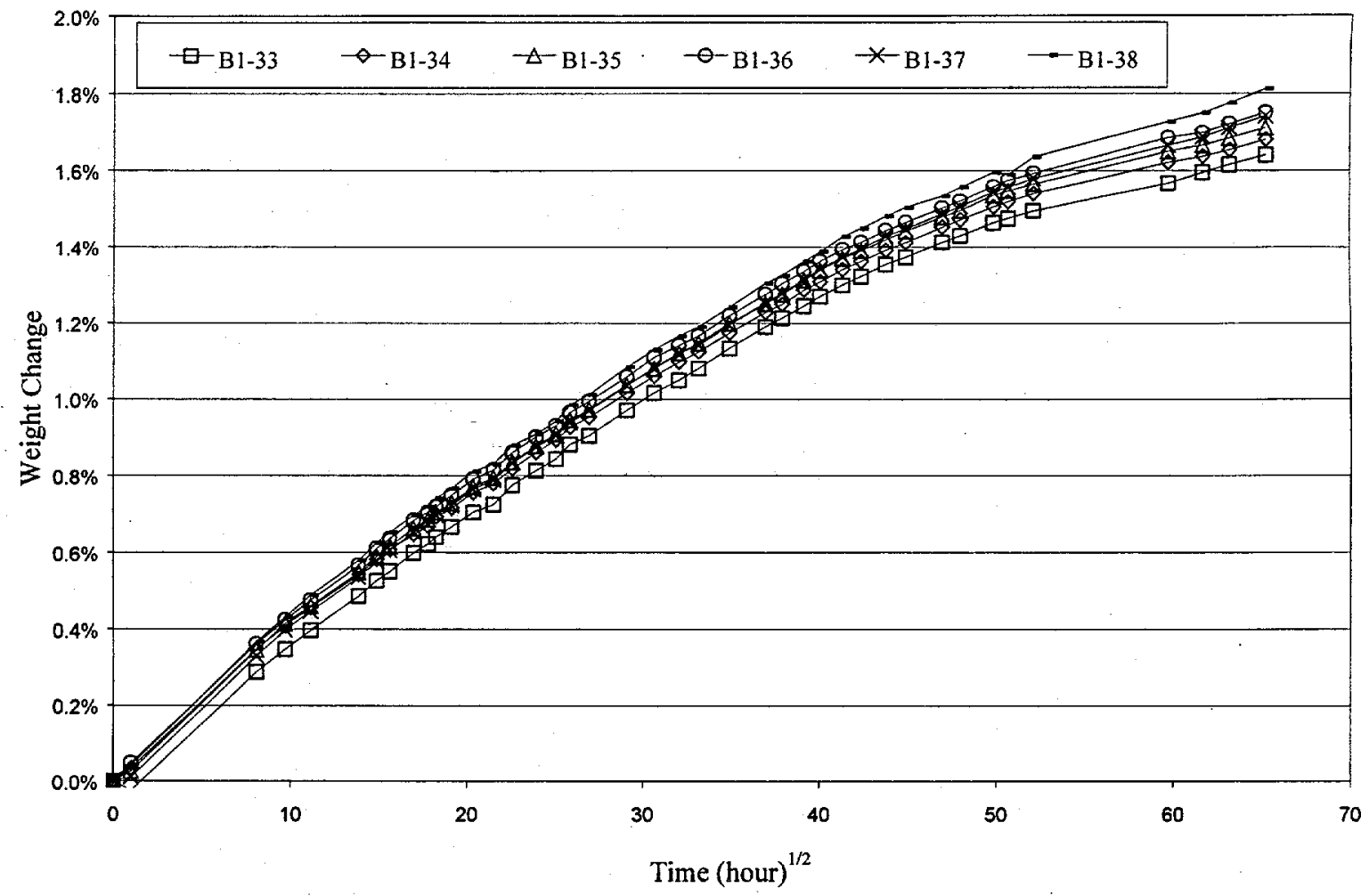

Fig. 39. Weight-gain data (in percent of dry weight) vs. square root of time for P4 chopped glass/urethane composite coupons, immersed in distilled water at temperature $\mathrm{T}=23^{\circ} \mathrm{C}$. Coupons were not pre-tested in creep prior to immersion. 


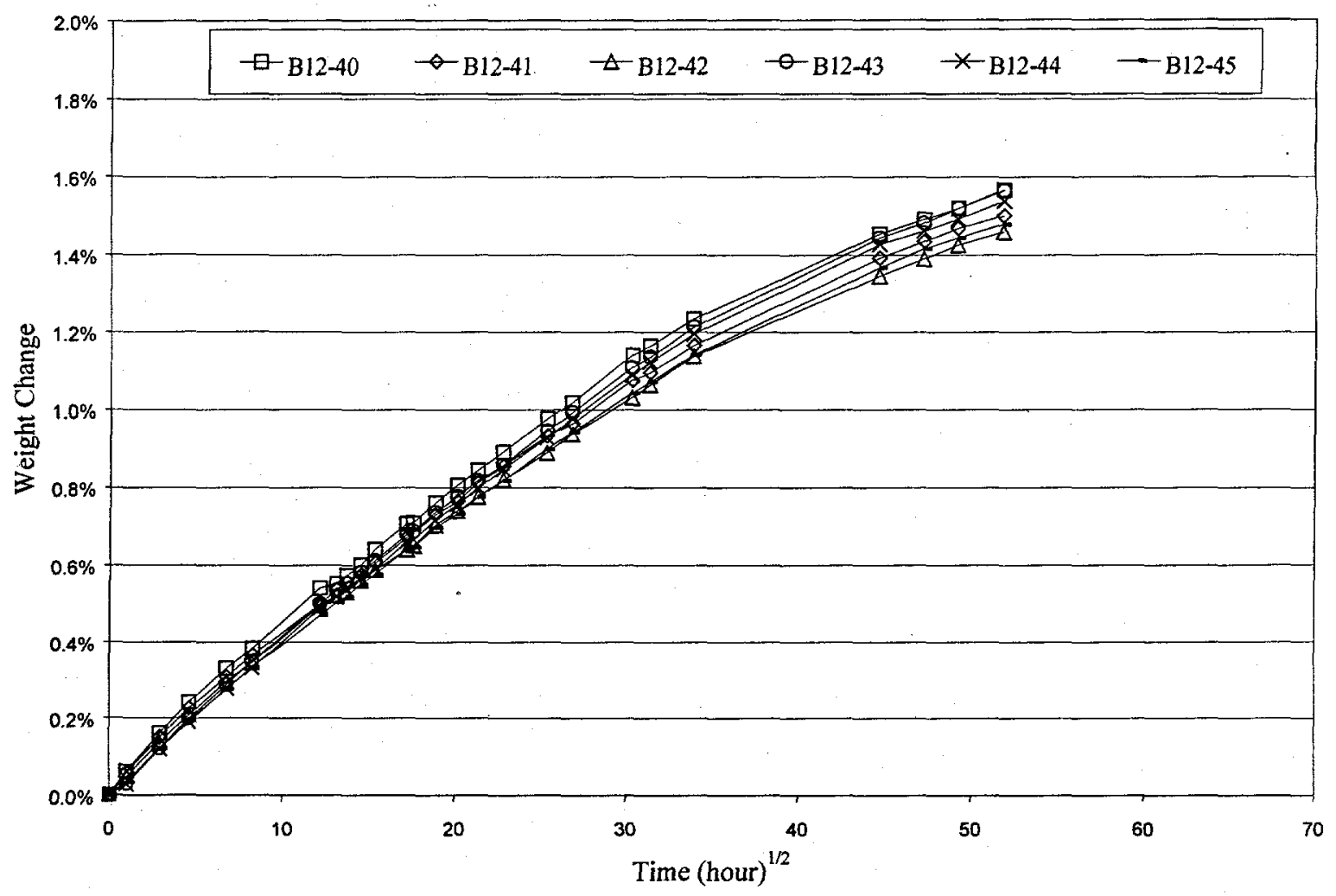

Fig. 40. Weight-gain data (in percent of dry weight) vs. square root of time for $P 4$ chopped glass/urethane composite coupons, immersed in distilled water at temperature $\mathrm{T}=23^{\circ} \mathrm{C}$. Coupons were pre-tested in creep upon drying and prior to immersion. 


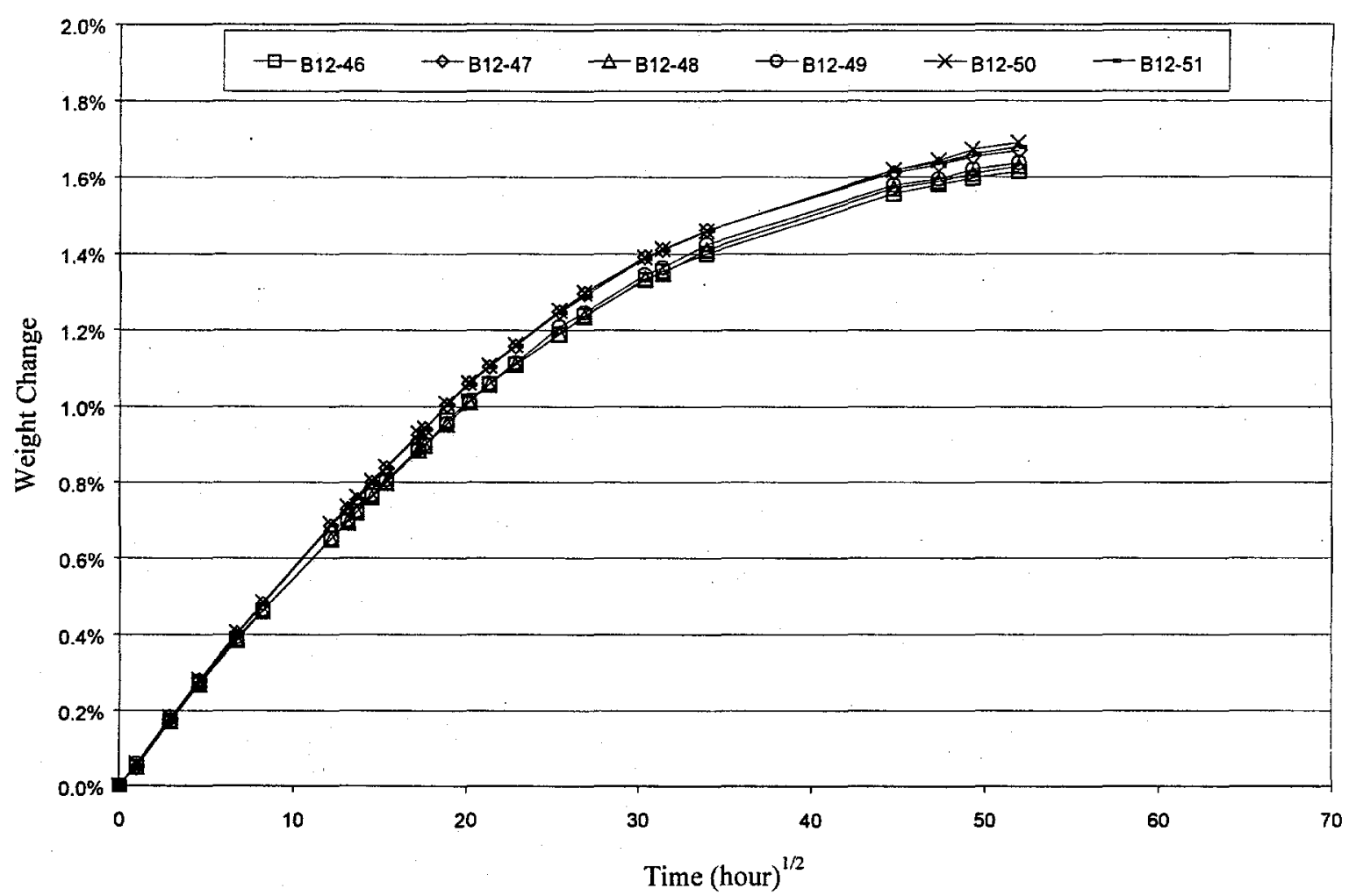

Fig. 41. Same as Fig. 40 , but with $\mathrm{T}=36^{\circ} \mathrm{C}$. 


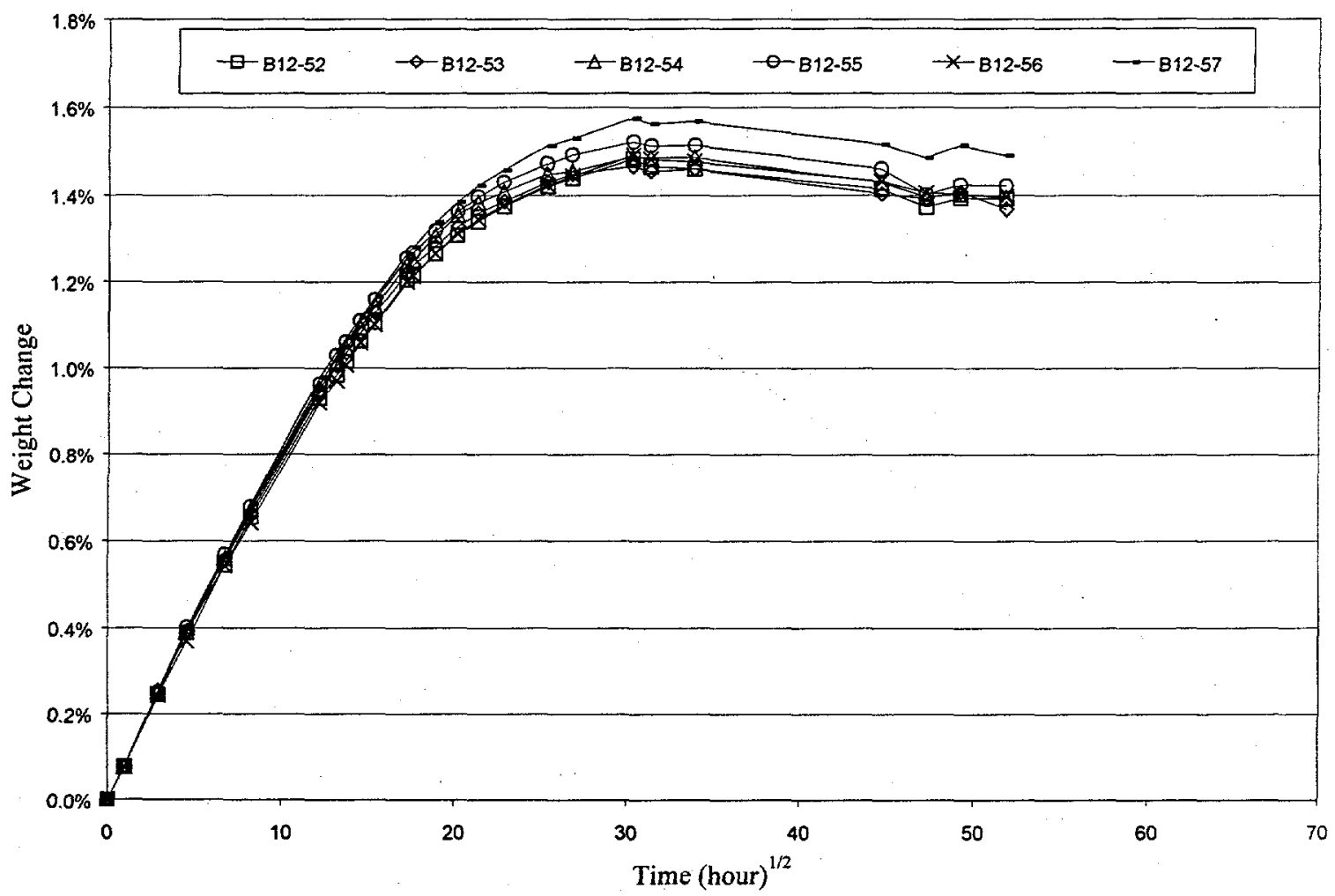

Fig. 42: Same as Fig. 40, but with $\mathrm{T}=50^{\circ} \mathrm{C}$. 


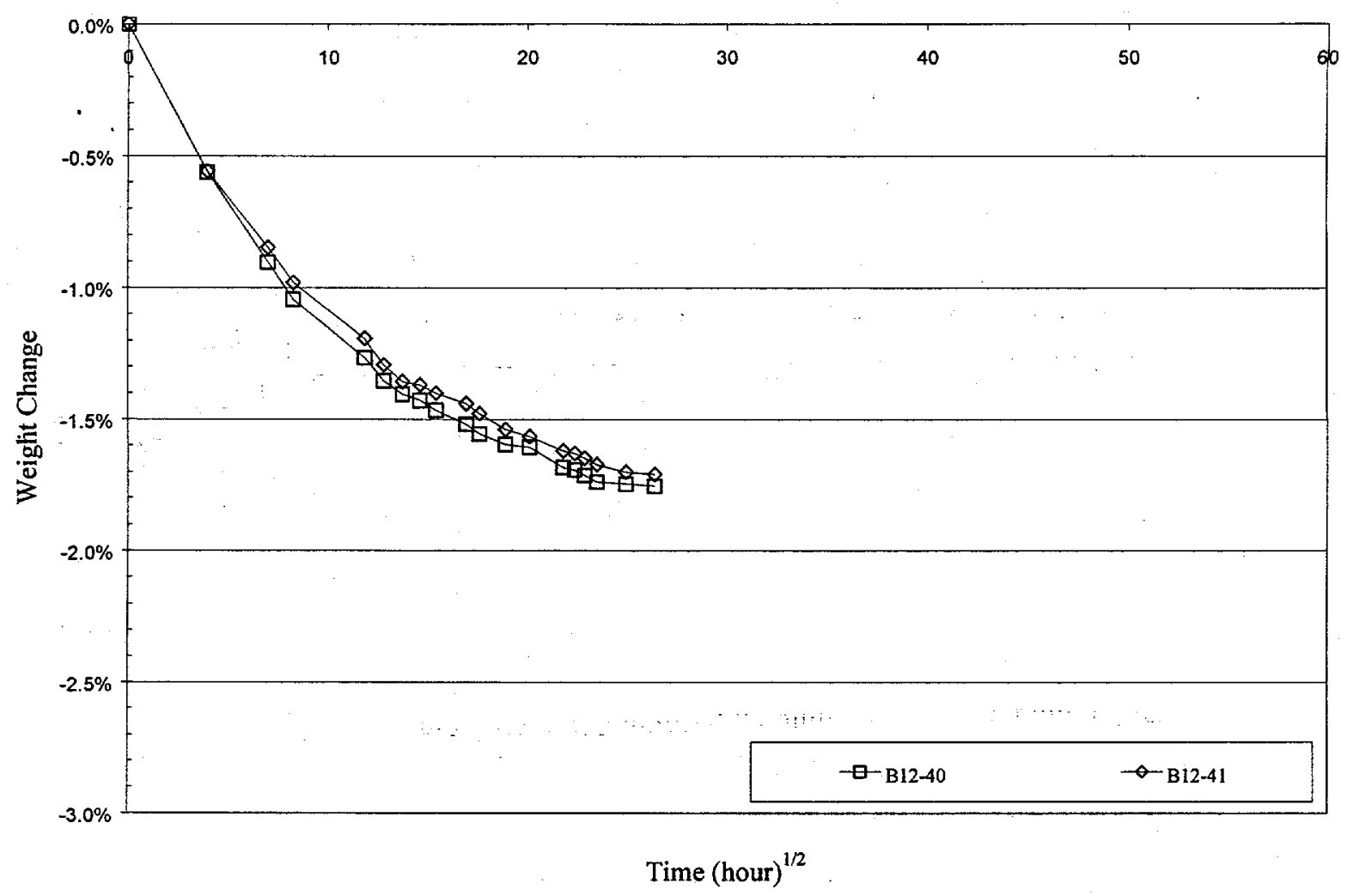

Fig. 43. Weight-loss data (in percent dry weight) upon re-drying of coupons immersed in distilled water at $\mathrm{T}=23^{\circ} \mathrm{C}$. 


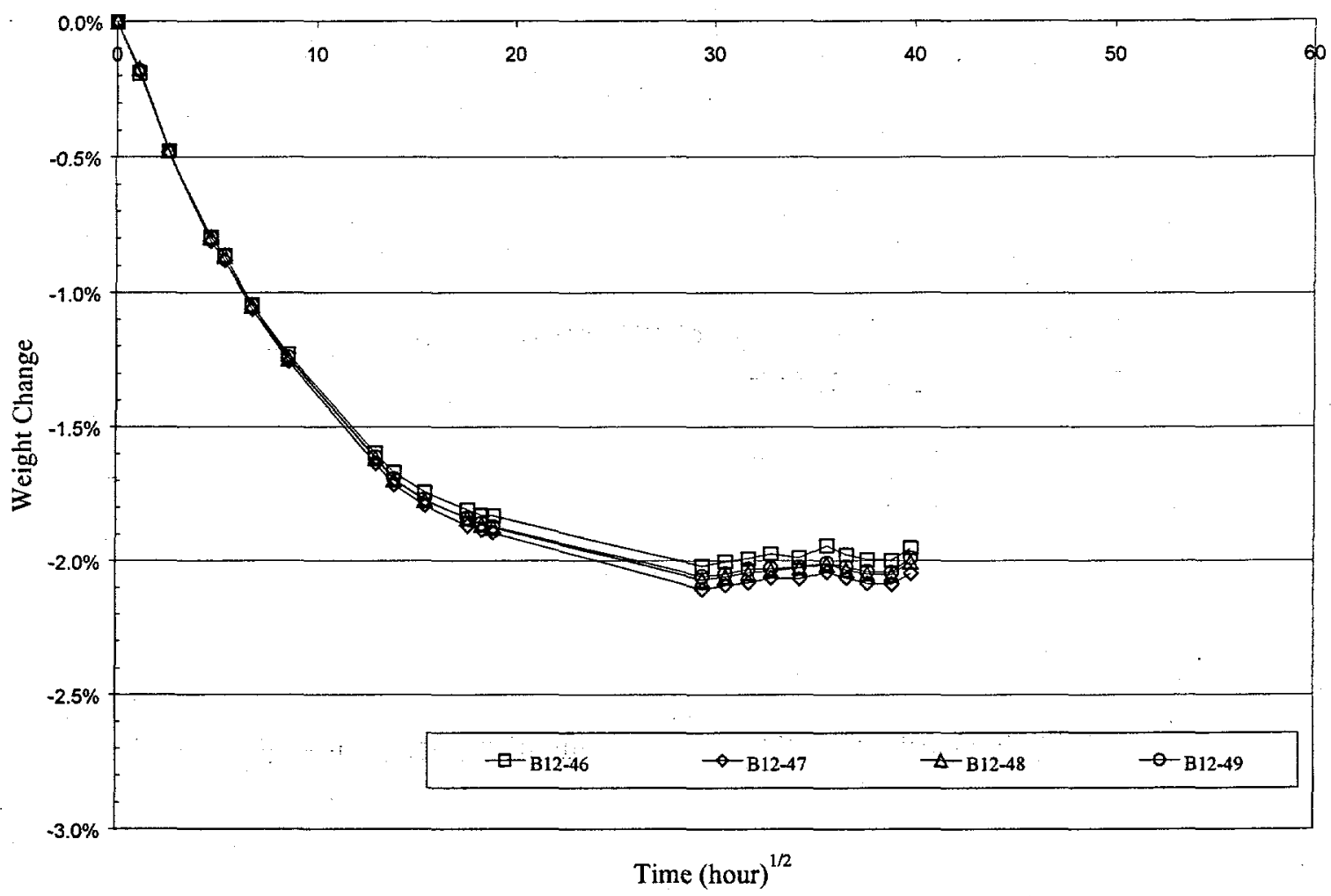

Fig. 44: Same as Fig. 43 , but $\mathrm{T}=36^{\circ} \mathrm{C}$. 


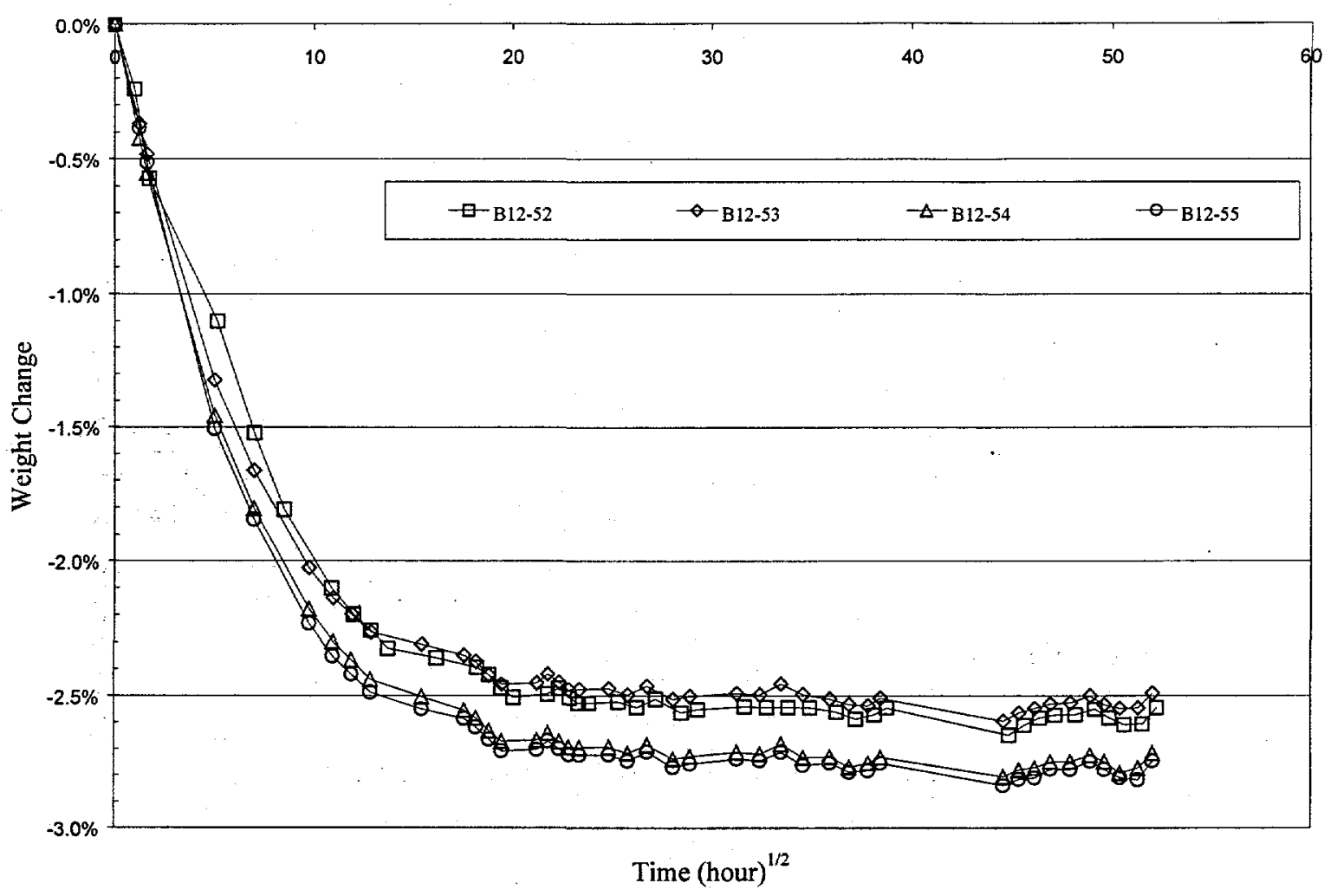

Fig. 45. Same as Fig. 43, but $\mathrm{T}=50{ }^{\circ} \mathrm{C}$. 


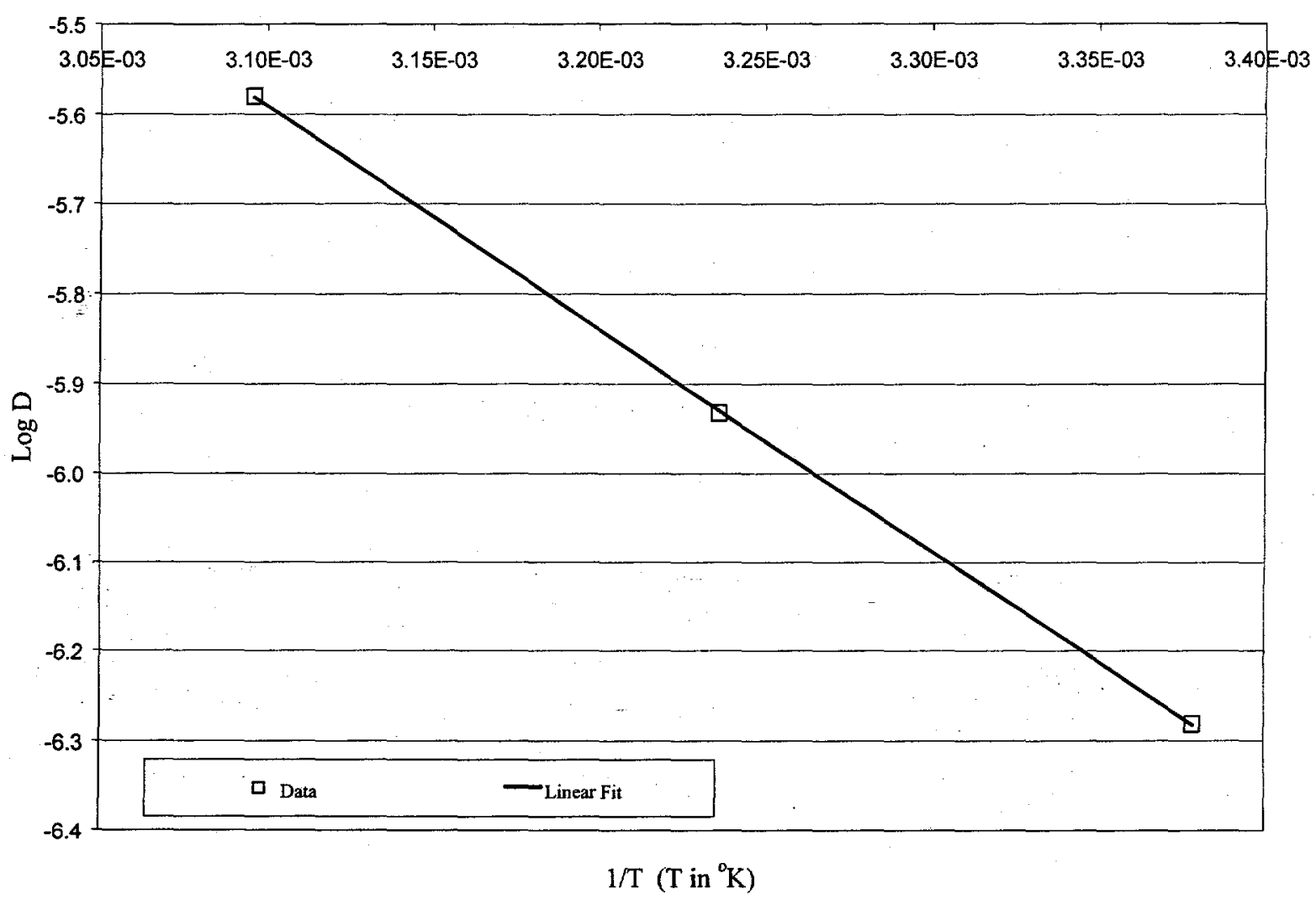

Fig. 46. Variation of the diffusion coefficient $D$ with temperature corresponding to data shown in Figs. 40-42. 


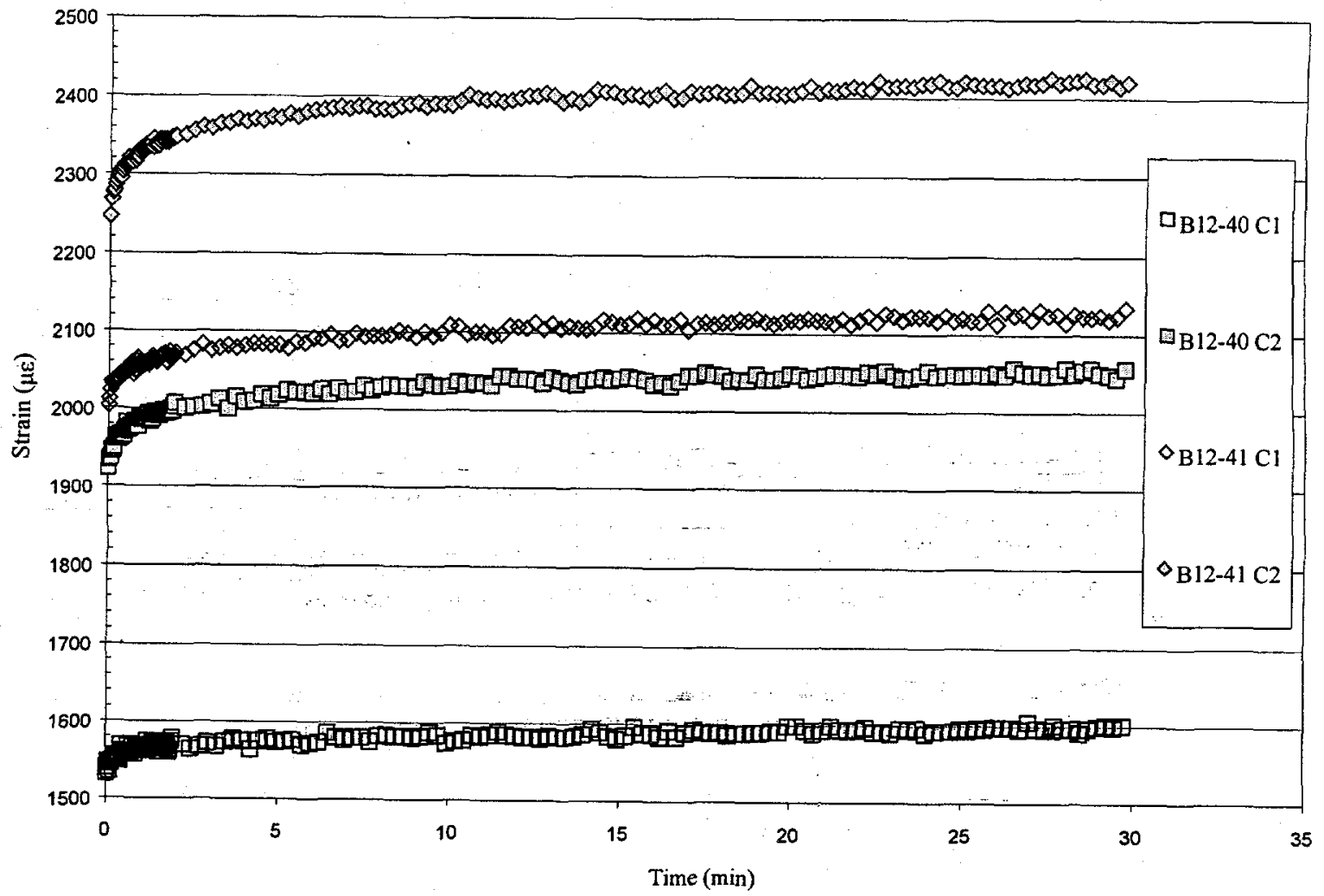

Fig. 47. Comparative data for creep strains of two P4 chopped glass/urethane composite coupons at initially dry state (open symbols) and after saturation in distilled water at $\mathrm{T}=23^{\circ} \mathrm{C}$ (filled symbols). Stress $\sigma=25 \mathrm{MPa}$, loading duration $t_{0}=30$ minutes. 


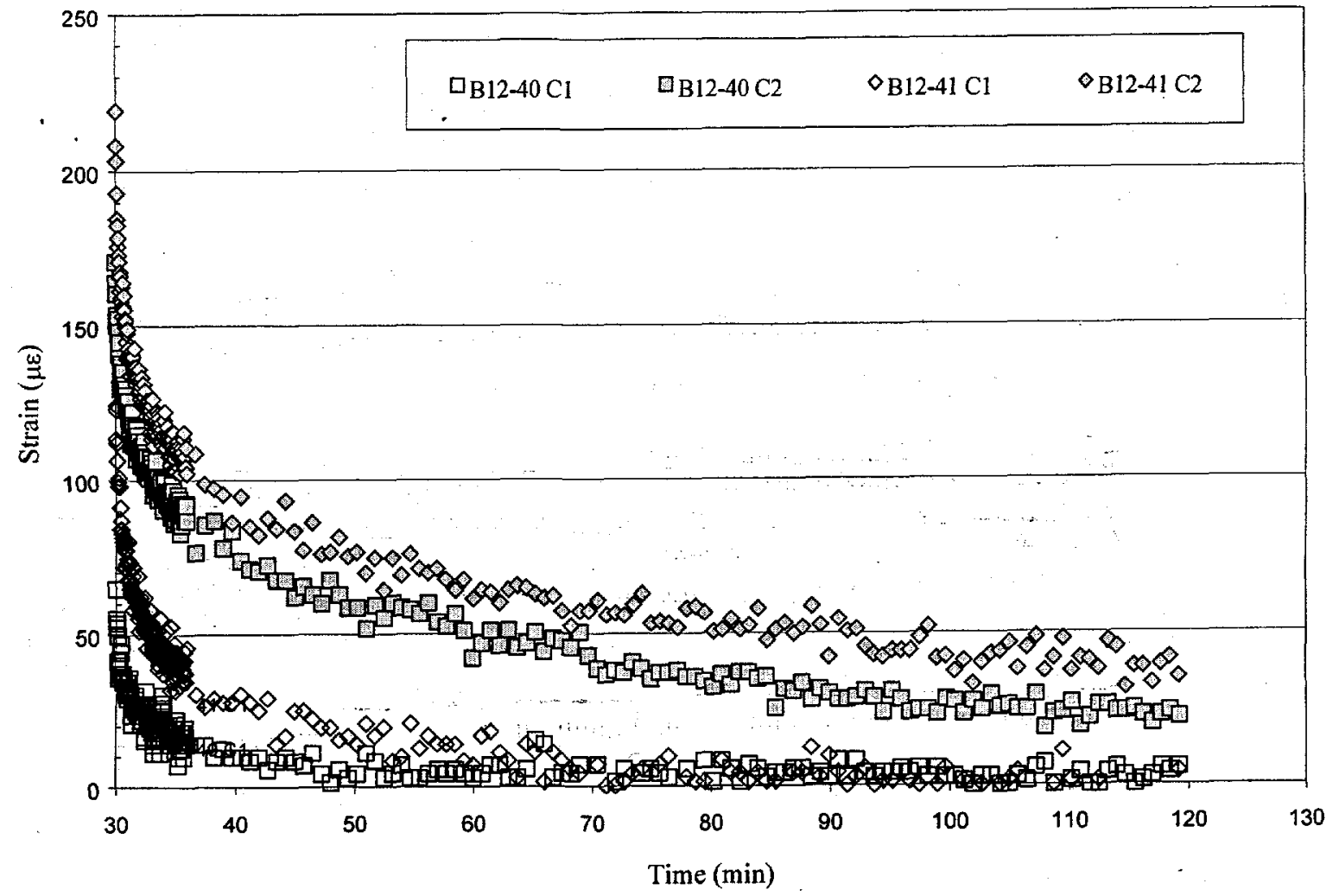

Fig. 48. Comparative data for recovery strains upon load removal at $t_{0}=30$ minutes. Exposure conditions and symbols same as in Fig. 47. 


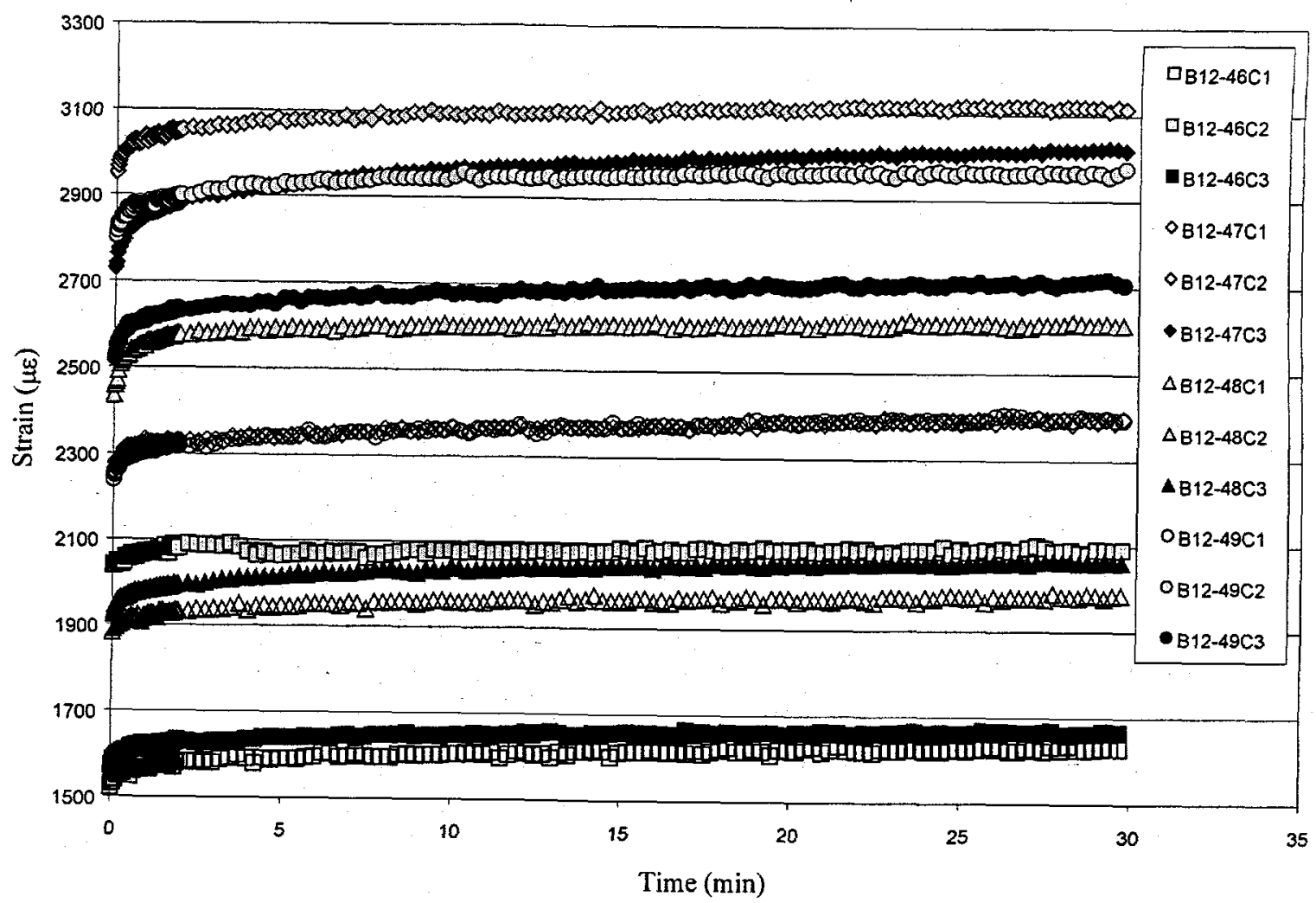

Fig. 49. Comparative data for creep strains of four $\mathrm{P} 4$ chopped glass/urethane composite coupons at initially dry state (open symbols), after saturation in distilled water at $\mathrm{T}=36^{\circ} \mathrm{C}$ (gray symbols), and after redrying (black symbols). Stress $\sigma=25$ $M P a$, loading duration $t_{0}=30$ minutes. 


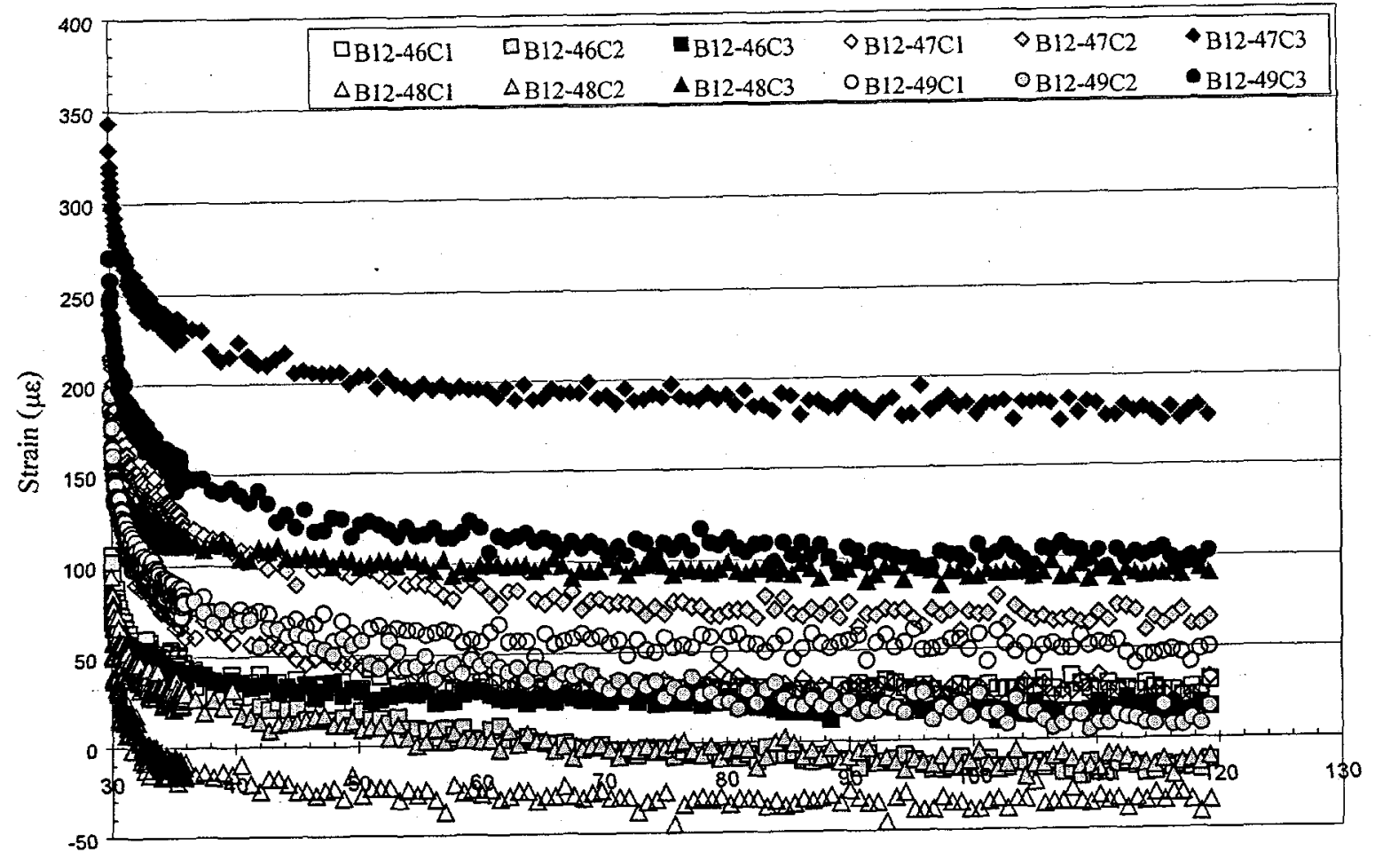

Time (min)

Fig. 50. Comparative data for recovery strains upon load removal at $t_{0}=30$ minutes. Exposure conditions and symbols same as Fig. 49. 


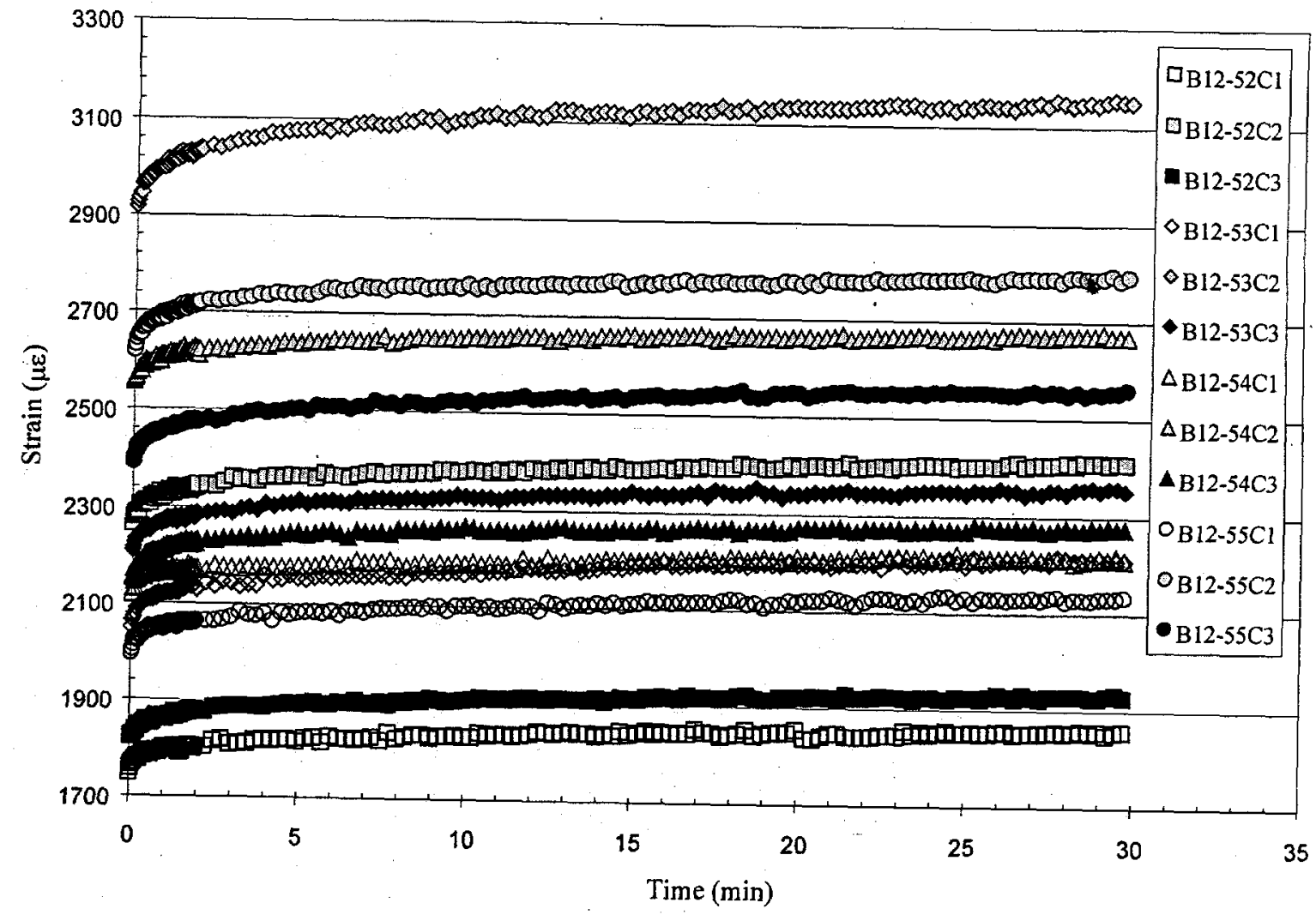

Fig. 51. Same as Fig. 49 , but $\mathrm{T}=50^{\circ} \mathrm{C}$. 


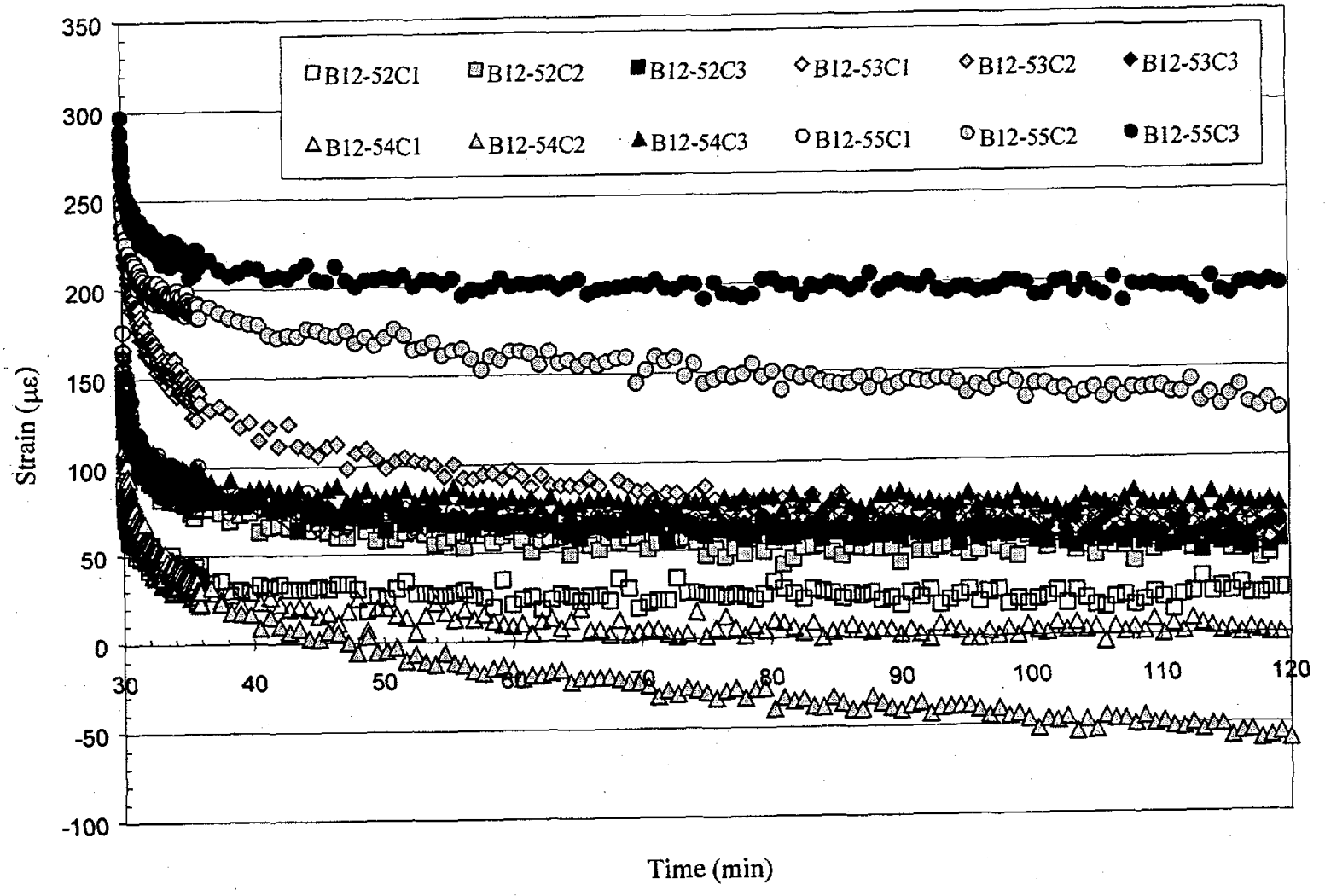

Fig. 52. Same as Fig. 50, but $\mathrm{T}=50^{\circ} \mathrm{C}$. 


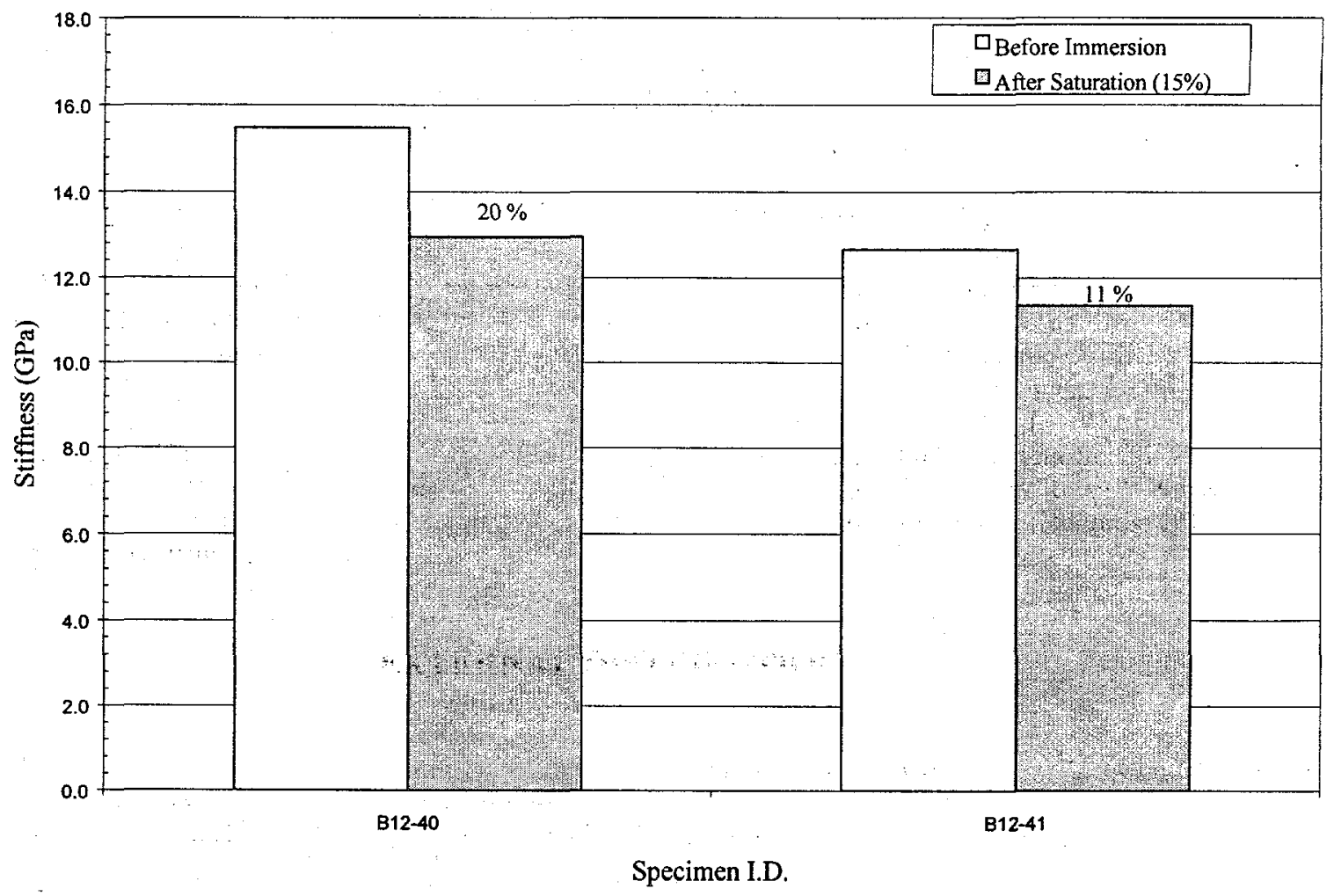

Fig. 53. Stiffness degradation of two $P 4$ chopped glass/urethane composite coupons due to immersion in distilled water at $\mathrm{T}=23^{\circ} \mathrm{C}$. 


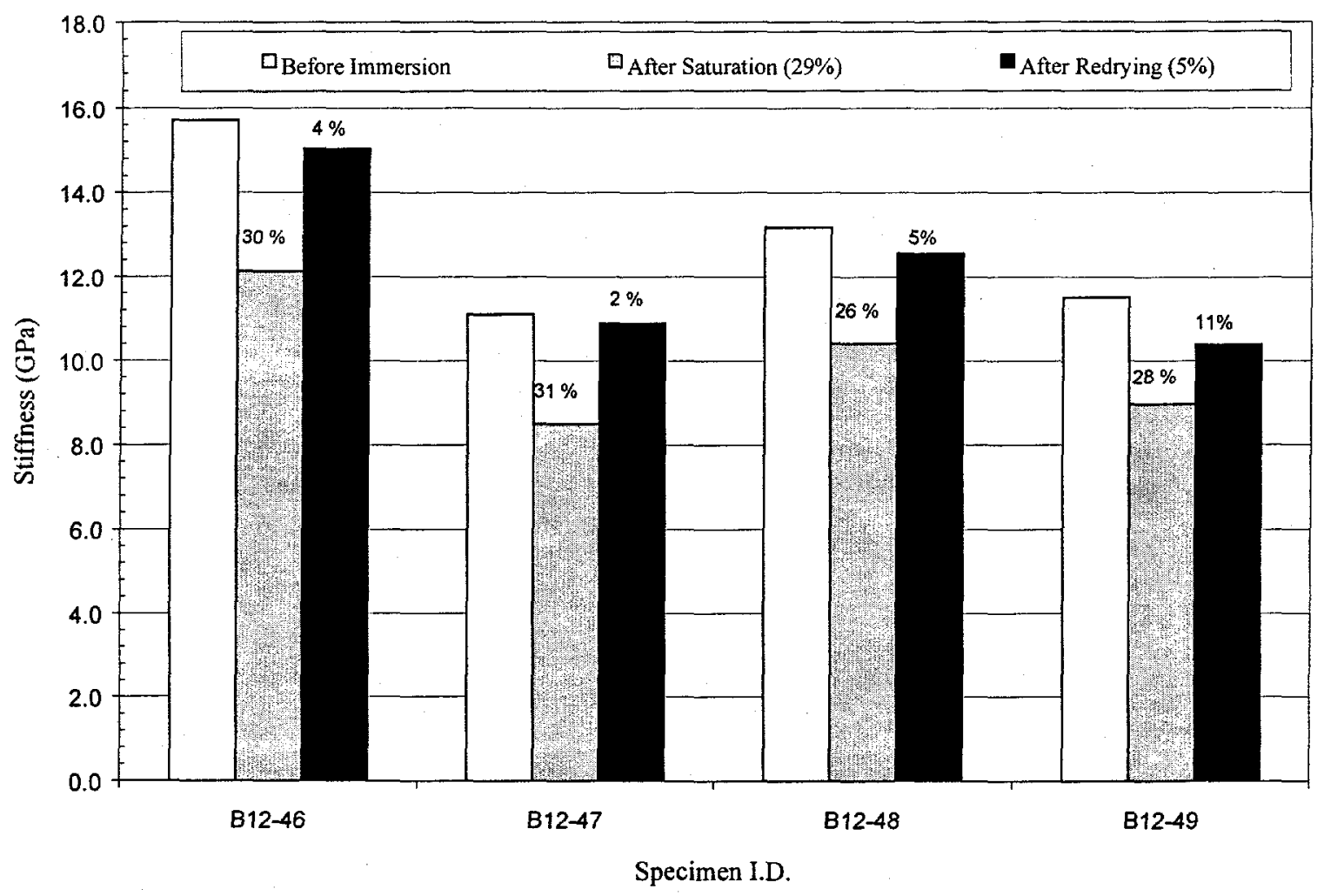

Fig. 54. Same as Fig. 53 , but $\mathrm{T}=36^{\circ} \mathrm{C}$. 


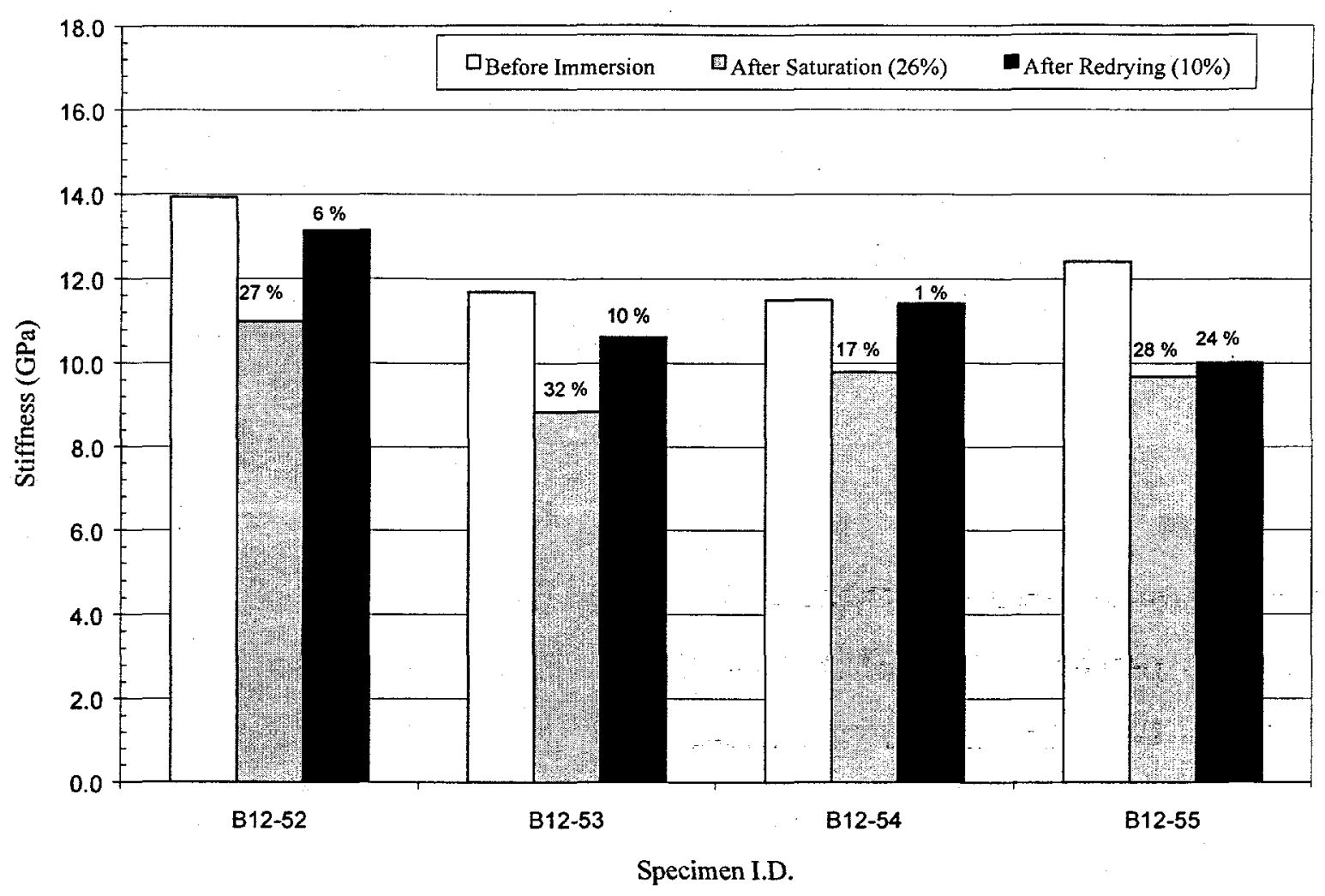

Fig. 55. Same as Fig. 53, but $\mathrm{T}=50^{\circ} \mathrm{C}$. 


\section{INTERNAL DISTRIBUTION}

1. R. L. Battiste

2. R. G. Bowman

3. C. R. Brinkman

4-7. J. M. Corum

8. W. G. Craddick

9. S. Deng

10. D. L. Erdman

11. J. G. Hansen

12. L. D. Klett

13. R. E. Norris

14. M. B. Ruggles
15. J. M. Starbuck

16. P. A. Sklad

17. C. D. Warren

18-30. Y. J. Weitsman

31. G. T. Yahr

32. S. Simunovic

33. R. E. Ziegler

34. ORNL Patent Section

35. Laboratory Records, ORNL-RC

36. Laboratory Records, OSTI

\section{EXTERNAL DISTRIBUTION}

37-65. E. M. Hagerman, Automotive Composite Consortium, General Motors, 30500 Mound Road, I-6, Box 9055, Warren, Michigan 48090-9055.

66. J. M. Henshaw, Department of Mechanical Engineering, The University of Tulsa, $600 \mathrm{~S}$. College Avenue, Tulsa, Oklahoma 74104-3189.

67. G. A. Holmes, National Institute of Standards and Technology, Bldg. 224, Room B116, MS: Room B108, Gaithersburg, Maryland 20899.

68. K. Liechti, Engineering Mechanics Research Laboratory, Department of Aerospace Engineering and Engineering Mechanics, The University of Texas at Austin, Austin, Texas 78712.

69. D. Oplinger, AAR-431, FAA William J. Hughes Technical Center, Atlantic City International Airport, New Jersey 08405.

70. T. A. Reinhart, The University of Dayton Research Institute, 300 College Park Drive, Dayton, Ohio 45469-0130.

71. W. Ren, AFRL/MLLN, 2230 Tenth St., Bldg. 655, Rm. 23, WPAFB, OH 45433-7817.

72. G. Sandgren, Owens Corning Science \& Technology Centre, 2790 Columbus Road, Route 16, Granville, Ohio 43023-1200.

73. R. A. Schapery, Engineering Mechanics Research Laboratory, Department of Aerospace Engineering and Engineering Mechanics, The University of Texas at Austin, Austin, Texas 78712.

74. C. R. Schultheisg, National Institute of Standards and Technology, Building 224, Room A209, Gaithersburg, Maryland 20899.

75. T. D. Seagrave, Bayer Corporation, 100 Bayer Road, Pittsburgh, Pennsylvania 15205.

76. L. V. Smith, Washington State University, School of Mechanics and Materials Engineering, Pullman, Washington 99164-2920.

76-80. J. A. Carpenter, U.S. Department of Energy, 1000 Independence Avenue, SW, Washington, DC 20588.

81. P. G. Patil, U.S. Department of Energy, 1000 Independence Avenue, SW, Washington, DC 20588.

82. M. Rowlins, U.S. Department of Energy, Oak Ridge Site Office, Oak Ridge, Tennessee 37831. 